\author{
UNIVERSIDADE DE SÃO PAULO \\ ESCOLA DE EDUCAÇÃO FÍSICA E ESPORTE
}

ESCOLARES COM INDICATIVOS DO TRANSTORNO DO DÉFICIT DE ATENÇÃO/HIPERATIVIDADE E OS COMPORTAMENTOS

SOCIOEMOCIONAIS EM AULAS DE EDUCAÇÃO FÍSICA E NO ÂMBITO

FAMILIAR: ESTUDO DE CASO

VERSÃO CORRIGIDA

DANIELA COELHO LASTÓRIA DE GODOI

SÃO PAULO

2020 


\section{ESCOLARES COM INDICATIVOS DO TRANSTORNO DO DÉFICIT DE ATENÇÃO/HIPERATIVIDADE E OS COMPORTAMENTOS SOCIOEMOCIONAIS EM AULAS DE EDUCAÇÃO FÍSICA E NO ÂMBITO FAMILIAR: ESTUDO DE CASO}

Dissertação apresentada à Escola de Educação Física e Esporte da Universidade de São Paulo, como requisito parcial para a obtenção do título de Mestre em Ciências.

Área de Concentração: Estudos Socioculturais e Comportamentais da Educação Física e Esporte.

Orientador: Prof. Dr. Jorge Alberto de Oliveira.

SÃO PAULO

2020 


\section{Catalogação da Publicação}

Serviço de Biblioteca

Escola de Educação Física e Esporte da Universidade de São Paulo

Godoi, Daniela Coelho Lastória de

Escolares com indicativos do transtorno do déficit de atenção / hiperatividade e os comportamentos socioemocionais em aulas de educação física e no âmbito familiar: estudo de caso / Daniela Coelho Lastória de Godoi. - São Paulo: [s.n.], 2020. 110p.

Dissertação (Mestrado) - Escola de Educação Física e Esporte da Universidade de São Paulo.

Orientador: Prof. Dr. Jorge Alberto de Oliveira

1. Déficit de atenção (Transtorno) 2. Hiperatividade 3. TDAH 4. Educação física I. Título. 


\section{FOLHA DE APROVAÇÃO}

AUTOR: GODOI, Daniela Coelho Lastória de

TÍTULO: ESCOLARES COM INDICATIVOS DO TRANSTORNO DO DÉFICIT DE ATENÇÃO/HIPERATIVIDADE E OS COMPORTAMENTOS SOCIOEMOCIONAIS EM AULAS DE EDUCAÇÃO FÍSICA E NO ÂMBITO FAMILIAR: ESTUDO DE CASO

Data: 23 / 12 / 2020

Dissertação apresentada à Escola de Educação Física e Esporte da Universidade de São Paulo, como requisito parcial para a obtenção do título de Mestre em Ciências.

\section{Banca Examinadora}

Prof. Dr.: Jorge Alberto de Oliveira

Instituição: Escola de Educacação Física e Esporte da Universidade de São Paulo. Sem direito a voto.

Prof. Dr.: Sérgio Roberto Silveira

Instituição: Escola de Educacação Física e Esporte da Universidade de São Paulo. Julgamento:

Aprovada

Prof.a Dr.a: Juliana Cristina Fernandes Bilhar Marques

Instituição: UNINOVE. Julgamento: Aprovada

Prof.a Dr.a: Maria Aparecida da Silva

Instituição: Hosp. Servidor Público. Julgamento: Aprovada 
Dedico este trabalho aos meus pais que sempre enxergaram o estudo como valor. 


\section{Agradecimentos}

Sou grata à vida que tenho, rodeada de pessoas incríveis e obstáculos que consigo transpor.

Agradeço ao meu orientador, Jorge Alberto, que depositou grande confiança em mim e através de uma conduta ética e amorosa me ensinou a ser pesquisadora, sempre buscando ampliar meu olhar sobre o fenômeno a ser investigado.

Agradeço a minha mãe, Maria Helena, por me mostrar que o estudo liberta e empodera, e por me alertar que devemos ler diferentes autores para formar nossa opinião. Sou grata ao meu pai, Antônio Carlos, que me ensinou valores essenciais para a vida ética, onde a palavra dada sempre deve ser cumprida, a honestidade é a base de todo relacionamento e a felicidade está em reunir a família ao redor da mesa.

Agradeço ao meu marido, Paulo Alexandre, que me incentivou a retomar os estudos, me motivou a ampliar os horizontes como mestranda segurando "as pontas" todas as vezes que eu viajei para estudar, me ofereceu seu ombro acolhedor sempre que eu encontrei dificuldades em minha jornada e me faz sentir amada.

Agradeço ao meu filho, Theo, por ser um menino maravilhoso, que eu amo, me orgulho muito e desenvolveu a autonomia em seus estudos para que eu pudesse estudar também.

Agradeço a minha irmã, Andréa, e ao meu cunhado, Evandro, que com seus exemplos me inspiraram na busca de aprofundamentos e me deram a alegria de ser tia do Ian e da Yasmin, dois sobrinhos queridos e muito amados.

Agradeço a minha sogra, Aparecida, e ao meu sogro, Paulo Ulisses, que sabem viver a vida com amor, felicidade, respeito e me acolheram como uma filha.

Agradeço imensamente a todos os diretores e coordenadores do Colégio Bandeirantes por investirem em meus estudos como pós-graduanda, apoiando todas as atividades do mestrado e por todo o suporte que recebi para realizar a viagem de intercâmbio à África do Sul.

Agradeço aos coordenadores de educação física, Cláudia Regina e Carlos Alberto, por me apoiarem e tornarem realidade todos os meus sonhos de crescimento profissional. 
Agradeço a todos os professores de educação física do Colégio Bandeirantes que me substituíram em aulas ou trocaram os seus horários comigo para que eu pudesse cumprir os 40 créditos da pós.

Agradeço aos grupos de pesquisas: Grupo de Estudos e Pesquisas em Atenção ao Desenvolvimento Infantil (GEADI) e Laboratório de Comportamento Motor (LACOM) pela ampliação do meu arcabouço de conhecimento, pelas ricas discussões em grupo e a generosidade dos colegas que dispensaram seus tempos para me ajudar com a pesquisa. 
"A vida me ensinou a nunca desistir, nem ganhar, nem perder, mas procurar evoluir."

Chorão - Charlie Brown Jr. 


\section{RESUMO}

\section{GODOI, D. C. L. ESCOLARES COM INDICATIVOS DO TRANSTORNO DO DÉFICIT DE ATENÇÃO/HIPERATIVIDADE E OS COMPORTAMENTOS SOCIOEMOCIONAIS EM AULAS DE EDUCAÇÃO FÍSICA E NO ÂMBITO FAMILIAR: ESTUDO DE CASO. 2020.}

110 f. Dissertação (Mestrado em Ciências) - Escola de Educação Física e Esporte, Universidade de São Paulo, São Paulo. 2020.

O Transtorno do Déficit de Atenção/Hiperatividade (TDAH) é o transtorno do neurodesenvolvimento mais comum na infância, está baseado na tríade de sintomas da desatenção, da hiperatividade e da impulsividade que interferem frequente e persistentemente no funcionamento e desenvolvimento levando a prejuízos nas atividades sociais, acadêmicas e profissionais, sendo observados ao longo da vida. A literatura também aponta que pessoas com o TDAH podem apresentar dificuldades nas interações sociais, que são agravadas pela coocorrência do transtorno de oposição desafiante (TOD). O objetivo deste estudo foi investigar o perfil socioemocional de escolares do ensino fundamental II com indicativos do transtorno do déficit de atenção/hiperatividade em dois contextos: nas aulas de educação física e no âmbito familiar. Método: um total de 950 escolares, com idades entre 10 e 15 anos, participou do processo de triagem para verificação de elegibilidade. Após 3 chamadas para participação, retornaram 328 questionários de pais e 57 de professores de educação física. O instrumento do Swanson, Nolan and Pelham Questionnaire (SNAP-IV) foi utilizado para identificar os indicativos do TDAH e classificar o TOD. Para avaliação dos aspectos socioemocionais foi utilizado o Strengths and Difficulties Questionnaire (SDQ). Primeiro foi feita a análise descritiva marginal de cada uma das variáveis, depois foi calculado o Coeficiente de Concordância Kappa de Cohen para analisar a existência de concordância entre pais e professores referente à classificação do SNAP-IV, do SDQ, do Pro-social e do TOD e, por fim, realizado um estudo das apresentações do SNAP-IV com as variáveis do estudo. Resultados: a prevalência do TDAH foi de 78.6\% (masculino) e 21.4\% (feminino). As meninas apresentaram mais indicativos da apresentação predominantemente desatenta e os meninos apresentaram mais indicativos da apresentação combinada. A prevalência do TOD no âmbito familiar foi de $35.7 \%$ e de $7.1 \%$ na escola, a média de idade foi de 12 anos e o índice de massa corporal (IMC) foi de $18.8 \mathrm{~kg} / \mathrm{m}^{2}$. As porcentagens de concordâncias entre pais e professores foram 57.1\% no SNAP-IV $(\mathrm{Kappa}=0.26)$, 64.3\% no SDQ $(\mathrm{Kappa}=0.44)$, 85.7\% no Pro-social (Kappa= $0.45)$ e a discordância de $57.1 \%$ para o TOD (Kappa=-014). Há concordância, embora baixa, nas classificações das subescalas do SDQ, na subescala do Pro-social e nas apresentações do SNAP-IV, enquanto há discordância na classificação do TOD. Conclusão: O perfil socioemocional medido pela subescala pró-social dos (as) escolares foi classificado como normal tanto no ambiente familiar quanto no escolar, permitindo inferir que os escolares possuem empatia e solidariedade, entretanto o perfil socioemocional medido pelas dificuldades totais foi classificado como anormal nos dois contextos, sinalizando que é preciso desenvolver as habilidades sociais específicas. O TOD foi mais relatado pelos pais/responsáveis, talvez isso se deva ao fato de que na escola as regras e os combinados estão mais explicitados e as sanções mais esclarecidas. Além disso, os (as) alunos (as) com indicativos do TDAH possuem baixo risco para a saúde em relação ao desenvolvimento corporal medido pelo IMC. Como limitação do nosso estudo podemos citar o pequeno tamanho da amostra, então sugerimos que futuros estudos incluam um número maior de participantes.

Palavras-chave: Transtorno do Déficit de Atenção/Hiperatividade, Transtorno Oposição Desafiante, Adolescente, Socioemocional. 


\begin{abstract}
GODOI, D. C. L. 2020. STUDENTS WITH ATTENTION DEFICIT HYPERACTIVITY DISORDER AND SOCIOEMOTIONAL BEHAVIORS IN PHYSICAL EDUCATION AND IN THE FAMILY ENVIRONMENT: CASE STUDY. Dissertation presented to the School of Physical Education and Sport of the University of São Paulo to obtain the title of Master in Science. 2020.
\end{abstract}

Attention Deficit/Hyperactivity Disorder (ADHD) is the most common neurodevelopmental disorder in childhood; it is based on the triad of symptoms of inattention, hyperactivity and impulsivity that frequently and persistently interfere in the functioning and development leading to impairments in social activities, academics and professionals, being observed throughout life. The literature points out that people with ADHD may experience difficulties in social interactions that are aggravated by the co-occurrence of oppositional defiant disorder (ODD). The aim of this study was to investigate the socioemotional profile of elementary school students with indications of attention deficit/hyperactivity disorder in two contexts: in physical education classes and in the family context. Method: a total of 950 students, aged between 10 and 15 years, participated in the screening process to verify eligibility. After 3 calls for participation, 328 questionnaires from parents and 57 from physical education teachers returned. The Swanson, Nolan and Pelham Questionnaire (SNAP-IV) instrument was used to analyze ADHD indications and classify the ODD. The Strengths and Difficulties Questionnaire (SDQ) was used to assess socioemotional aspects. First, a marginal descriptive analysis of each of the variables was performed, then Cohen's Kappa Agreement Coefficient was calculated to analyze the existence of agreement between parents and teachers regarding the classification of SNAP-IV, SDQ, Pro-social and ODD, finally, carried out a study of the SNAP-IV presentations with the study variables. Results: The prevalence of ADHD was 78.6\% (male) and 21.4\% (female). The girls showed more indications of the predominantly inattentive presentation and the boys showed more indications of the combined presentation. The prevalence of ODD in the family was $35.7 \%$ and $7.1 \%$ at school, average age was 12 years, and the body mass index (BMI) was $18.8 \mathrm{~kg} / \mathrm{m}^{2}$. The percentages of agreement between parents and teachers were 57.1\% in SNAP-IV (Kappa = 0.26), 64.3\% in SDQ (Kappa = 0.44), 85.7\% in Pro-social $(\mathrm{Kappa}=0.45)$ and the disagreement of 57.1\% for the ODD (Kappa $=-014)$. There is agreement, although low, in the classifications of the subscales of the SDQ, in the subscale of the Prosocial and in the presentations of the SNAP-IV, while there is disagreement in the classification of the ODD. Conclusion: The socioemotional profile measured by the prosocial subscale of the students was classified as normal both in the family and in the school environment, allowing to infer that the students have empathy and solidarity, however the socioemotional profile measured by the total difficulties was classified as abnormal in both contexts, signaling that it is necessary to develop specific social skills. ODD was more reported by parents / guardians, perhaps this is due to the fact that at school the rules and arrangements are more explicit and the sanctions more clarified. Furthermore, students with indications of ADHD have low risk to health in relation to body development measured by BMI. As a limitation of our study, we can mention its small sample size, so we suggest that future studies include a larger number of participants.

Keywords: Attention Deficit/Hyperactivity Disorder, Oppositional Defiant Disorder, Adolescent, Socioemotional. 


\section{LISTA DE QUADROS}

Quadro 1 Critérios de Diagnóstico de Desatenção Característicos no TDAH

Quadro 2 Critérios de Diagnóstico de Hiperatividade e Impulsividade Característicos no TDAH

Quadro 3 Classificação Estatística Internacional de Doenças e Problemas Relacionados à Saúde - TDAH

Quadro 4 Escores de pais e professores, segundo pontuação geral do SDQ-Por

Quadro 5 Escores de pais e professores, segundo pontuação da subescala Pró-social

Quadro 6 Índice de massa corporal, segundo sexo, OMS, 2017 


\section{LISTA DE TABELAS}

Tabela 1 Frequência da variável Sexo na amostra. Feminino Masculino 44

Tabela 2 Estatística descritiva da variável Idade na amostra 45

Tabela 3 Estatística descritiva da variável Peso na amostra 45

Tabela $4 \quad$ Estatística descritiva da variável Altura na amostra 46

Tabela 5 Estatística descritiva da variável IMC na amostra 47

Tabela 6 Frequência da variável SNAP-IV Pais na amostra 48

Tabela 7 Frequência da variável SNAP-IV Professores na amostra 48

Tabela 8 Frequência da variável TOD na amostra 49

Tabela 9 Frequência da variável TOD Pais na amostra 50

Tabela 10 Frequência da variável TOD Professores na amostra 50

Tabela 11 Frequência da variável SDQ dificuldades totais Pais na amostra 51

Tabela 12 Frequência da variável SDQ dificuldades totais Professores na amostra 52

Tabela 13 Frequência da variável SDQ Pró-social Pais na amostra 53

Tabela 14 Frequência da variável SDQ Pró-social Professores na amostra 54

Tabela 15 Classificação de pais e professores em relação ao SNAP-IV (Kappa = 0,26) 55

Tabela 16 Classificação de pais e professores em relação ao TOD $($ Kappa = -0.14) 55

Tabela 17 Classificação de pais e professores em relação ao SDQ $($ Kappa $=0.44) \quad 55$

Tabela 18 Classificação de pais e professores em relação ao Pro-social (Kappa $=0.45) 56$

Tabela 19 Frequência das variáveis Sexo e SNAP-IV Pais na amostra $(p=1) \quad 57$

Tabela 20 Estatística descritiva da variável Idade pela variável SNAP-IV Pais na 58

Tabela 21 Estatística descritiva da variável Peso pela variável SNAP-IV Pais na 59

Tabela 22 Estatística descritiva da variável Altura pela variável SNAP-IV Pais na 60

Tabela 23 Estatística descritiva da variável IMC pela variável SNAP-IV Pais na 61 $\operatorname{amostra}(\mathrm{p}=0.465)$

Tabela 24 Frequência das variáveis SDQ Pais e SNAP-IV Pais na amostra $(p=0.175) \quad 62$

Tabela 25 Frequência das variáveis Pró-social Pais e SNAP-IV Pais na amostra $(p=63$ 0.487)

Tabela 26 Frequência das variáveis SDQ Professores e SNAP-IV Pais na amostra $(p=64$ $0.38)$

Tabela 27 Frequência das variáveis Pró-social Professores e SNAP-IV Pais na 65 $\operatorname{amostra}(\mathrm{p}=1)$

Tabela 28 Frequência das variáveis TOD Pais e SNAP-IV Pais na amostra $(p=0.248) \quad 66$

Tabela 29 Frequência das variáveis TOD Professores e SNAP-IV Pais na amostra $(p=66$ $0.143)$

Tabela $30 \quad$ Frequência das variáveis TOD e SNAP-IV Pais na amostra $(\mathrm{p}=0.079) \quad 67$

Tabela 31 Frequência das variáveis Sexo e SNAP-IV Professores na amostra $(\mathrm{p}=\quad 68$ $0.703)$

Tabela 32 Estatística descritiva da variável Idade pela variável SNAP-IV Professores 69 na amostra $(\mathrm{p}=0.621)$

Tabela 33 Estatística descritiva da variável Peso pela variável SNAP-IV Professores 70 na amostra $(\mathrm{p}=0.087)$

Tabela 34 Estatística descritiva da variável Altura pela variável SNAP-IV Professores 71 na amostra $(\mathrm{p}=0.116)$ 
Tabela 35 Estatística descritiva da variável IMC pela variável SNAP-IV Professores 72 na $\operatorname{amostra}(\mathrm{p}=0.22)$

Tabela 36 Frequência das variáveis SDQ Pais e SNAP-IV Professores na amostra $(p=73$ $0.004)$

Tabela 37 Frequência das variáveis Pró-social Pais e SNAP-IV Professores na 74 amostra $(\mathrm{p}=0.769)$

Tabela 38 Frequência das variáveis SDQ Professores e SNAP-IV Professores na 75 $\operatorname{amostra}(\mathrm{p}=0.124)$

Tabela 39 Frequência das variáveis Pró-social Professores e SNAP-IV Professores na 76 $\operatorname{amostra}(\mathrm{p}=1)$

Tabela 40 Frequência das variáveis TOD Pais e SNAP-IV Professores na amostra $(\mathrm{p}=77$ $0.559)$

Tabela 41 Frequência das variáveis TOD Pais e SNAP-IV Professores na amostra $(\mathrm{p}=78$ $0.559)$

Tabela 42 Frequência das variáveis TOD e SNAP-IV Professores na amostra $(\mathrm{p}=$ 79 $0.748)$ 


\section{LISTA DE GRÁFICOS}

Gráfico 1 Frequência da variável Sexo na amostra. Feminino Masculino 44

Gráfico 2 Histograma da variável Idade 45

Gráfico 3 Histograma da variável Peso 46

Gráfico 4 Histograma da variável Altura 46

Gráfico 5 Histograma da variável IMC 47

Gráfico 6 Frequência da variável SNAP-IV Pais na amostra 48

Gráfico 7 Frequência da variável SNAP-IV Professores na amostra 49

Gráfico 8 Frequência da variável TOD na amostra 49

Gráfico 9 Frequência da variável TOD Pais na amostra 50

Gráfico $10 \quad$ Frequência da variável TOD Professores na amostra 51

Gráfico 11 Frequência da variável SDQ dificuldades totais Pais na amostra 52

Gráfico 12 Frequência da variável SDQ dificuldades totais Professores na amostra 52

Gráfico 13 Frequência da variável SDQ Pró-social Pais na amostra 53

Gráfico 14 Frequência da variável SDQ Pró-social Professores na amostra 54

Gráfico 15 Frequência da variável SNAP-IV Pais em cada categoria da variável Sexo 57

Gráfico 16 Box-plot da variável Idade pela variável SNAP-IV Pais 58

Gráfico 17 Box-plot da variável Peso pela variável SNAP-IV Pais 59

Gráfico 18 Box-plot da variável Altura pela variável SNAP-IV Pais 60

Gráfico 19 Box-plot da variável IMC pela variável SNAP-IV Pais 61

Gráfico 20 Frequência da variável SNAP-IV Pais em cada categoria da variável SDQ 62 Pais

Gráfico 21 Frequência da variável SNAP-IV Pais em cada categoria da variável Pró- 63 social Pais

Gráfico 22 Frequência da variável SNAP-IV Pais em cada categoria da variável SDQ 64 Professores

Gráfico 23 Frequência da variável SNAP-IV Pais em cada categoria da variável Pró- 65 social Professores

Gráfico 24 Frequência da variável SNAP-IV Pais em cada categoria da variável 66 TOD Pais

Gráfico 25 Frequência da variável SNAP-IV Pais em cada categoria da variável TOD Professores

Gráfico 26 Frequência da variável SNAP-IV Professores em cada categoria da $\quad 68$ variável Sexo

Gráfico 27 Frequência da variável SNAP-IV Professores em cada categoria da $\quad 69$

Gráfico 28 Box-plot da variável Idade pela variável SNAP-IV Professores 70

Gráfico 29 Box-plot da variável Peso pela variável SNAP-IV Professores 71

Gráfico $30 \quad$ Box-plot da variável Altura pela variável SNAP-IV Professores $\quad 72$

Gráfico 31 Box-plot da variável IMC pela variável SNAP-IV Professores 73

Gráfico 32 Frequência da variável SNAP-IV Professores em cada categoria da 74

Gráfico 33 Frequência da variável SNAP-IV Professores em cada categoria da 75 variável Pró-social Pais

Gráfico 34 Frequência da variável SNAP-IV Professores em cada categoria da 76

Gráfico 35 Frequência da variável SNAP-IV Professores em cada categoria da 77 variável Pró-social Professores 
Gráfico 36 Frequência da variável SNAP-IV Professores em cada categoria da variável TOD Pais

Gráfico 37 Frequência da variável SNAP-IV Professores em cada categoria da variável TOD Pro- fessores

Gráfico 38 Frequência da variável SNAP-IV Professores em cada categoria da variável TOD 


\section{LISTA DE FIGURAS}

Figura 1

"The Story of Fidgety" de Hoffman (1845)

Figura 3

Fluxograma do estudo com base no SNAP-IV relacionando as

40 respostas de Pais e Professores e Professores de Educação 


\section{LISTA DE SIGLAS}

APA - Associação Psiquiátrica Americana.

DSM - Manual Diagnóstico e Estatístico de Transtornos Mentais.

CID - Código Internacional de Doença.

EEFEUSP - Escola de Educação Física e Esporte da Universidade de São Paulo.

OMS - Organização Mundial da Saúde.

SDQ-Por - Strengths Difficulties Questionnaires - Portuguese.

SNAP-IV - Swanson, Nolan and Pelham Questionnaire IV.

TDAH - Transtorno do Déficit de Atenção/Hiperatividade.

TOD - Transtorno de Oposição Desafiante.

NCHS - National Center Health Statistics 


\section{SUMÁRIO}

1 INTRODUÇÃO

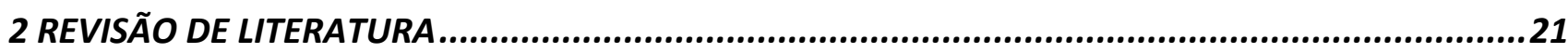

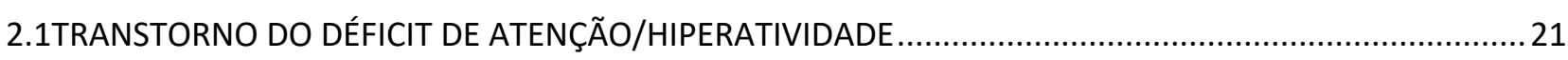

2.2 QUADRO CLÍNICO DO TRANSTORNO DO DÉFICIT DE ATENÇÃO/HIPERATIVIDADE ................................24

2.3 EPIDEMIOLOGIA DO TRANSTORNO DE DÉFICIT DE ATENÇÃO/HIPERATIVIDADE ..................................28

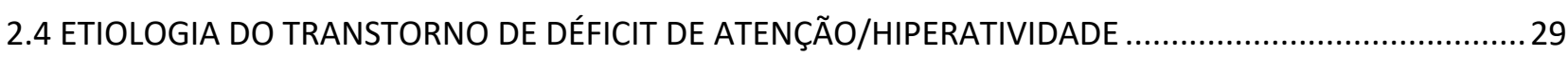

2.5 COMPORTAMENTO SOCIAL DO TRANSTORNO DO DÉFICIT DE ATENÇÃO/HIPERATIVIDADE ...................29

3 JUSTIFICATIVA E QUESTÃO

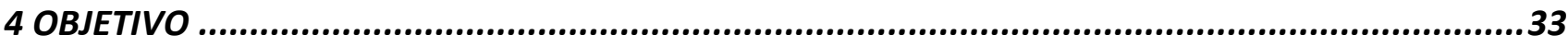

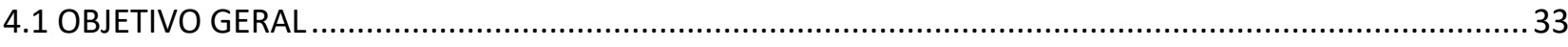

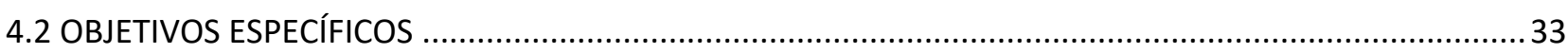

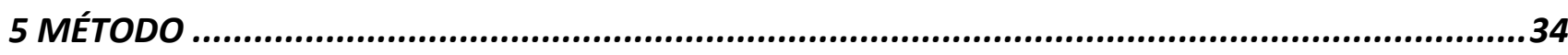

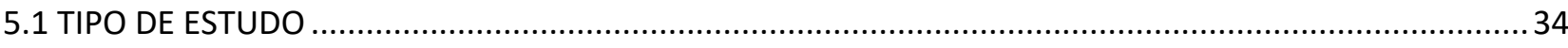

5.2 AMOSTRA

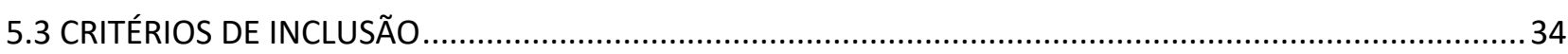

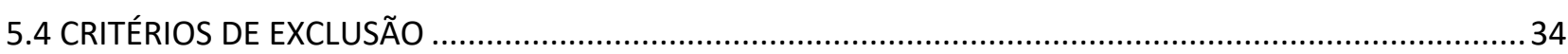

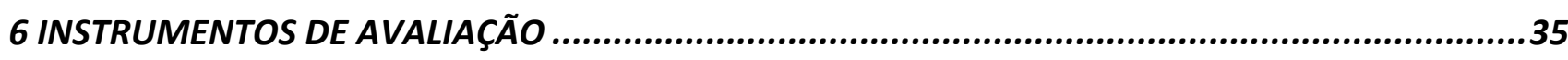

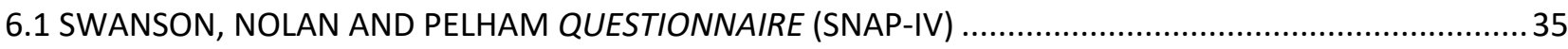

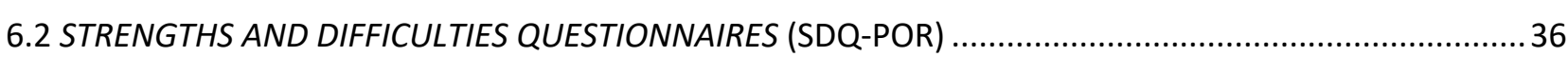

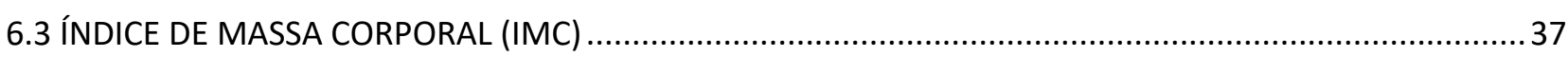

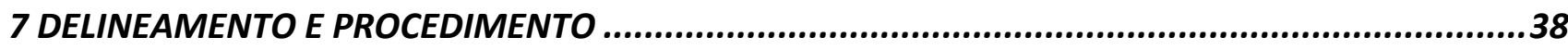

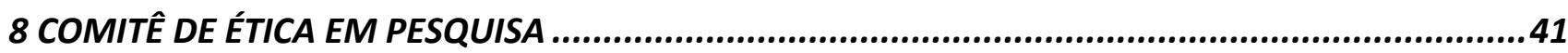

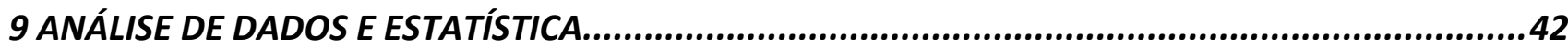

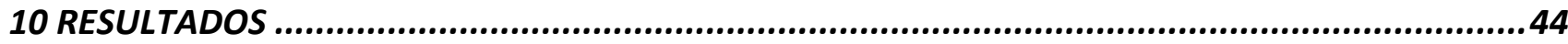

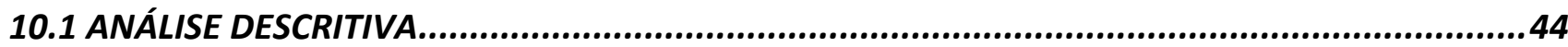

10.1.1 ESTATÍSTICA DESCRITIVA DA VARIÁVEL SEXO....................................................................

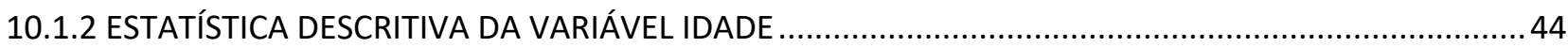

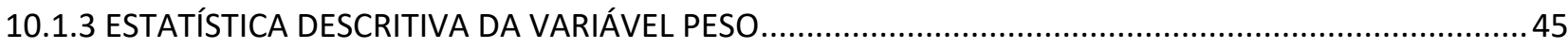

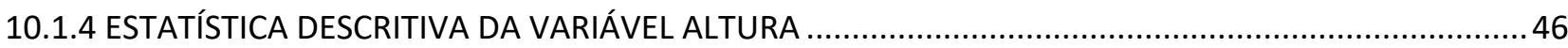

10.1.5 ESTATÍSTICA DESCRITIVA DA VARIÁVEL ÍNDICE DE MASSA CORPORAL (IMC) .................................4

10.1.6 ESTATÍSTICA DESCRITIVA DA VARIÁVEL SNAP-IV ………......................................................4

10.1.6.1 Estatística descritiva da variável SNAP-IV, segundo os Pais ...................................................................47

10.1.6.2 Estatística descritiva da variável SNAP-IV, segundo os Professores...................................................48 
10.1.7 ESTATÍSTICA DESCRITIVA DA VARIÁVEL TOD 49

10.1.7.1 Estatística descritiva da variável TOD, segundo os Pais ........................................................................... 50

10.1.7.2 Estatística descritiva da variável TOD, segundo os Professores..............................................................50

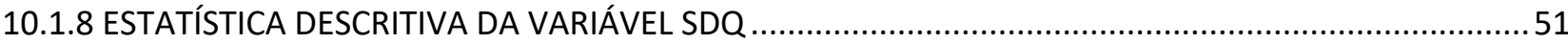

10.1.8.1 Estatística descritiva da variável SDQ dificuldades totais, segundo os Pais ............................................. 51

10.1.8.2 Estatística descritiva da variável SDQ dificuldades totais, segundo os Professores.................................52

10.1.9.1 Estatística descritiva da variável SDQ Pró-social, segundo os pais .........................................................53

10.1.9.2 Estatística descritiva da variável SDQ Pró-social, segundo os Professores ............................................53

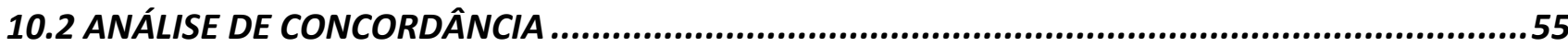

10.3 ANÁLISE DAS VARIÁVEIS DA PESQUISA E RELAÇÃO COM O SNAP-IV.................................57

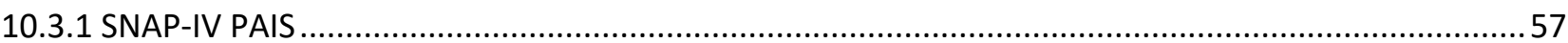

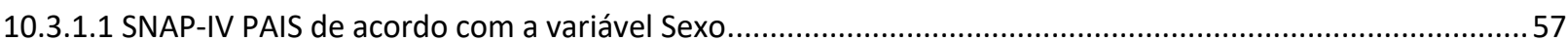

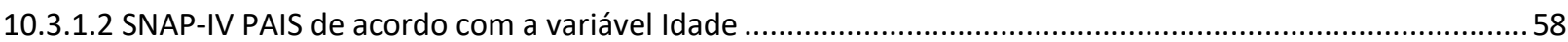

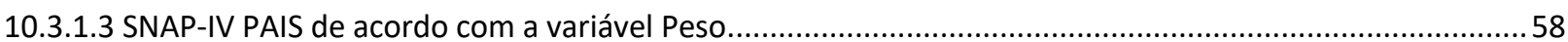

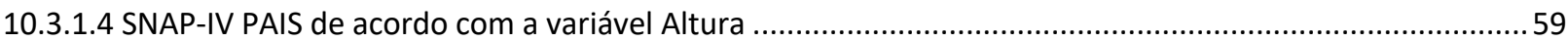

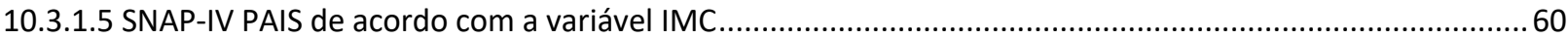

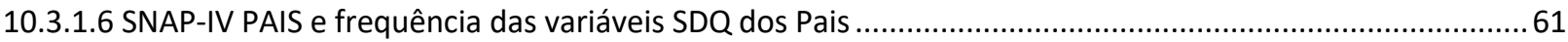

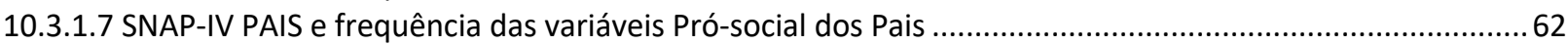

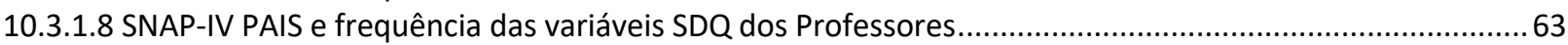

10.3.1.9 SNAP-IV PAIS e frequência das variáveis Pró-social dos Professores ........................................................64

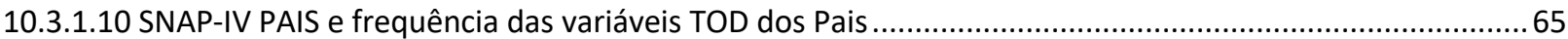

10.3.1.11 SNAP-IV PAIS e frequência das variáveis TOD dos Professores.............................................................6

10.3.1.12 SNAP-IV PAIS e frequência das variáveis TOD dos Professores................................................................67

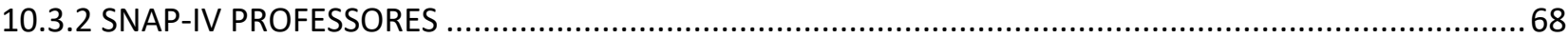

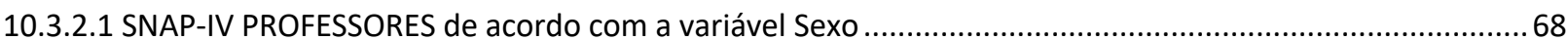

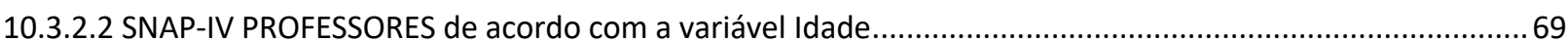

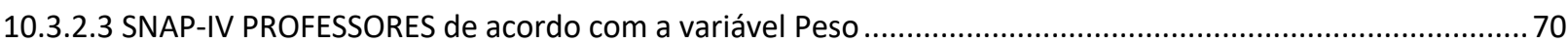

10.3.2.4 SNAP-IV PROFESSORES de acordo com a variável Altura ................................................................. 71

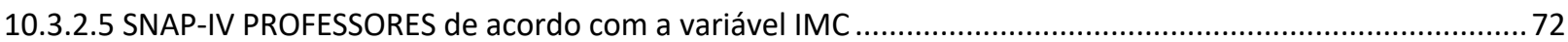

10.3.2.6 SNAP-IV PROFESSORES e frequência das variáveis SDQ dos Pais .............................................................73

10.3.2.7 SNAP-IV PROFESSORES e frequência da variável Pró-social dos Pais....................................................... 74

10.3.2.8 SNAP-IV PROFESSORES e frequência das variáveis SDQ dos Professores .................................................... 75

10.3.2.9 SNAP-IV PROFESSORES e frequência das variáveis Pró-social dos Professores ...........................................76

10.3.2.10 SNAP-IV PROFESSORES e frequência das variáveis TOD dos Pais ............................................................. 77

10.3.2.11 SNAP-IV PROFESSORES e frequência das variáveis TOD dos Professores ............................................... 78

10.3.2.12 SNAP-IV PROFESSORES e frequência das variáveis TOD ...................................................................... 79

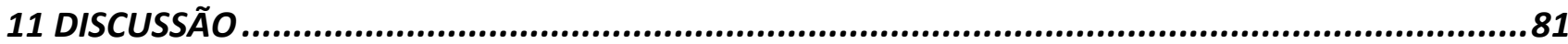

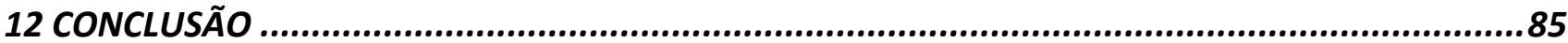

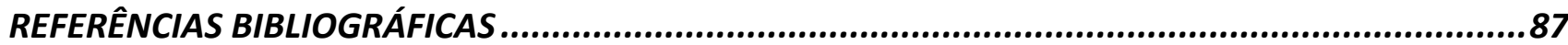




\section{INTRODUÇÃO}

$\mathrm{Na}$ maioria das vezes, os professores caracterizam como comportamentos inadequados, observado nos alunos, a hiperatividade, a impulsividade e a desatenção (GUIDOLIM et al., 2013). Tais comportamentos podem ser percebidos durante as realizações de tarefas individuais em classe, trabalhos em grupos, explicações das matérias e situações em que os alunos precisam ouvir as apresentações de outros colegas. Verifica-se que as alterações comportamentais afetam o ambiente de aprendizagem, resultando em prejuízos acadêmicos e dificuldades na interação social dos alunos. O comportamento inadequado observado em alguns alunos pode estar relacionado a transtornos neurodesenvolvimentais, como o Transtorno do Déficit de Atenção/Hiperatividade (TDAH), que é caracterizado por sintomas desatencionais e/ou de hiperatividade e impulsividade (RANGEL JÚNIOR; LOOS, 2011).

Os desafios dos alunos com o TDAH, de apresentação predominantemente desatenta, giram em torno da dificuldade em manter o foco atencional, o que compromete o recebimento e processamento de estímulos vindos do ambiente, não permitindo a compreensão clara dos sinais externos, causando prejuízos para o eficiente desenvolvimento das interações sociais. Enquanto os alunos com TDAH com apresentação predominantemente hiperativa/impulsiva, além de apresentarem dificuldades em solucionar problemas, mostram-se impacientes em esperarem por sua vez para falar/realizar tarefas, movimentam-se em excesso e, também, apresentam dificuldade de relacionamento com outros alunos. Na apresentação combinada, são verificadas todas as dificuldades relatadas previamente. Além do baixo rendimento acadêmico, os alunos com esse transtorno, independente da apresentação, evidenciam maiores problemas em demonstrar atitudes assertivas, ser empáticos e estabelecer uma boa comunicação com os outros, mostrando inabilidades no desenvolvimento das habilidades sociais, tais comprometimentos os acompanham até a idade adulta (ARAUJO; SILVA, 2004; ARTIGAS-PALLARES, 2003; FARRE; NARBONA, 2001; DIAMOND, 2000; POETA; ROSA NETO, 2005).

O comportamento inadequado, demonstrado por alguns alunos com indicativos do TDAH, pode ser externado por comportamentos agressivos e/ou antissociais. Este estudo assume o conceito socioemocional do comportamento agressivo, verificado no contexto da escola pesquisada e manifestado na interação social, como sendo referente à intencionalidade e deliberação de qualquer agressão física e moral contra a integridade física ou psíquica de um indivíduo ou grupo. Além disso, compreende que o comportamento agressivo pode ser ofensivo ou defensivo. O comportamento agressivo pode ser devido a uma condição emocional explicada no contexto da situação, sendo uma 
expressão comportamental esperada, portanto aceitável, dentro de certos limites (CÂMARA, 2018). Por outro lado, o comportamento inadequado caracterizado por antissocial é caracterizado pelo isolamento social, rompimento de normas, comportamento opositivo, destrutivo e a agressão direcionada a outros (Del PRETTE et al., 2005).

O comportamento inapropriado expressado pelas alterações frequentes e persistentes de emoções (raiva e irritação) e comportamentos de questionamento e desafio são característicos do Transtorno de Oposição Desafiante (TOD), que possui alta comorbidade com o TDAH. Sendo o TOD expresso por um padrão de humor raivoso/irritável e de comportamento questionador/desafiante ou índole vingativa, as interações sociais se tornam problemáticas - como especificado no Manual Diagnóstico e Estatístico de Transtornos Mentais 5a Edição (DSM-5) (APA, 2013).

Portanto, considerando que os sintomas do transtorno do déficit de atenção/hiperatividade podem influenciar nos aspectos socioemocionais dos indivíduos, o presente estudo pretende identificar o perfil socioemocional de escolares do ensino fundamental II (10 a 15 anos), com indicativos do transtorno do déficit de atenção/hiperatividade em dois diferentes contextos: nas aulas de educação física e no âmbito familiar. 


\section{REVISÃO DE LITERATURA}

\subsection{TRANSTORNO DO DÉFICIT DE ATENÇÃO/HIPERATIVIDADE}

A problemática acerca da dificuldade em manter o foco atencional não é uma preocupação recente. Louzã Neto (2010) cita a comédia “Le Distrait” (1697), do dramaturgo Jean François Regnard, onde o personagem principal é descrito como desatento e impulsivo e enfrenta vários problemas no âmbito social. A primeira descrição encontrada na literatura médica sobre o "déficit de atenção" é datada de 1775, feita pelo médico alemão Melchior Adam Weikard (BARKLEY; PETERS, 2012). Em 1798, o médico escocês Alexander Crichton escreve 3 volumes sobre doenças mentais e classifica como "Doenças da Atenção" toda a dificuldade em manter o foco atencional. Crichton (1798) afirmou que a pessoa nascia com a falta de atenção e, devido a isso, apresentava um comportamento socialmente inadequado, que podia ser atenuado com o passar dos anos.

Segundo Silva (2014), a atenção é definida pela ocupação da mente por um objeto externo ou um pensamento em tal grau que a pessoa não recebe clara percepção de qualquer outro estímulo ao seu redor. No artigo de Rey (2012) é relatado que, em 1845, o médico alemão Dr. Reinrich Hoffman publicou um livro de poemas voltados para o público infantil, "Der Struwwelpeter", cuja tradução para a língua portuguesa é "O menino desleixado" (ANDRADE et al., 2009), e em uma das histórias intitulada "Zappel-Philipp" - no Brasil foi traduzido para "Felipe irrequieto" (LOUZÃ NETO, 2010) - é contada a história de um menino com características hiperativas, que ocasionou um conflito familiar devido ao seu comportamento irrequieto durante o jantar (SILVA, 2009). Em outro poema "Hans Guck-in-die-Luft" (João olha-para-o-ar), o mesmo autor descreve um menino com características de desatenção (LOUZÃ NETO, 2010).

A seguir é apresentado um trecho, adaptado para o português por Hallowell e Ratey (1994), do poema "The Story of Fidgety" de Hoffman (1845).

"Deixem-me ver se Philip é capaz

De ser um bom rapaz

Deixem-me ver se ele vai saber

Sentar-se quieto na hora de comer

Assim papai mandou Phil se comportar

E muito séria mamãe parecia estar

Mas Phil das Mãozinhas sem Paz, 
Não vai ficar parado jamais

Remexe-se o corpo, as mãozinhas

E também dá risadinhas

E então, posso declarar

Para frente e para trás põe-se a balançar,

Inclinando sua cadeira,

Como se fosse um cavalinho de madeira

"Philip! Não estou de brincadeira!"

Veja como é levada, e não se cansa

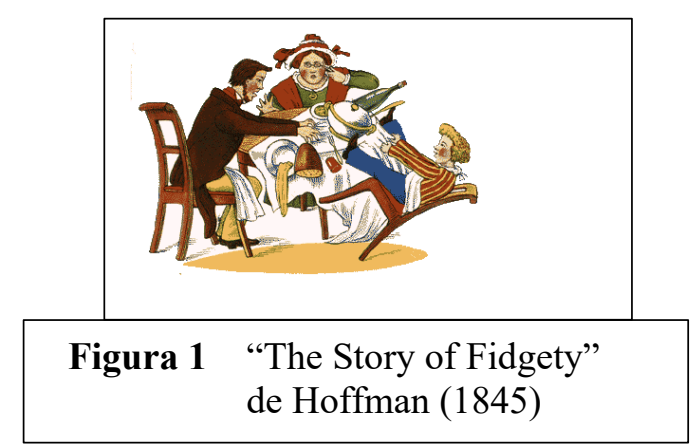

Cada vez mais selvagem essa criança...”

Grande parte dos pesquisadores, ao relatarem sobre o prejuízo em manter a atenção, descreviam que o componente emocional era a principal característica do transtorno que hoje é conhecido por Transtorno do Déficit de Atenção/Hiperatividade (TDAH) (BARKLEY, 1990). Concordando com o pensamento da época, Still (1902) descreve o comportamento observado em 43 crianças com problemas graves em manter a atenção e dificuldades em autorregulação, gerando agressividade, atitudes excessivamente emocionais ou passionais, mas sem comprometimento intelectual e o caracterizou como "Defeito de Controle Moral". Por outro lado, Strauss em 1918 (COLLARES; MOYSÉS, 2010) relaciona o comportamento de desatenção apresentado por algumas crianças a problemas de origem orgânica e, em 1944, STRAUSS (apud KRAINER, 1972), sugere o termo “Lesões Cerebrais Mínimas”, que não acometem outras funções neurológicas.

Ainda neste contexto histórico, foi demonstrado que devido à falta de estudos comprobatórios dos problemas neurológicos associados à desatenção e ao comportamento observado, em 1962, foi realizado um simpósio internacional, que reuniu pesquisadores dispostos a realizar um estudo longitudinal com os sujeitos diagnosticados com "Lesão Cerebral Mínima", mas os achados não sustentaram a ocorrência de lesões cerebrais (COLLARES; MOYSÉS, 2010). Por conseguinte, a doença da desatenção foi classificada como uma disfunção e o quadro passou a ser chamado de “Disfunção Cerebral Mínima” (FRANÇA, 2012). A primeira versão do Diagnostic and Statistical Manual (DSM-I), de 1952, não faz menção específica do TDAH (LOUZÃ NETO et al., 2009). Mas em 1968, a Associação Psiquiátrica Americana (APA) incluiu no DSM-II (Diagnostic and Statistical Manual) o termo "Síndrome Hipercinética", proposto por Clements (1966). Entretanto em 1980, o DSM-III propõe a alteração da denominação para "Síndrome de Déficit de Atenção com ou sem Hiperatividade". Uma nova terminologia ocorreu na revisão do DSM-IIIR (1987), que passou a ser reportado como “Distúrbio de Déficit de Atenção/Hiperatividade”. Sendo que, em 1993, a American 
Psychiatric Association, no DSM-IV, o termo passou a ser "Transtorno do Déficit de Atenção e Hiperatividade". Na versão atual do DSM-V (APA, 2013), a terminologia especificada é "Transtorno do Déficit de Atenção/Hiperatividade".

A figura 2 apresenta um resumo do histórico dos achados, na revisão de literatura deste trabalho, sobre o Transtorno do Déficit de Atenção/Hiperatividade, ao longo do tempo (Figura 2).

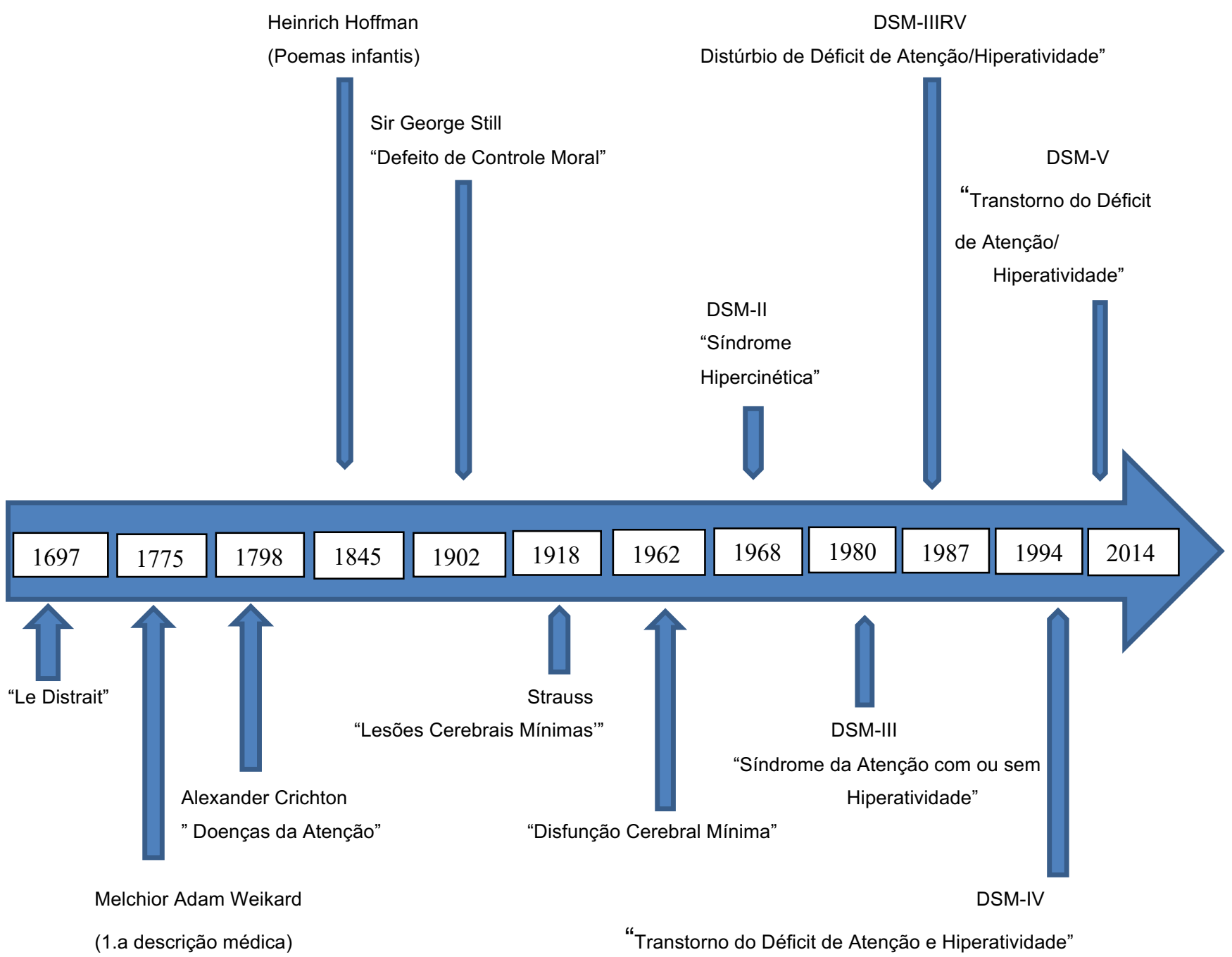

Figura 2 Histórico da nomenclatura do TDAH.

Com o passar dos tempos, houve um avanço no conhecimento sobre biologia molecular e em tecnologia de imagem cerebral, fatores que permitiram uma maior compreensão do desenvolvimento e comprometimento neural envolvido no transtorno, possibilitando assim, uma melhor adequação de sua nomenclatura. 
É interessante salientar que o critério diagnóstico para doenças mentais na infância foi incluído na terceira edição da DSM (1980) e isso facilitou as coletas de dados estatísticos, o que contribuiu para o planejamento de recursos de políticas públicas direcionadas à saúde (POLANCZYK et al., 2015).

\subsection{QUADRO CLÍNICO DO TRANSTORNO DO DÉFICIT DE ATENÇÃO/HIPERATIVIDADE}

O transtorno do déficit de atenção/hiperatividade é caracterizado por uma tríade de sintomas de desatenção, hiperatividade e impulsividade que interferem frequente e persistentemente no funcionamento e desenvolvimento do indivíduo, levando a prejuízos nas atividades sociais, acadêmicas/profissionais longo da vida (BARKLEY, 1998; APA, 2013).

Entende-se por desatenção "a incapacidade de permanecer em uma tarefa, aparência de não ouvir e perda de materiais em níveis inconsistentes com a idade ou o nível de desenvolvimento" (DSM5, 2013, p. 105). Já a hiperatividade e impulsividade estão relacionadas à "atividade excessiva, inquietação, incapacidade de permanecer sentado, intromissão em atividades de outros e incapacidade de aguardar, sintomas que são excessivos para a idade ou o nível de desenvolvimento" (DSM-5, 2013, p. 105). A manifestação dos sintomas do TDAH deve aparecer antes dos 12 anos de idade e estar presente em dois ou mais contextos diferentes (APA, 2013).

O critério diagnóstico do TDAH classifica por desatenção a ocorrência de seis ou mais sintomas persistentes (Quadro 1), por pelo menos seis meses, e que causem prejuízos nas atividades psicossociais. Em pessoas com 17 anos ou mais, pelo menos cinco sintomas devem estar presentes. Além disso, os sintomas não são apenas caracterizados pela manifestação do comportamento opositor, desafio, hostilidade ou dificuldade para compreender tarefas ou instruções. 
Quadro 1 - Critérios de Diagnóstico de Desatenção Característicos no TDAH.

\begin{tabular}{|c|l|}
\hline Critérios & \multicolumn{1}{c|}{ Características } \\
\hline A & $\begin{array}{l}\text { Frequentemente não presta atenção em detalhes ou comete erros por descuido em } \\
\text { tarefas acadêmica, profissionais ou outras atividades. }\end{array}$ \\
\hline B & $\begin{array}{l}\text { Frequentemente tem dificuldade em manter a atenção em tarefas de lazer ou } \\
\text { acadêmicas. }\end{array}$ \\
\hline C & Frequentemente parece não escutar quando é solicitado. \\
\hline D & Frequentemente não segue instruções até o fim e não conclui tarefas. \\
\hline E & Frequentemente tem dificuldade na organização de tarefas e atividades. \\
\hline F & $\begin{array}{l}\text { Frequentemente evita ou se mostra resistente às tarefas de esforço mental } \\
\text { prolongado. }\end{array}$ \\
\hline G & Frequentemente perde objetos necessários para tarefas e atividades. \\
\hline H & Frequentemente é distraído por estímulos externos. \\
\hline I & Frequentemente esquece compromissos ou atividades cotidianas. \\
\hline
\end{tabular}

Fonte: DSM - 5 (2013).

O critério diagnóstico do TDAH classifica por "Hiperatividade e Impulsividade" a ocorrência de seis ou mais sintomas persistentes (Quadro 2), por pelo menos seis meses, apresentem um grau incompatível com a idade de desenvolvimento e tenham impacto negativo nas atividades acadêmica/profissionais e sociais. Em pessoas com 17 anos ou mais, pelo menos cinco sintomas devam estar presentes.

Quadro 2 - Critérios de Diagnóstico de Hiperatividade e Impulsividade Característicos no TDAH.

\begin{tabular}{|c|l|}
\hline Critérios & \multicolumn{1}{c|}{ Características } \\
\hline A & Frequentemente remexe ou batuca mãos ou pés ou se contorce na cadeira. \\
\hline B & Frequentemente se levanta da cadeira, quando não deveria. \\
\hline C & Frequentemente corre ou sobe nas coisas inapropriadamente. \\
\hline D & Frequentemente é incapaz de realizar tarefas calmamente. \\
\hline E & Frequentemente "não para" é agitado. \\
\hline F & Frequentemente fala em excesso. \\
\hline G & Frequentemente deixa escapar uma resposta antes que a pergunta seja feita. \\
\hline H & Frequentemente tem dificuldade em esperar sua vez. \\
\hline I & Frequentemente interrompe ou se intromete quando não deveria. \\
\hline
\end{tabular}

Fonte: DSM - 5 (2013).

É caracterizada por Apresentação Combinada do TDAH quando os sintomas da desatenção e da hiperatividade/impulsividade estão presentes simultaneamente nos últimos seis meses. Rohde et al. (1999) estudou adolescentes na faixa etária entre 12 e 14 anos, e encontrou uma maior prevalência da apresentação combinada do transtorno do déficit de atenção/hiperatividade, sendo um total de 62,5\%. 
A apresentação predominantemente desatenta encontrada foi de $26,3 \%$ e a predominantemente hiperativa/impulsiva, em $11,2 \%$ das crianças avaliadas, estando de acordo com outros estudos (FARAONE, 1998; GADOW et al., 2000; FONTANA et al., 2007).

WILLCUTT (2012) realizou um estudo de metanálise da literatura internacional publicada entre os anos de 1994 a 2010, encontrando 86 artigos que utilizaram os mesmos critérios para o TDAH (DSM-IV) em crianças e adolescentes. O resultado encontrando como apresentação mais frequente foi a predominantemente desatenta, havendo grande concordância entre as respostas de pais, professores e criança/adolescente. As apresentações predominantemente hiperativa e combinada obtiveram diferentes respostas que dependeram do informante - pai, professor ou criança/adolescente - mas os resultados mostraram que mais critérios foram indicados para a apresentação combinada quando comparada à apresentação hiperativa.

Ainda no manual do DSM-5 (APA, 2013) é orientado que a gravidade atual do transtorno deve estar especificada no diagnóstico, podendo ser: leve, se ocorrerem poucos sintomas e os sintomas resultarem em não mais do que pequenos prejuízos no funcionamento social ou profissional; moderada, se estão presentes sintomas ou prejuízo funcional entre "leve" e "grave"; e grave, se estão presentes muitos sintomas, além dos necessários para fazer o diagnóstico, ou vários sintomas particularmente graves estão presentes, ou os sintomas podem resultar em prejuízo acentuado no funcionamento social ou profissional.

$\mathrm{Na}$ falta de marcadores biológicos específicos, o diagnóstico do TDAH é baseado nos achados clínicos, através da observação da frequência, da persistência e da intensidade da sintomatologia listada nos sistemas classificatórios de saúde e observados os prejuízos ocasionados na vida da pessoa com o transtorno. Atualmente existem dois sistemas internacionais de classificação das doenças: o Manual Diagnóstico e Estatístico de Transtornos Mentais (DSM) e a Classificação Estatística Internacional de Doenças e Problemas Relacionados à Saúde (CID - Quadro 3), sendo o DSM mais amplamente utilizado em pesquisas (DEMPSEY, 2017; GOULARDINS, 2016; SILVA, 2014).

Quadro 3 - Classificação Estatística Internacional de Doenças e Problemas Relacionados à Saúde TDAH.

\section{CID - 11}

6A05 $\quad$ Transtorno do Déficit de Atenção/Hiperatividade

6A05.0 Apresentação predominantemente desatenta.

6A05.1 Apresentação predominantemente hiperativa/impulsiva.

6A05.2 Apresentação combinada.

Fonte: OMS (2018). 
A manifestação dos sintomas do TDAH pode diferir de acordo com a idade em que a criança é diagnosticada (BIEDERMAN, MICK E FARAONE, 2000; VAN LIER et al., 2007; LARSSON et al., 2011; DOFNER et al., 2014). Parece haver uma diminuição do grau de hiperatividade/ impulsividade no decorrer do desenvolvimento, haja visto que as crianças da fase pré-escolar tendem a apresentar mais o comportamento hiperativo. Já as crianças na fase escolar parecem demonstrar características mais de desatenção, enquanto na adolescência ficam evidentes características de inquietude, irritação e impaciência (BIEDERMAN et al., 1998; DSM-5, 2013; FARAONE, BIEDERMAN E MONUTEAUX, 2002).

Os pesquisadores Rohde et al. (2004), através da revisão de literatura, apontaram os aspectos históricos, epidemiológicos, etiológicos, neurobiológicos, clínicos, comórbidos, diagnósticos e evolutivos no tratamento do transtorno do déficit de atenção/hiperatividade e trazem um resumo da "história clássica" da sintomatologia encontrada em cada fase de desenvolvimento da pessoa com o transtorno do déficit de atenção/hiperatividade, sendo que na fase caracterizada por "escola elementar", os sintomas são a incapacidade de colocar foco, a distração, a impulsividade, o desempenho inconsistente, a presença ou não de hiperatividade. Na fase dita "adolescência", os sintomas se apresentam como inquietude e com desempenho inconsistente, sem conseguir colocar foco, dificuldade de memória na escola, abuso de substância e acidentes.

Jain et al. (2017) também estudaram o impacto do TDAH nas fases do desenvolvimento humano e enfatizam que na fase escolar, além das dificuldades acadêmicas, ocorrem dificuldades em se relacionar com os pares, baixa autoestima, uso do cigarro, pequenos delitos e maior risco de acidentes.

Um importante ponto destacado por Barkley (1997) é de que o TDAH, com o passar do tempo, ficou caracterizado por apenas duas de suas características, sendo estas: a dificuldade atencional e o quadro de hiperatividade que está associado a impulsividade. Barkley (2017), em uma palestra para pais e familiares de crianças com TDAH, faz uma crítica à união destes prejuízos, enfatizando a necessidade de valorizar o aspecto da impulsividade emocional, que é entendido por ficar facilmente empolgado, ter baixa tolerância à frustração, rapidez em se irritar, mostrar emoção muito mais rapidamente que outros, falha em regular as emoções normais, incapacidade de se acalmar e se tranquilizar para ser melhor aceito no contexto social e, o que considera o cerne do transtorno, a dificuldade em autorregulação. Encontram-se, na literatura, opiniões enfatizando a fraca inibição comportamental como o prejuízo fundamental do TDAH (BARKLEY, 1990, 1994; SCHACHAR; TANNOK; MARRIOT; LOGAN, 1995). 


\subsection{EPIDEMIOLOGIA DO TRANSTORNO DE DÉFICIT DE ATENÇÃO/HIPERATIVIDADE}

A prevalência mundial de doença mental entre crianças e adolescentes é estimada em $13.4 \%$ e em relação ao TDAH é de 3,4\% (POLANCZYK et al., 2015), enquanto nos adultos o índice é de 2,5\% (APA, 2013).

Através de uma revisão sistematizada de literatura, os pesquisadores Polanczyk et al. (2015) analisaram 41 estudos, sendo 33 sobre o TDAH, publicados entre 1985 a 2012, em 27 países. Esses autores perceberam que as variações nas estimativas de prevalências do TDAH dependeram dos critérios metodológicos e diagnósticos utilizados nos estudos encontrados e não das datas de realização das pesquisas e da geografia do local do estudo, pois havia poucas pesquisas conduzidas na África, Oceania e Leste Europeu.

No Brasil, o estudo de Pastura et al. (2007) realizado em uma escola de aplicação, na cidade do Rio de Janeiro, com amostra composta por 304 alunos do ensino fundamental, diagnosticou 26 alunos com o TDAH, indicando a prevalência de $8,6 \%$, sendo deste total $88 \%(n=23)$ do sexo masculino e 12\% ( $\mathrm{n}=3)$ do sexo feminino. O estudo de Freire e Pondé (2005 apud HORA et al., 2015), também realizado no Brasil, com a mesma faixa etária do estudo de Pastura et al. (2007), 6 a 17 anos, encontrou a prevalência do TDAH de $6.7 \%$.

Em relação ao gênero, nota-se uma maior frequência do transtorno no sexo masculino em relação ao feminino, com uma proporção de cerca de 2:1 nas crianças, em amostras populacionais, e de 10:1 em amostras clínicas (SCAHILL E SCHWAB-STONE, 2000; WILLCUTT, 2012; APA, 2013). Nos adultos, a prevalência populacional é de 1,6:1 (WILLCUTT, 2012; APA, 2013). Poucos estudos correlacionaram o nível sócio econômico e o TDAH (AMIRI et al., 2010; COSTELLO et al., 2001; PINEDA et al., 1999; BIERDEMAN et al., 1995). Alguns estudos apontaram que indivíduos de nível socioeconômico mais baixo apresentam 1,5-4 vezes maior probabilidade de apresentar os critérios para o TDAH do que os de classes mais altas, embora alguns pesquisadores não obtiveram dados significativos ou relação direta do transtorno com o nível socioeconômico (FARAONE, ASHERSON, BANASCHEWSKI et al., 2015). 


\subsection{ETIOLOGIA DO TRANSTORNO DE DÉFICIT DE ATENÇÃO/HIPERATIVIDADE}

Embora a etiologia do TDAH ainda não esteja evidente (SONUGA-BARKE, 2005), múltiplos fatores de risco genéticos e ambientais parecem atuar conjuntamente, criando um espectro de responsáveis neurobiológicos (CURATOLO et al., 2010). Estima-se que os fatores ambientais contribuam em $40 \%$ e a herdabilidade em $60 \%$ para o desenvolvimento do transtorno (LEHN et al., 2007).

- Fatores genéticos:

Os fatores de ordem genética revelam uma maior incidência familiar do TDAH, com um risco de 2 a 8 vezes maior em familiares de $1^{\circ}$ grau (FARAONE et al., 2005). Estudos com gêmeos mostram que o TDAH é uma condição altamente herdada, sendo de $80 \%$ entre os gêmeos monozigóticos e de $30 \%$ entre os dizigóticos, mas devido à complexa arquitetura genética do TDAH (PURPER-OUAKIL et al., 2011), ainda se fazem necessários mais estudos para identificar os genes implicados na etiologia deste transtorno. Faraone (2010) faz uma metanálise sobre os possíveis genes envolvidos no TDAH e observa que muitos genes (DBH, MAOA, SLC6A2, TPH-2, SLC6A4, CHRNA4, GRIN2A, etc.) atuam com pequenos efeitos, sendo difícil discriminar o efeito de cada gene.

- Fatores ambientais:

Os fatores ambientais no TDAH podem ser de origem pré, peri ou pós-natal, como nos casos em que a gestante é exposta ao tabaco, álcool e outras drogas, ocasionando diminuição de oxigênio para o feto; retardo do crescimento intra-uterino; complicações no parto; baixo peso ao nascer e prematuridade (APA, 2013). Os conflitos familiares graves, abuso infantil, negligência, múltiplos lares, também podem estar associados ao TDAH (BANERJEE, MIDDLETON e FARAONE, 2007).

Faz-se necessário entender a etiologia do TDAH para a identificação de estratégias de tratamentos assertivas que promovam uma melhor qualidade de vida para a pessoa com o TDAH.

\subsection{COMPORTAMENTO SOCIAL DO TRANSTORNO DO DÉFICIT DE ATENÇÃO/HIPERATIVIDADE}

Segundo Pelham \& Bender (1982), mais de 50\% das crianças com TDAH têm problemas significativos nos relacionamentos sociais com outras crianças. As mães (CAMPBELL; PAULAUSKAS, 1979), os professores (BARKLEY; PELHAM; MURPHY, 1989) e outras crianças (JOHNSTON; PELHAM; MURPHY, 1985; POPE; BIERMAM; MUMMA, 1989) consideram as 
crianças hiperativas significativamente mais agressivas, perturbadoras, dominadoras, intrusivas, ruidosas e socialmente rejeitadas nos relacionamentos quando comparadas às crianças típicas (DUPAUL et al., 2001; HINSHAW, MELNICK, 1995; MILICH, LANDAU, KILBY, WHTTEN, 1982; PELHAM, BENDER, 1982). Estudos que observaram diretamente as interações infantis, sugerem que os comportamentos desatentos, disruptivos, distraídos, imaturos e provocadores suscitam um padrão de comportamento controlador e diretivo sobre seus colegas, quando deveriam trabalhar juntos (CLARK, CHEYNE, CUNNINGHAM, SIEGEL, 1988; HINSHAW, 1992; HINSHAW; MELNICK, 1995; STROES, ALBERTS, VAN DER MEERE, 2003). O estudo de Cunningham e Siegel (1987) analisou 120 crianças, de 5 a 12 anos de idade, separadas por faixas etárias de 5 a 8 anos e 9 a 12 anos e divididas em 60 duplas, onde 30 duplas mistas foram compostas por uma criança com TDAH e a outra sem o TDAH e 30 duplas típicas, onde as duas crianças não apresentavam o TDAH. Esses pesquisadores observaram as crianças interagindo por 45 minutos, distribuídos em 15 minutos de atividades de cooperação, 15 minutos de brincadeiras livres e 15 minutos de atividades de estimulação. E puderam concluir que as duplas mistas, formadas por crianças mais novas, interagiram de forma mais controladora e menos complacente, ao passo que as crianças do grupo etário mais velho (9 a 12 anos), mostraram ser mais hábeis em evitar conflitos e manter um comportamento mais colaborativo, o que diminuiu a tendência de interromper a atividade proposta. Entretanto, foi verificado um aumento de independência e isolamento nas brincadeiras e atividades direcionadas.

Stroes et al. (2003) também observaram crianças com TDAH interagindo entre si e verificaram que elas se envolvem menos com as outras crianças e falam mais consigo mesmas, pois quando questionadas por outras crianças, não parecem responder às questões ou interações verbais. Este comportamento sugere que há menos reciprocidade nas trocas sociais entre elas e seus pares.

A criança com TDAH pode apresentar um comportamento agitado, marcado pela troca contínua de atividades que leva a problemas na organização acadêmica e dificuldade de estabelecer relações de amizade (POETA; ROSA NETO, 2004).

Evidências indicam que a competência motora e participação física são cruciais para o funcionamento positivo nos domínios sociais e emocionais (AHN; FEDWA, 2011; CAIRNEY, RIGOLI \& PIEK, 2013). O engajamento de crianças com sintomas de desatenção e/ou hiperatividade e impulsividade, em programas bem estruturados de atividade física, parece surtir efeito positivo para o desenvolvimento de habilidades sociais destas crianças. Corroborando com essa ideia, a autora Piek (2013) desenvolveu o programa Animal Fun, durante 6 meses, 4 vezes por semana, junto a 511 crianças, de 4 a 6 anos de idade, que apresentavam dificuldades nas habilidades pró-sociais e baixo desempenho motor e concluiu que o programa resultou em significativa melhora no comportamento pró-social e motor do grupo de intervenção. 
O desenvolvimento social de pessoas com o TDAH pode ser piorado pela presença do Transtorno de Oposição Desafiante (TOD), cuja prevalência de associação é de $60 \%$ nas crianças e $40 \%$ nos adultos (BIEDERMAN et al., 1999). As crianças com o diagnóstico diferencial do TOD se mostram resistentes às tarefas/trabalhos escolares que exijam autodeterminação e atenção, têm dificuldades em aceitar a autoridade dos adultos, apresentam comportamentos hostis, desafiantes e negativos (APA, 2013). Os autores Grevet et al. (2007) analisaram os efeitos da comorbidade dos transtornos de oposição desafiante (TOD), de conduta (TC) e de personalidade antissocial (TPAS) de indivíduos com TDAH ao longo da vida, e concluíram que o TOD intensifica as características de impulsividade e isolamento social da pessoa diagnosticada com o TDAH.

Na revisão bibliográfica deste estudo, foi evidenciado que pessoas com o transtorno do déficit de atenção/hiperatividade podem apresentar prejuízos nas interações sociais e tais dificuldades podem ser agravadas pela coocorrência do transtorno de oposição desafiante (TOD). Frente a isso, o presente estudo pretende identificar o perfil socioemocional de escolares do ensino fundamental II, com indicativos do transtorno do déficit de atenção/hiperatividade e observar se há a ocorrência do TOD nesta população. 


\section{JUSTIFICATIVA E QUESTÃO}

A inabilidade social, os problemas de autorregulação e o comportamento inadequado apresentado por muitos escolares com indícios de TDAH podem gerar problemas com os seus pares escolares sem o TDAH, resultando em dificuldades de relacionamento. Desta forma, a pessoa com indicativos do TDAH pode vivenciar situações em que é menosprezado(a), desvalorizado(a) ou mesmo rotulado(a) negativamente, o que pode levá-lo(a) à depressão, ansiedade, problemas de alimentação, abuso de substâncias e evasão escolar, entre tantos outros (MIKAMI, 2015; APA, 2013).

A identificação de escolares com indicativos do TDAH, bem como a compreensão do impacto negativo deste transtorno, é muito importante para a intervenção, tanto na infância quanto na adolescência, por meio de programas que visem reduzir os prejuízos ao longo da vida (FERREIRA, 2011).

Os conflitos gerados pelo comportamento inadequado do(a) escolar com indicativos do TDAH podem ser evitados ou mais bem encaminhados se há um aumento do entendimento do transtorno (JOU et al., 2010).

A questão norteadora deste trabalho é: Qual o perfil socioemocional de escolares do ensino fundamental II (10 a 15 anos), com indicativos do transtorno do déficit de atenção/hiperatividade em dois contextos: nas aulas de educação física e no âmbito familiar? 


\section{OBJETIVO}

\subsection{OBJETIVO GERAL}

Identificar o perfil socioemocional de escolares do ensino fundamental II (de 10 a 15 anos), com indicativos do transtorno do déficit de atenção/hiperatividade em dois contextos: nas aulas de educação física e no âmbito familiar.

\subsection{OBJETIVOS ESPECÍFICOS}

$\checkmark$ Identificar os(as) escolares com indicativos do TDAH;

$\checkmark$ Identificar o transtorno de oposição desafiante (TOD) como comorbidade do TDAH;

$\checkmark$ Descrever o perfil socioemocional dos(as) escolares com indicativos do TDAH e

$\checkmark$ Correlacionar o índice de massa corporal dos(as) escolares com indicativos do TDAH. 


\section{MÉTODO}

\subsection{TIPO DE ESTUDO}

O estudo teve característica transversal e descritiva com delineamento quantitativo, além de ser um estudo que envolveu um único estabelecimento de ensino privado, com característica de alto padrão socioeconômico.

\subsection{AMOSTRA}

O estudo investigou um total de 950 alunos(as), que cursavam os $6^{\circ}, 7^{\circ}, 8^{\circ}$ e $9^{\circ}$ anos do ensino fundamental II, de um colégio da rede privada de ensino, do município de São Paulo, de ambos os sexos, com idades compreendidas entre 10 a 15 anos de idade. Todos os(as) alunos(as) da instituição de ensino que apresentaram diagnóstico com indicativos do TDAH foram alvos deste estudo.

\subsection{CRITÉRIOS DE INCLUSÃO}

Todos os(as) alunos(as) seguiram os critérios de inclusão: idade entre 10 e 15 anos, com indicativos do TDAH, podendo estar em tratamento medicamentoso específico do TDAH, colaboração no processo de avaliação, aceitação dos pais e/ou responsáveis da participação no estudo, assinatura do Termo de Consentimento Livre e Esclarecido (TCLE) (ANEXO 1) e não estar dispensado das aulas de Educação Física.

\subsection{CRITÉRIOS DE EXCLUSÃO}

Todos os(as) alunos(as) seguiram os critérios de exclusão: alunos(as) que não se enquadraram na faixa etária de 10 e 15 anos, a não aceitação dos pais e/ou responsáveis da participação no estudo, a não assinatura do Termo de Consentimento Livre e Esclarecido (TCLE) e estar dispensado das aulas de Educação Física. 


\section{INSTRUMENTOS DE AVALIAÇÃO}

\subsection{SWANSON, NOLAN AND PELHAM QUESTIONNAIRE (SNAP-IV)}

O SNAP-IV (ANEXO 2) é um instrumento de domínio público, desenvolvido para avaliação de sintomas do transtorno de déficit de atenção/hiperatividade em crianças e adolescentes, podendo ser preenchido por pais ou professores e que emprega 26 sintomas, a versão completa, e 18 sintomas, a versão resumida, listados no DSM-V para transtorno do déficit de atenção/hiperatividade (MATTOS et al., 2006).

Nesta pesquisa foi utilizada a versão completa com 26 itens no SNAP - IV, pois pretendeu-se averiguar a ocorrência do TOD. Os pesquisadores Andrade \& Vasconcelos (2018) analisaram a literatura relacionada ao TDAH do período compreendido entre 2013 a 2017 e encontraram a taxa de comorbidade entre 30 a 50\% entre o TDAH e os transtornos disruptivos de comportamento, como o TOD.

No SNAP-IV estão incluídos 8 sintomas característicos do TOD, sendo necessários um mínimo de 4 sintomas para indicar o TOD. Seguem abaixo as frases do SNAP-IV referente ao TOD:

Itens de 19 a 26

19 - Descontrola-se

20 - Discute com adultos

21 - Desafia ativamente ou se recusa a atender pedidos ou regras de adultos

22 - Faz coisas de propósito que incomodam outras pessoas

23 - Culpa os outros pelos seus erros ou mau comportamento

$24-E$ É irritável ou facilmente incomodado pelos outros

$25-E$ Eangado e ressentido

26-É maldoso ou vingativo

A gravidade do TOD deve ser especificada em leve, quando os sintomas limitam-se a apenas um ambiente; moderada, quando sintomas estão presentes em pelo menos dois ambientes; e grave, se sintomas estão presentes em três ou mais ambientes (APA, 2013). 


\subsection{STRENGTHS AND DIFFICULTIES QUESTIONNAIRES (SDQ-POR)}

Os pesquisadores Piek et al. (2013, 2015), Ayaz et al. (2013) e Cairney et al. (2013) utilizaram, para investigar os aspectos socioemocionais de crianças e adolescentes, o instrumento de avaliação Strengths and Difficulties Questionnaire (SDQ), que é um questionário de avaliação comportamental com alta confiabilidade. O Strengths and Difficulties Questionnaire foi traduzido e validado para população brasileira (FLEITLICH; BACY; CORTÁZAR; PILAR GARCIA; GOODMAN; ROBERT, 2000) ficou com a seguinte descrição Strengths and Difficulties Questionnaire - Português (SDQPor).

Neste estudo foi utilizado o questionário SDQ-Por (ANEXO 3) para crianças compreendidas na faixa etária de 4 a 17 anos. Tal questionário consta de 25 itens, que podem ser respondidos por pais ou professores, e contém 5 subescalas, incluindo: problemas emocionais, problemas de conduta, hiperatividade, problemas entre pares e avaliação do comportamento pró-social. A partir da soma da pontuação das 4 primeiras subescalas, citadas previamente, é gerada uma pontuação total de dificuldades e, separadamente, é contabilizada a subescala do comportamento pró-social. O SDQ-Por tem demonstrado efeito psicométricamente satisfatório, alta confiabilidade e validade (GOODMAN, 2001). A pontuação total gera um escore para classificação em: normal, limítrofe e anormal, como apontam os quadros abaixo:

Quadro 4 - Escores de pais e professores, segundo pontuação geral do SDQ-Por.

\begin{tabular}{|ccc|}
\hline Categoria & Pais & Professor \\
\hline Normal & $0-13$ & $0-11$ \\
\hline Limítrofe & $14-16$ & $12-15$ \\
\hline Anormal & $17-40$ & $16-40$ \\
\hline
\end{tabular}

Quadro 5 - Escores de pais e professores, segundo pontuação da subescala Prósocial.

\begin{tabular}{|ccr|}
\hline Categoria & Pais & Professor \\
\hline Normal & $6-10$ & $6-10$ \\
\hline Limítrofe & 5 & 5 \\
\hline Anormal & $0-4$ & $0-4$ \\
\hline
\end{tabular}




\section{3 ÍNDICE DE MASSA CORPORAL (IMC)}

O Índice de Massa Corporal (IMC) é uma da medida antropométrica usada para determinar o risco de acometimento por doenças relacionadas ao excesso de peso da população. A seguir são mostrados os valores para o IMC de pré-adolescentes e adolescentes.

Para a determinação do índice de massa corporal (IMC) foi aferido o peso com a utilização de balança antropométrica, onde os avaliados foram pesados vestindo apenas roupas leves e sem calçados. No momento do exame, os alunos(as) estavam eretos, no centro da balança com os braços estendidos ao lado do corpo, sem se movimentar. A balança foi colocada em uma superfície plana e lisa. O peso foi expresso em quilogramas. Para determinar a estatura foi utilizada uma fita métrica fixada na parede e os avaliados estavam em posição ereta, com pés e calcanhares paralelos, ombros e nádegas encostados na parede. A estatura foi expressa em metro, com uma casa decimal. O IMC foi obtido pela divisão do peso, pela estatura elevada ao quadrado $\left(\mathrm{Kg} / \mathrm{m}^{2}\right)$ e comparada em relação ao padrão NCHS/OMS. O índice foi expresso em unidades de escore Z, segundo recomendações da Organização Mundial de Saúde para avaliação nutricional de populações.

Quadro 6 - Índice de massa corporal, segundo sexo (OMS, 2017).

\begin{tabular}{|c|c|c|c|}
\hline \multicolumn{4}{|c|}{ FEMININO } \\
\hline$I D A D E$ & BAIXO PESO & $A D E Q U A D O$ & SOBREPESO \\
\hline 11 & $A T E ́$ 14,5 & 14,6 A 21,0 & A PARTIR DE 21,1 \\
\hline 12 & $A T E ́$ 15,0 & 15,1 A 22,0 & A PARTIR DE 22,1 \\
\hline 13 & $A T E ́$ 15,5 & 15,6 A 23,0 & A PARTIR DE 23,1 \\
\hline 14 & $A T E ́ 15,6$ & 15,7 A 24,0 & A PARTIR DE 24,1 \\
\hline 15 & $A T E ́$ 16,0 & $16,1 \mathrm{~A} 24,0$ & A PARTIR DE 24,3 \\
\hline \multicolumn{4}{|c|}{ MASCULINO } \\
\hline$I D A D E$ & BAIXO PESO & $A D E Q U A D O$ & SOBREPESO \\
\hline 11 & $A T E ́$ 15,0 & $15,1 A 20,5$ & A PARTIR DE 20,6 \\
\hline 12 & $A T E ́ 15,2$ & 15,3 A 21,0 & A PARTIR DE 21,1 \\
\hline 13 & $A T E ́$ 15,6 & 15,7 A 22,0 & A PARTIR DE 22,1 \\
\hline 14 & $A T E ́$ 16,0 & 16,2 A 23,0 & A PARTIR DE 23,1 \\
\hline 15 & $A T E ́$ 16,5 & 16,7 A 23,5 & A PARTIR DE 23,6 \\
\hline
\end{tabular}

Fonte: http://portalms.saude.gov.br/component/content/article/804-imc/40510-imc-em-criancas-eadolescentes (acesso em 3/7/2018 às 14hs). 


\section{DELINEAMENTO E PROCEDIMENTO}

A pesquisa foi realizada em um colégio da rede particular do município de São Paulo. O critério de escolha da escola foi por conveniência e o diretor pedagógico aprovou e assinou o TERMO DE ANUÊNCIA (ANEXO 4). Os(as) alunos(as) abordados(as) cursavam o ensino fundamental II, que compreende os $6^{\circ}, 7^{\circ}, 8^{\circ}$ e $9^{\circ}$ anos, do período vespertino.

Em um segundo momento, os pesquisadores deste estudo realizaram uma palestra para os professores do ensino fundamental II, coordenadores pedagógicos e orientadores educacionais da instituição. Os temas abordados foram as características do TDAH, suas implicações acadêmicas, seus aspectos socioemocionais e motores.

A seguir será explicado como foi a abordagem em relação aos pais ou responsáveis dos(as) escolares pesquisados(as) e na sequência o procedimento junto aos professores de educação física.

Na primeira chamada da pesquisa (ANEXO 5), foram enviados 2.000 e-mails aos responsáveis. Desses 1.153 abriram o e-mail, desses que abriram, 285 clicaram nos links dos questionários e 158 responderam os questionários; ocorreu uma segunda chamada da pesquisa, em que foram enviados 1.996 e-mails aos responsáveis. Desses 1.204 abriram o e-mail, desses que abriram, 230 clicaram nos links dos questionários e 137 responderam os questionários; ocorreu a terceira e última chamada da pesquisa em que foram enviados 1.985 e-mails aos responsáveis. Desses, 802 abriram o e-mail, desses que abriram, 94 clicaram nos links dos questionários e 33 responderam os questionários.

O total de questionários retornados foi de 328 questionários do SNAP-IV e 325 questionários do SDQ-Por.

Em relação ao questionário do SNAP-IV, que foi a ferramenta utilizada para rastreamento dos indicativos do TDAH, dos 328 questionários retornados, 21 preencheram o critério de exclusão, por estarem fora da idade-alvo da nossa pesquisa. Desta forma, 307 questionários foram analisados e encontramos os indicativos do TDAH em 27 escolares.

Em relação à abordagem junto aos professores de educação física do colégio pesquisado, os pesquisadores foram às aulas de educação física durante o período de 3 de novembro de 2019 a 11 de março de 2020. A estrutura das aulas de educação física permitiu que os pesquisadores pudessem solicitar aos professores que observassem a turma e respondessem os questionários durante a própria aula. Haja visto que uma turma possui em média 34 alunos, com dois professores e dois monitores, e as aulas aconteceram duas vezes na semana, com duração de 50 minutos cada. Os pesquisadores solicitaram aos professores que observassem os alunos e apontassem se algum chamava atenção por atitudes como, por exemplo, manter-se afastado do grupo constantemente, não prestar atenção nas explicações e parecer ficar "perdido" na atividade, desrespeito aos professores e monitores, envolver- 
se em desentendimentos entre pares, etc. Após isso, os professores receberam um tablete constando os dois questionários (SNAP-IV e SDQ-Por), o que facilitou o preenchimento e envio desses.

O total de respostas dos professores foram de 57 em ambos os questionários. Todavia, 10 escolares estavam fora da idade estipulada neste estudo e 3 alunos saíram do colégio, restando 44 escolares para análise. Dos 44 escolares, 33 apresentaram os indicativos para o TDAH.

Após a análise isolada das respostas de pais/responsáveis e professores de educação física, os pesquisadores viram quais escolares apresentavam os indicativos do TDAH de acordo com os dois informantes e encontraram 14 escolares alvos da pesquisa.

O total de questionários válidos do SNAP-IV analisados foi composto por: 307 indicados pelos pais/responsáveis e 44 indicados pelos professores de educação física, sendo que desses, apenas 21 não estavam nas indicações dos pais/responsáveis, então somando todos os questionários elegíveis obtivemos o total de 328 questionários.

A figura 3 apresenta um fluxograma baseado nas respostas do questionário SNAP-IV, pois foi o instrumento usado para detectar os indicativos do TDAH e para identificar os alunos alvos deste estudo.

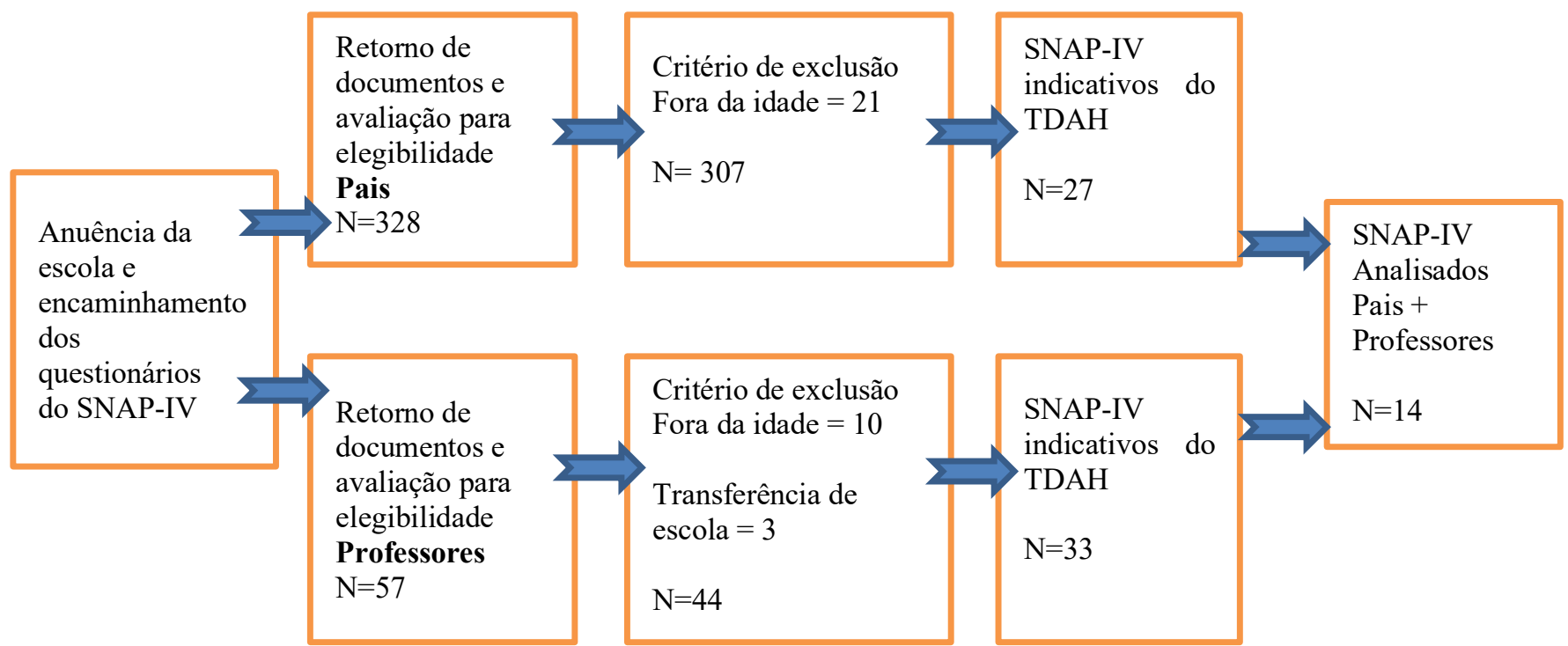

Figura 3 - Fluxograma do estudo com base no SNAP-IV e relacionando as respostas de Pais e de Professores de Educação Física.

Os professores de educação física do colégio realizam a avaliação biométrica, para acompanhar o crescimento e desenvolvimento dos(as) escolares, três vezes durante o ano, nas aulas de educação física. A primeira medição foi realizada na segunda semana de fevereiro, quando todos os(as) 
alunos(as) foram pesados(as) e medidos(as) para a determinação do Índice de Massa Corporal (IMC). Os pesquisadores acompanharam as avaliações biométricas dos(as) escolares.

As famílias envolvidas na pesquisa serão chamadas ao colégio para uma conversa com a psicóloga da instituição e com os pesquisadores do estudo, para que sejam orientadas e encaminhadas para uma avaliação e verificação do diagnóstico. Além disso, nesta reunião serão esclarecidas as apresentações do TDAH quanto sua sintomatologia, a necessidade de acompanhamento profissional e apoio familiar para o desenvolvimento saudável do(a) escolar. Será, também, indicado um médico para dar um parecer sobre a suspeita do TDAH. Todos os professores, orientadores educacionais e coordenadores do colégio serão convidados para uma reunião sobre os resultados deste estudo. 


\section{COMITÊ DE ÉTICA EM PESQUISA}

Este trabalho foi submetido e aprovado pelo Comitê de Ética em Pesquisa vinculado à escola de Educação Física e Esporte da Universidade de São Paulo (CEP- EEFEUSP), sob o número CAAE 04938818.8.00005391 (ANEXO 6). 


\section{ANÁLISE DE DADOS E ESTATÍSTICA}

Neste tópico será apresentado o tratamento estatístico empregado neste estudo.

Em um primeiro momento foi feita a Análise Descritiva Marginal de cada uma das variáveis envolvidas no estudo. Para cada variável categórica, apresentaremos uma tabela e um gráfico de frequências, contendo a frequência e percentual de observações para cada categoria da variável. Para cada variável numérica, apresentamos uma tabela contendo as estatísticas descritivas da variável e um gráfico de histograma.

As estatísticas descritivas apresentadas, além da média, são:

- Tamanho Amostral (N): quantidade de observações na amostra.

- Desvio Padrão: medida da variação dos dados. Quanto maior o desvio padrão, maior é a variação das observações da amostra.

- Mínimo: menor valor observado na amostra.

- $\quad 1^{\circ}$ Quartil: valor tal que $25 \%$ das observações possuem um valor na variável abaixo dele.

- Mediana: valor tal que 50\% das observações possuem um valor da variável abaixo dele e 50\% das observações possuem um valor da variável acima dele.

- $\quad 3^{\circ}$ Quartil: valor tal que $75 \%$ das observações possuem um valor da variável abaixo dele.

- Máximo: maior valor observado na amostra.

Na segunda parte da análise, para estudar a concordância entre pais e professores referente à classificação do SNAP-IV, SDQ, Pro-social e TOD e para mensurar a existência da concordância, foi calculado o Coeficiente de Concordância Kappa de Cohen (COHEN, 1960). O valor máximo deste coeficiente é 1 e quanto mais próximo de 1, maior é a concordância. Valores negativos deste coeficiente significam discordância entre pais e professores. O valor deste coeficiente está na legenda como "Kappa".

Na terceira parte da análise, foi estudada a relação entre cada variável da pesquisa e a classificação no SNAP-IV dada por pais e professores, separadamente. A fim de estudar a relação entre uma variável numérica e a classificação no SNAP-IV, calculamos as estatísticas descritivas da variável numérica dentre os(as) estudantes em cada categoria do SNAP-IV. O box-plot da variável numérica foi apresentado em cada categoria do SNAP-IV.

Para determinar se houve diferença estatisticamente significativa entre as médias da variável numérica nas categorias do SNAP-IV realizamos o Teste F (NETER et al., 1990) tendo em vista que, de acordo com o Teste de Normalidade de Shapiro-Wilk (CONOVER, 1999), todas as variáveis 
numéricas possuem distribuição Normal $(\mathrm{p}>0.01)$. Se o $p$-valor do Teste $F$ for menor do que 0.05 concluímos, a uma significância estatística de 5\%, que a média da variável numérica não é a mesma em todas as categorias do SNAP-IV, ou seja, há relação entre a variável e a classificação no SNAPIV. Caso contrário, se o p-valor for maior do 0.05 , concluímos que não há relação entre a variável numérica e a classificação no SNAP-IV. Os p-valores estão na legenda da tabela respectiva com as estatísticas descritivas.

Por outro lado, para estudar a associação entre uma variável categórica e a classificação no SNAP-IV, apresentamos as frequências de cada classificação do SNAP-IV dentro de cada categoria da variável categórica. Essas frequências são apresentadas em tabelas e gráficos. A fìm de testar se há associação estatisticamente significativa entre a variável categórica e a classificação no SNAP-IV, realizamos o Teste Exato de Fisher (CONOVER, 1999). Se o p-valor deste teste for menor do que 0.05 concluímos, a uma significância estatística de 5\%, que há associação entre a variável categórica e a classificação no SNAP-IV. Caso contrário, se o p-valor for maior do que 0.05 , concluímos que não há associação entre a variável a classificação no SNAP-IV. O p-valor do teste está na legenda da tabela de frequências respectiva.

Todas as análises foram realizadas utilizando o software estatístico R (2018). 


\section{RESULTADOS}

Os resultados serão apresentados de três formas. A primeira forma será a Análise Descritiva, a segunda será a Análise de Concordância e a terceira será o estudo das variáveis da pesquisa e a relação com o TDAH (identificado pelo SNAP-IV) como se segue.

\subsection{ANÁLISE DESCRITIVA}

\subsubsection{ESTATÍSTICA DESCRITIVA DA VARIÁVEL SEXO}

Na Tabela 1, vemos que a média do sexo mostrou que a amostra foi composta por $21.4 \%$ de pessoas do sexo feminino e $78.6 \%$ de pessoas do sexo masculino.

Tabela 1: Frequência da variável Sexo na amostra. Feminino Masculino

\begin{tabular}{cc}
\hline Feminino & Masculino \\
\hline $3(21.4 \%)$ & $11(78.6 \%)$ \\
\hline
\end{tabular}

Gráfico 1: Frequência da variável Sexo na amostra. Feminino Masculino

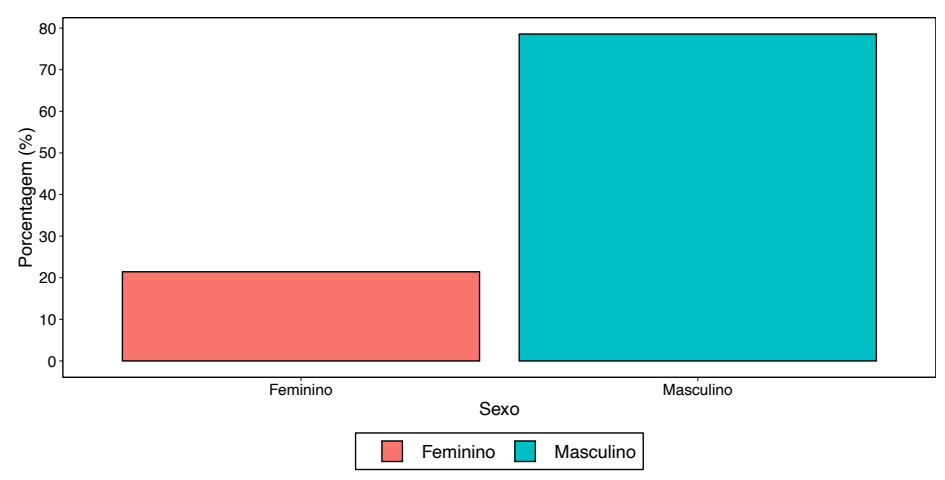

\subsubsection{ESTATÍSTICA DESCRITIVA DA VARIÁVEL IDADE}

Na Tabela 2, observamos que a média da idade na amostra é de 12,2 anos. Além disso, temos que $25 \%$ dessa amostra tem idade inferior a 11 anos, e $75 \%$ inferior a 13 anos e que metade da amostra 
tem menos de 12,2 anos e a outra metade tem 12,2 ou mais. No Gráfico 2, vemos que há maior concentração de pessoas na amostra com idades entre 11 e 13 anos.

Tabela 2: Estatística descritiva da variável Idade na amostra.

\begin{tabular}{cccccccc}
\hline $\mathrm{N}$ & Média & Desvio Padrão & Mínimo & $1^{\circ}$ Quartil & Mediana & $3^{\circ}$ Quartil & Máximo \\
\hline 14 & 12,2 & 1,1 & 11 & 11 & 12,2 & 13 & 14 \\
\hline
\end{tabular}

Gráfico 2: Histograma da variável Idade

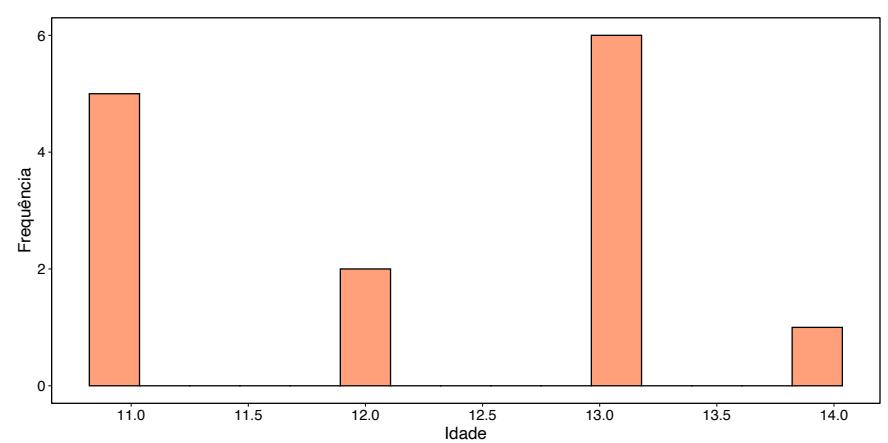

\subsubsection{ESTATÍSTICA DESCRITIVA DA VARIÁVEL PESO}

$\mathrm{Na}$ Tabela 3, observamos que a média do peso na amostra é de $44 \mathrm{Kg}$. Além disso, temos que $25 \%$ dessa amostra tem peso inferior a $36,8 \mathrm{Kg}, 75 \%$ inferior a $50,5 \mathrm{Kg}$ e que metade da amostra tem menos $44,3 \mathrm{Kg}$ e a outra metade tem $44,3 \mathrm{Kg}$ ou mais. No Gráfico 3, vemos que há maior concentração de pessoas na amostra com pesos entre 36,8 a $50,5 \mathrm{Kg}$.

Tabela 3: Estatística descritiva da variável Peso na amostra.

\begin{tabular}{cccccccc}
\hline $\mathrm{N}$ & Média & Desvio Padrão & Mínimo & $1^{\circ}$ Quartil & Mediana & $3^{\circ}$ Quartil & Máximo \\
\hline 14 & 44 & 9,3 & 30,9 & 36,8 & 44,3 & 50,5 & 58 \\
\hline
\end{tabular}


Gráfico 3: Histograma da variável Peso.

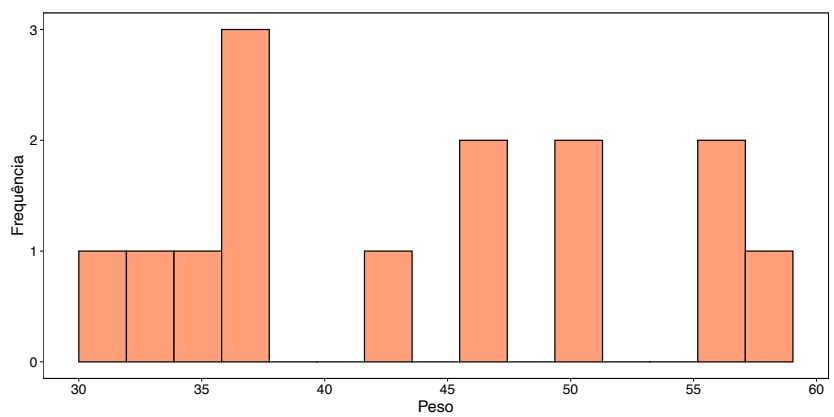

\subsubsection{ESTATÍSTICA DESCRITIVA DA VARIÁVEL ALTURA}

$\mathrm{Na}$ Tabela 4, observamos que a média da altura na amostra é de 1,5 metro. Além disso, temos que $25 \%$ da amostra tem altura inferior a 1,5 metro, e $75 \%$ inferior a 1,6 metro e que metade da amostra tem menos de 1,5 metro e a outra metade tem 1,5 metro ou mais. No Gráfico 4, vemos que há maior concentração de pessoas na amostra com alturas entre 1,5 metro e 1,6 metro.

Tabela 4: Estatística descritiva da variável Altura na amostra.

\begin{tabular}{cccccccc}
\hline $\mathrm{N}$ & Média & Desvio Padrão & Mínimo & $1^{\circ}$ Quartil & Mediana & $3^{\circ}$ Quartil & Máximo \\
\hline 14 & 1,5 & 0,1 & 1,4 & 1,5 & 1,5 & 1,6 & 1,7 \\
\hline
\end{tabular}

Gráfico 4: Histograma da variável Altura.

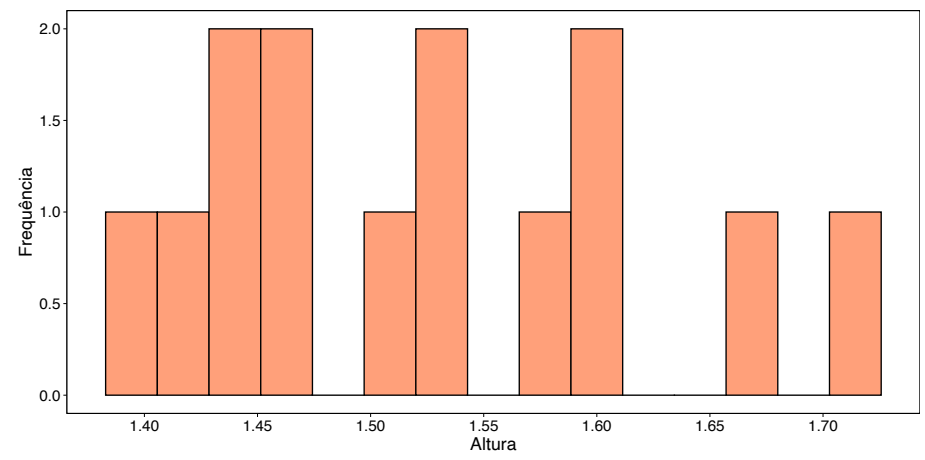




\subsubsection{ESTATÍSTICA DESCRITIVA DA VARIÁVEL ÍNDICE DE MASSA}

\section{CORPORAL (IMC)}

O IMC foi obtido pela divisão do peso, em $\mathrm{Kg}$, pela estatura, em metro, elevada ao quadrado $\left(\mathrm{Kg} / \mathrm{m}^{2}\right)$. Na Tabela 5, observamos que a média do IMC na amostra é de $18,8 \mathrm{Kg} / \mathrm{m}^{2}$. Além disso, temos que $25 \%$ dessa amostra tem IMC inferior a $17,6 \mathrm{Kg} / \mathrm{m}^{2}$, e $75 \%$ inferior a $20,2 \mathrm{Kg} / \mathrm{m}^{2}$ e que metade da amostra tem menos de $18,8 \mathrm{Kg} / \mathrm{m}^{2}$ e a outra metade tem $18,8 \mathrm{Kg} / \mathrm{m}^{2}$ ou mais. No Gráfico 5 , vemos que há maior concentração de pessoas na amostra com IMC entre $17,6 \mathrm{Kg} / \mathrm{m}^{2}$ e $20,2 \mathrm{Kg} / \mathrm{m}^{2}$.

Tabela 5: Estatística descritiva da variável IMC na amostra.

\begin{tabular}{cccccccc}
\hline $\mathrm{N}$ & Média & Desvio Padrão & Mínimo & $1^{\circ}$ Quartil & Mediana & $3^{\circ}$ Quartil & Máximo \\
\hline 14 & 18,8 & 2,4 & 14,5 & 17,6 & 19,2 & 20,2 & 23 \\
\hline
\end{tabular}

Gráfico 5: Histograma da variável IMC.

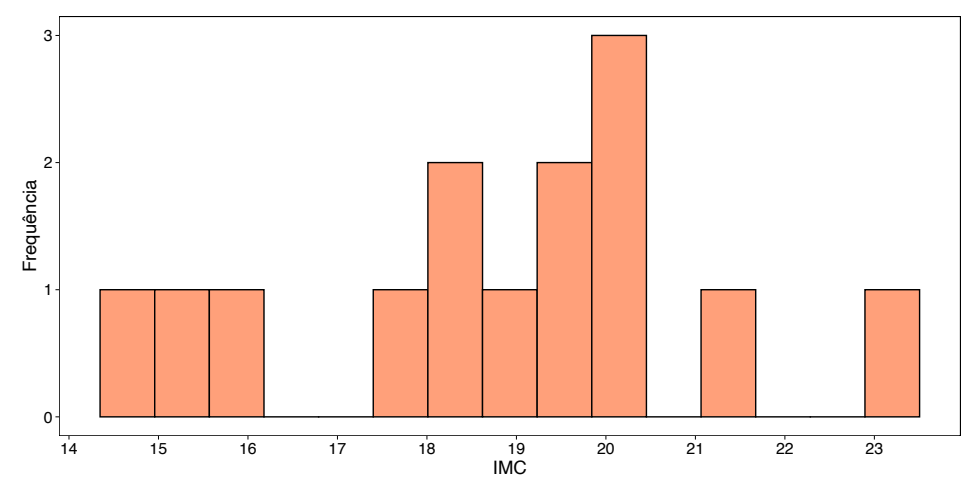

\subsubsection{ESTATÍSTICA DESCRITIVA DA VARIÁVEL SNAP-IV}

10.1.6.1 Estatística descritiva da variável SNAP-IV, segundo os Pais

Na Tabela 6, observamos que na variável SNAP-IV de acordo com os pais, a amostra foi composta por $35.7 \%$ de pessoas na categoria combinada, $50 \%$ de pessoas na categoria 
predominantemente desatenta e $14,3 \%$ de pessoas na categoria predominantemente hiperativa/impulsiva.

Tabela 6: Frequência da variável SNAP-IV Pais na amostra.

\begin{tabular}{ccc}
\hline Combinada & Desatenta & Hiperativa \\
\hline $5(35.7 \%)$ & $7(50 \%)$ & $2(14,3 \%)$ \\
\hline
\end{tabular}

Gráfico 6: Frequência da variável SNAP-IV Pais na amostra.

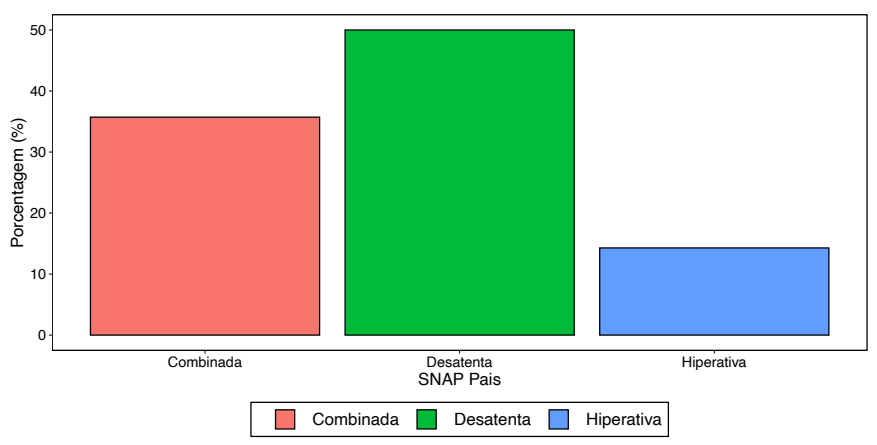

10.1.6.2 Estatística descritiva da variável SNAP-IV, segundo os Professores

Na Tabela 7, observamos que na variável SNAP-IV de acordo com os professores, a amostra foi composta por $21.4 \%$ de pessoas na categoria combinada, $64.3 \%$ de pessoas na categoria predominantemente desatenta e $14.3 \%$ de pessoas na categoria predominantemente hiperativa/impulsiva.

Tabela 7: Frequência da variável SNAP-IV Professores na amostra.

\begin{tabular}{ccc}
\hline Combinada & Desatenta & Hiperativa \\
\hline $3(21.4 \%)$ & $9(64.3 \%)$ & $2(14.3 \%)$ \\
\hline
\end{tabular}


Gráfico 7: Frequência da variável SNAP-IV Professores na amostra.

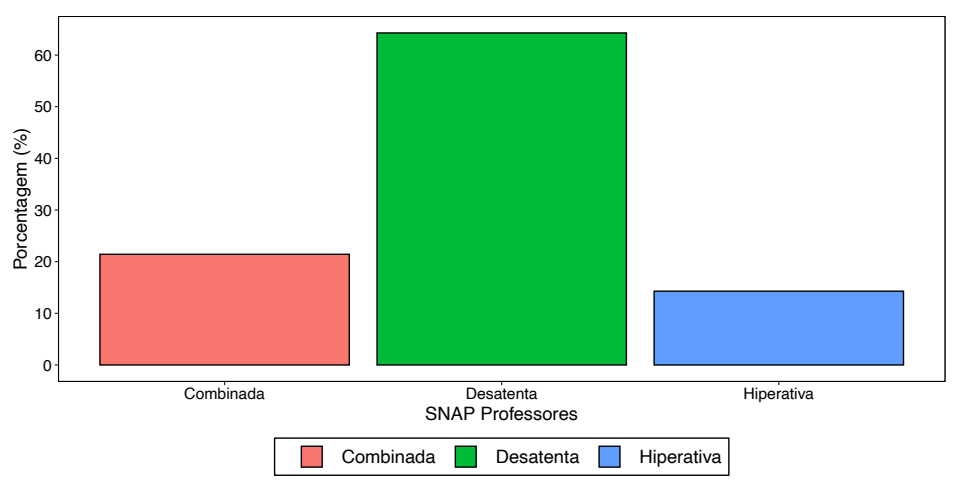

\subsubsection{ESTATÍSTICA DESCRITIVA DA VARIÁVEL TOD}

Na Tabela 8, observamos que na variável TOD, de acordo com os pais e professores, a amostra foi composta por $42.9 \%$ de respostas Leve e $57.1 \%$ de respostas Não para o TOD.

Tabela 8: Frequência da variável TOD na amostra.

\begin{tabular}{cc}
\hline Leve & Não \\
\hline $6(42.9 \%)$ & $8(57.1 \%)$ \\
\hline
\end{tabular}

Gráfico 8: Frequência da variável TOD na amostra.

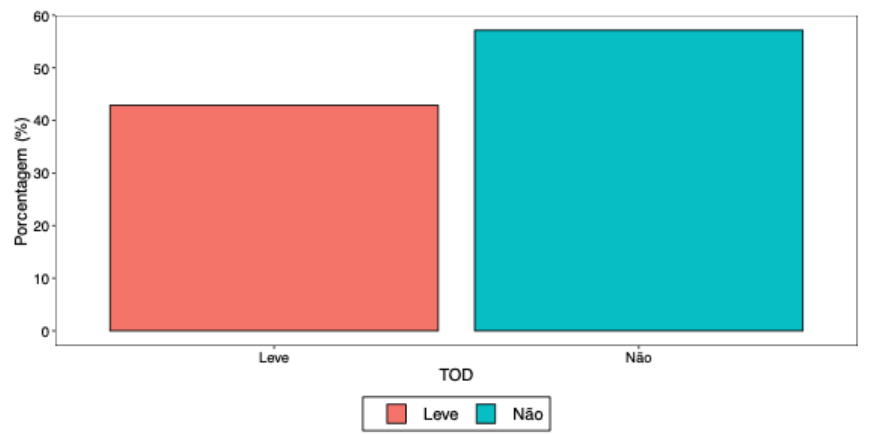


10.1.7.1 Estatística descritiva da variável TOD, segundo os Pais

Na Tabela 9, observamos que na variável TOD, de acordo com os pais, a amostra foi composta por $64.3 \%$ de respostas Não e $35.7 \%$ de respostas Sim para o TOD.

Tabela 9: Frequência da variável TOD Pais na amostra.

\begin{tabular}{cc}
\hline Não & Sim \\
\hline $9(64.3 \%)$ & $5(35.7 \%)$
\end{tabular}

Gráfico 9: Frequência da variável TOD Pais na amostra.

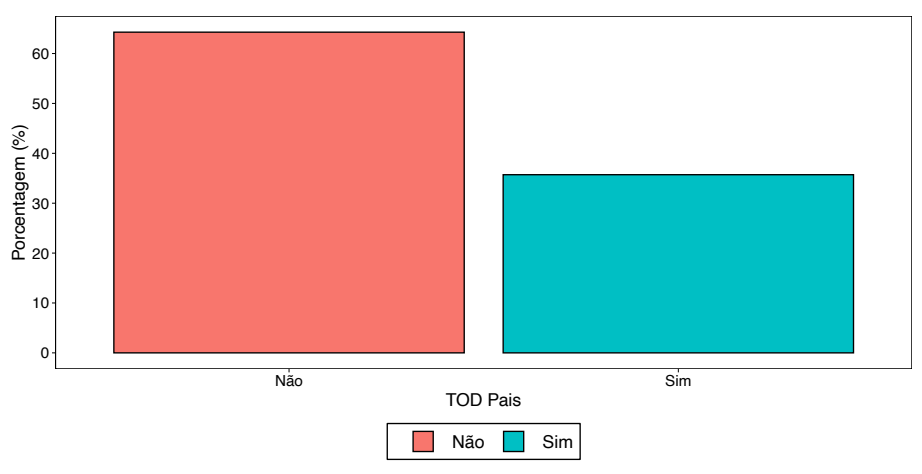

10.1.7.2 Estatística descritiva da variável TOD, segundo os Professores

Na Tabela 10, observamos que na variável TOD, de acordo com os professores, a amostra foi composta por $92.9 \%$ de respostas Não e $7.1 \%$ de respostas Sim para o TOD.

Tabela 10: Frequência da variável TOD Professores na amostra.

\begin{tabular}{cc}
\hline Não & Sim \\
\hline $13(92.9 \%)$ & $1(7.1 \%)$ \\
\hline
\end{tabular}


Gráfico 10: Frequência da variável TOD Professores na amostra.

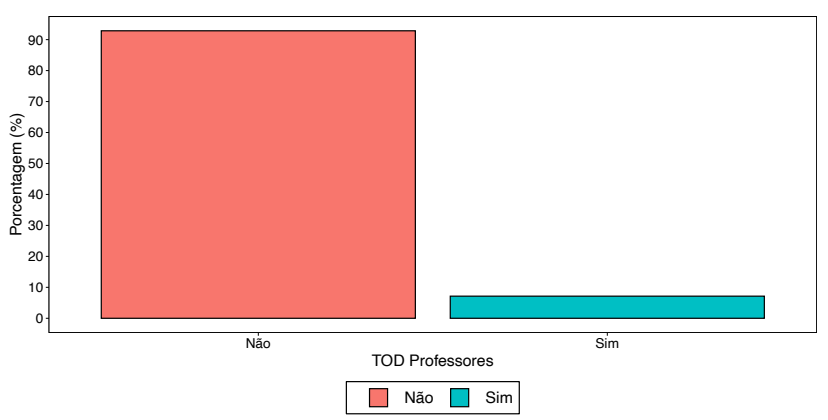

\subsubsection{ESTATÍSTICA DESCRITIVA DA VARIÁVEL SDQ}

10.1.8.1 Estatística descritiva da variável SDQ dificuldades totais, segundo os Pais

Na Tabela 11, observamos que no SDQ total e de acordo com os pais, a amostra foi composta por $28.6 \%$ de pessoas na categoria normal, $21.4 \%$ de pessoas na categoria limítrofe e $50 \%$ de pessoas na categoria anormal.

Tabela 11: Frequência da variável SDQ dificuldades totais Pais na amostra.

\begin{tabular}{ccc}
\hline Normal & Limítrofe & Anormal \\
\hline $4(28.6 \%)$ & $3(21.4 \%)$ & $7(50 \%)$ \\
\hline
\end{tabular}


Gráfico 11: Frequência da variável SDQ dificuldades totais Pais na amostra.

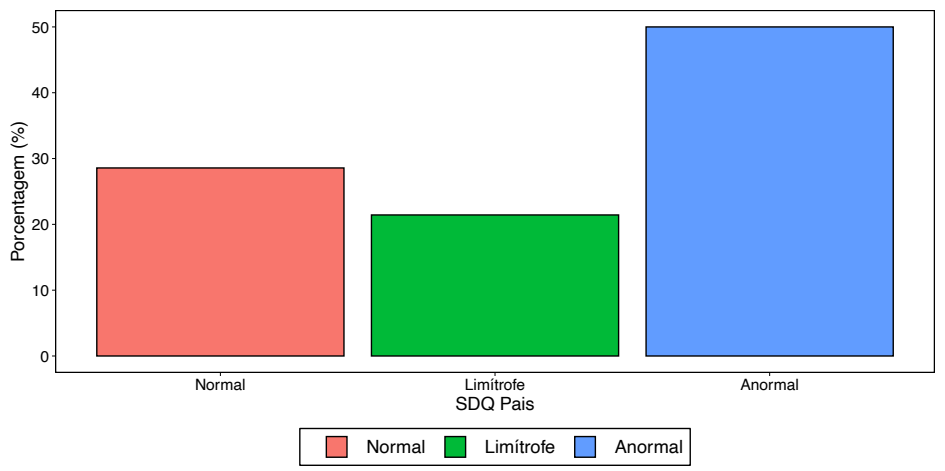

10.1.8.2 Estatística descritiva da variável SDQ dificuldades totais, segundo os Professores

Na Tabela 12, observamos que na variável SDQ dificuldades totais e de acordo com os professores, a amostra foi composta por $35.7 \%$ de pessoas na categoria normal, $21.4 \%$ de pessoas na categoria limítrofe e $42.9 \%$ de pessoas na categoria anormal.

Tabela 12: Frequência da variável SDQ dificuldades totais Professores na amostra.

\begin{tabular}{ccc}
\hline Normal & Limítrofe & Anormal \\
\hline $5(35.7 \%)$ & $3(21.4 \%)$ & $6(42.9 \%)$
\end{tabular}

Gráfico 12: Frequência da variável SDQ dificuldades totais Professores na amostra.

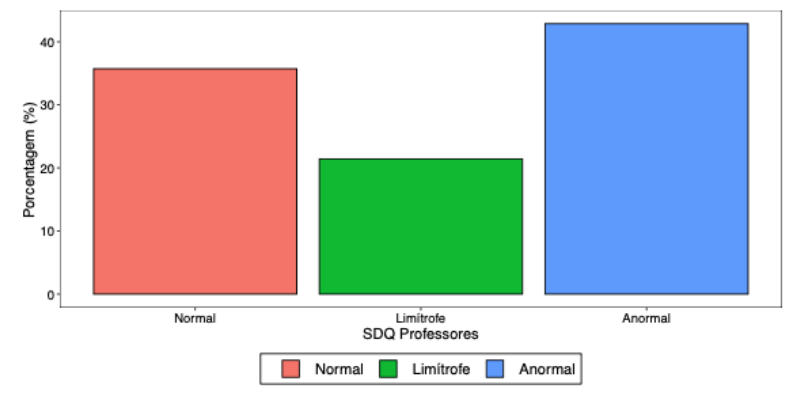




\subsubsection{ESTATÍSTICA DESCRITIVA DA VARIÁVEL SDQ PRÓ-SOCIAL}

10.1.9.1 Estatística descritiva da variável SDQ Pró-social, segundo os pais

Na Tabela 13, observamos que na subescala Pró-social do SDQ e de acordo com os pais, a amostra foi composta por $78.6 \%$ de pessoas na categoria normal, $14.3 \%$ de pessoas na categoria limítrofe e $7.1 \%$ de pessoas na categoria anormal.

Tabela 13: Frequência da variável SDQ Pró-social Pais na amostra.

\begin{tabular}{ccc}
\hline Normal & Limítrofe & Anormal \\
\hline $11(78.6 \%)$ & $2(14.3 \%)$ & $1(7.1 \%)$
\end{tabular}

Gráfico 13: Frequência da variável SDQ Pró-social Pais na amostra.

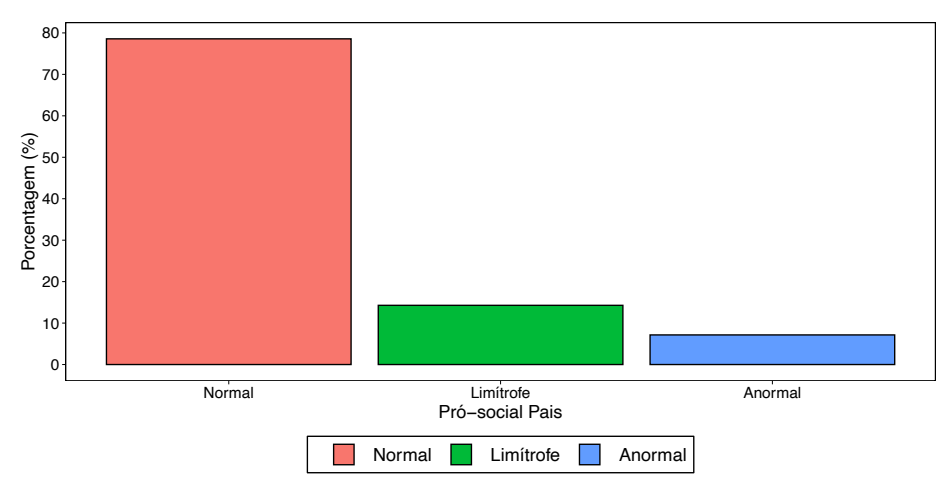

10.1.9.2 Estatística descritiva da variável SDQ Pró-social, segundo os Professores

Na Tabela 14, observamos que na subescala Pró-social do SDQ e de acordo com os pais, a amostra foi composta por $92.9 \%$ de pessoas na categoria normal, $7.1 \%$ de pessoas na categoria limítrofe e nenhuma pessoa foi encontrada na categoria anormal. 
Tabela 14: Frequência da variável Pró-social Professores na amostra.

\begin{tabular}{ccc}
\hline Normal & Limítrofe & Anormal \\
\hline $13(92,9 \%)$ & $1(7.1 \%)$ & $0(0 \%)$ \\
\hline
\end{tabular}

Gráfico 14: Frequência da variável Pró-social Professores na amostra.

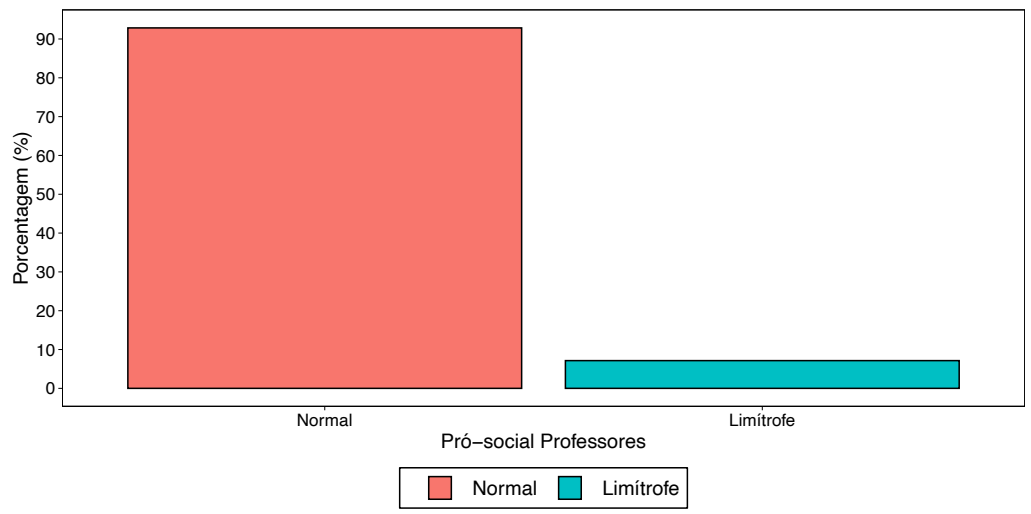




\subsection{ANÁLISE DE CONCORDÂNCIA}

Na tabela 15, podemos observar que a porcentagem de concordância entre pais e professores no SNAP- IV foi de 57.1\% e Coeficiente de Concordância Kappa de Cohen foi 0,26.

Tabela 15: Classificação de pais e professores em relação ao SNAP-IV (Kappa = 0,26).

\begin{tabular}{lllll}
\hline & Combinada & Desatenta & Hiperativa & Total \\
\hline Combinada & $1(7.1 \%)$ & $3(21.4 \%)$ & $1(7.1 \%)$ & $5(35.7 \%)$ \\
Desatenta & $1(7.1 \%)$ & $6(42.9 \%)$ & $0(0 \%)$ & $7(50 \%)$ \\
Hiperativa & $1(7.1 \%)$ & $0(0 \%)$ & $1(7.1 \%)$ & $2(14.3 \%)$ \\
\hline \multicolumn{1}{c}{ Total } & $3(21.4 \%)$ & $9(64.3 \%)$ & $2(14.3 \%)$ & $14(100 \%)$ \\
\hline
\end{tabular}

Na tabela 16, podemos observar que a porcentagem de concordância entre pais e professores no TOD foi de 57.1\% e o Coeficiente de Concordância Kappa de Cohen foi de - 0,14.

Tabela 16: Classificação de pais e professores em relação ao TOD (Kappa = -0.14).

\begin{tabular}{llll}
\hline & Não & Sim & Total \\
\hline Não & $8(57.1 \%)$ & $1(7.1 \%)$ & $9(64.3 \%)$ \\
Sim & $5(35.7 \%)$ & $0(0 \%)$ & $5(35.7 \%)$ \\
\hline Total & $13(92.9 \%)$ & $1(7.1 \%)$ & $14(100 \%)$ \\
\hline
\end{tabular}

Na tabela 17, podemos observar que a porcentagem de concordância entre pais e professores no SDQ foi de $64.3 \%$ e o Coeficiente de Concordância Kappa de Cohen foi de 0.44 .

Tabela 17: Classificação de pais e professores em relação ao SDQ (Kappa =0,44).

\begin{tabular}{rllll}
\hline & Normal & Limítrofe & Anormal & Total \\
\hline Normal & $3(21.4 \%)$ & $0(0 \%)$ & $1(7.1 \%)$ & $4(28.6 \%)$ \\
Limítrofe & $0(0 \%)$ & $2(14.3 \%)$ & $1(7.1 \%)$ & $3(21.4 \%)$ \\
Anormal & $2(14.3 \%)$ & $1(7.1 \%)$ & $4(28.6 \%)$ & $7(50 \%)$ \\
\hline \multicolumn{1}{c}{ Total } & $5(35.7 \%)$ & $9(64.3 \%)$ & $6(42.9 \%)$ & $14(100 \%)$ \\
\hline
\end{tabular}


Na tabela 18, podemos observar que a porcentagem de concordância no Pró-social foi de $85.7 \%$ e o Coeficiente de Concordância Kappa de Cohen foi de 0,45.

Tabela 18: Classificação de pais e professores em relação ao Pro-social (Kappa $=0.45)$.

\begin{tabular}{lllll}
\hline & Normal & Limítrofe & Anormal & Total \\
\hline Normal & $11(78.6 \%)$ & $0(0 \%)$ & $0(0 \%)$ & $11(78.6 \%)$ \\
Limítrofe & $1(7.1 \%)$ & $1(7.1 \%)$ & $0(0 \%)$ & $2(14.3 \%)$ \\
Anormal & $1(7.1 \%)$ & $0(0 \%)$ & $0(0 \%)$ & $1(7.1 \%)$ \\
\hline \multicolumn{1}{c}{ Total } & $13(92.9 \%)$ & $9(64.3 \%)$ & $6(42.9 \%)$ & $14(100 \%)$ \\
\hline
\end{tabular}




\subsection{ANÁLISE DAS VARIÁVEIS DA PESQUISA E RELAÇÃO COM O SNAP-IV}

\subsubsection{SNAP-IV PAIS}

\subsubsection{SNAP-IV PAIS de acordo com a variável Sexo}

Na Tabela 19 e no Gráfico 15, vemos que, em relação à variável Sexo 33.33\% das meninas e $36.36 \%$ dos meninos foram classificados pelos pais como apresentação combinada, 66.67\% das meninas e $45.45 \%$ dos meninos foram classificados como apresentação predominantemente desatenta e $18.18 \%$ dos meninos foram classificados como apresentação predominantemente hiperativa/impulsiva. Entretanto, esta diferença observada na amostra não é estatisticamente significativa, a uma significância estatística de 5\%, tendo em vista que o p-valor do Teste F é maior que 0,05 .

Tabela 19: Frequência das variáveis Sexo e SNAP-IV Pais na amostra $(\mathrm{p}=1)$.

\begin{tabular}{rllll}
\hline & Combinada & Desatenta & Hiperativa & Total \\
\hline Feminino & $1(33.33 \%)$ & $2(66.67 \%)$ & $0(0 \%)$ & $3(21.43 \%)$ \\
Masculino & $4(36.36 \%)$ & $5(45.45 \%)$ & $2(18.18 \%)$ & $11(78.57 \%)$ \\
\hline Total & $5(35.71 \%)$ & $9(50 \%)$ & $2(14.29 \%)$ & $14(100 \%)$ \\
\hline
\end{tabular}

Gráfico 15: Frequência da variável SNAP-IV Pais em cada categoria da variável Sexo.

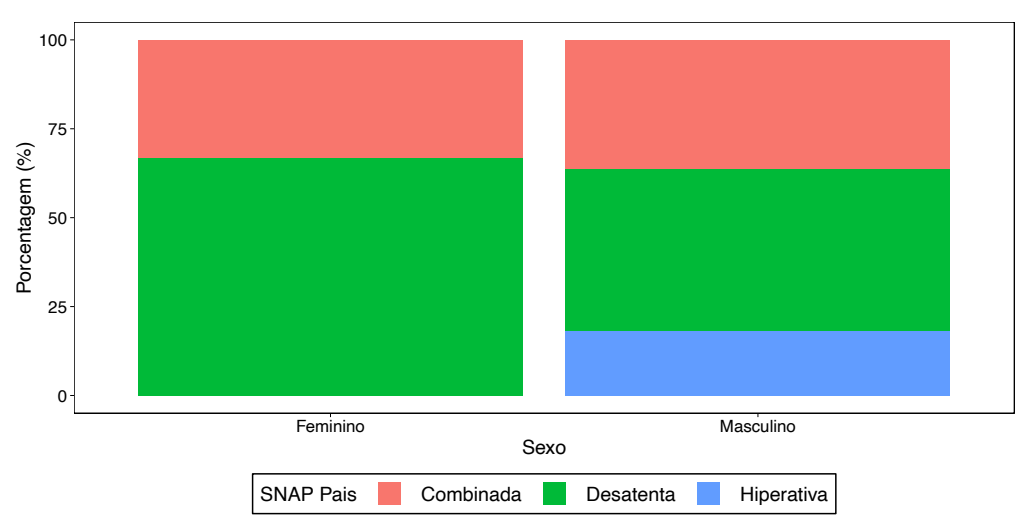


10.3.1.2 SNAP-IV PAIS de acordo com a variável Idade

Na Tabela 20 e no Gráfico 16, vemos que, em geral, a média das idades das pessoas classificadas pelos pais como apresentação combinada ou como apresentação predominantemente desatenta é maior do que a média das idades das pessoas classificadas como apresentação predominantemente hiperativa/impulsiva, tendo em vista que a média e mediana do grupo predominantemente hiperativa/impulsiva é menor. Entretanto, esta diferença observada na amostra não é estatisticamente significativa, a uma significância estatística de 5\%, tendo em vista que o p-valor do Teste $\mathrm{F}$ é maior que 0,05 .

Tabela 20: Estatística descritiva da variável Idade pela variável SNAP-IV Pais na amostra ( $\mathrm{p}=$ $0.479)$.

\begin{tabular}{lllllllll}
\hline & $\mathrm{N}$ & Média & Desvio Padrão & Mínimo & $1^{\mathrm{o}}$ Quartil & Mediana & $3^{\mathrm{o}}$ Quartil & Máximo \\
\hline Combinada & 5 & 12,60 & 0,89 & 11 & 13 & 13 & 13 & 13 \\
Desatenta & 7 & 12,14 & 1,21 & 11 & 11 & 12 & 13 & 14 \\
Hiperativa & 2 & 11,50 & 0,71 & 11 & 11,25 & 11,50 & 11,75 & 12 \\
\hline
\end{tabular}

Gráfico 16: Box-plot da variável Idade pela variável SNAP-IV Pais.

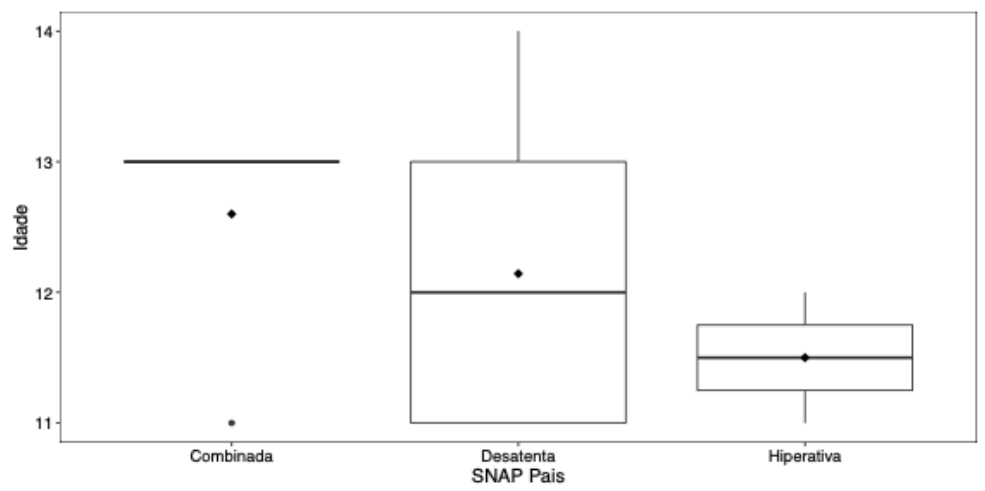

10.3.1.3 SNAP-IV PAIS de acordo com a variável Peso

Na Tabela 21 e no Gráfico 17, vemos que, em geral, o peso das pessoas classificadas pelos pais como apresentação combinada ou como apresentação predominantemente desatenta é maior do que o peso das pessoas classificadas como apresentação predominantemente hiperativa/impulsiva, tendo em vista que a média e mediana do grupo predominantemente hiperativa/impulsiva é menor. Entretanto, 
esta diferença observada na amostra não é estatisticamente significativa, a uma significância estatística de $5 \%$, tendo em vista que o p-valor do Teste $\mathrm{F}$ é maior que 0,05 .

Tabela 21: Estatística descritiva da variável Peso pela variável SNAP-IV Pais na amostra ( $\mathrm{p}=$ $0.358)$.

\begin{tabular}{lllllllll}
\hline & $\mathrm{N}$ & Média & Desvio Padrão & Mínimo & $1^{\circ}$ Quartil & Mediana & $3^{\circ}$ Quartil & Máximo \\
\hline Combinada & 5 & 47,64 & 8,51 & 37,00 & 42,90 & 45,70 & 55,80 & 56,80 \\
Desatenta & 7 & 43,74 & 10,34 & 30,90 & 34,75 & 47,40 & 50,20 & 58,00 \\
Hiperativa & 2 & 36,19 & 0,85 & 35,50 & 35,80 & 36,10 & 36,40 & 36,70 \\
\hline
\end{tabular}

Gráfico 17: Box-plot da variável Peso pela variável SNAP-IV Pais.

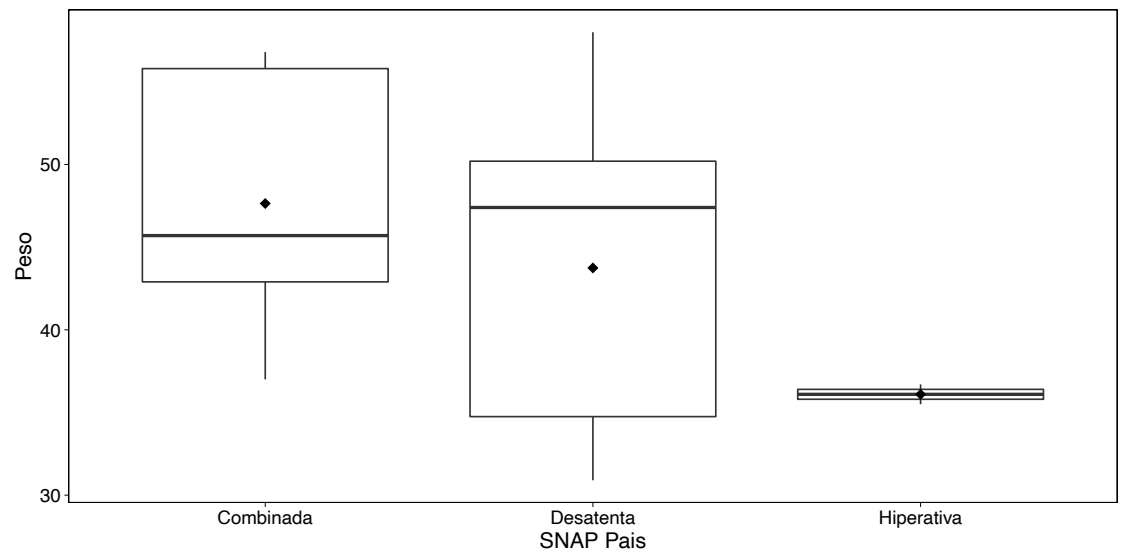

10.3.1.4 SNAP-IV PAIS de acordo com a variável Altura

Na Tabela 22 e no Gráfico 18, vemos que, em geral, a média e mediana de altura das pessoas classificadas, pelos pais, como apresentação combinada ou como apresentação predominantemente desatenta é maior do que a média e mediana de altura das pessoas classificadas como apresentação predominantemente hiperativa/impulsiva, tendo em vista que a média e mediana do grupo predominantemente hiperativa/impulsiva é menor. Entretanto, esta diferença observada na amostra não é estatisticamente significativa, a uma significância estatística de 5\%, tendo em vista que o p-valor do Teste $\mathrm{F}$ é maior que 0,05 . 
Tabela 22: Estatística descritiva da variável Altura pela variável SNAP-IV Pais na amostra $(\mathrm{p}=0.282)$.

\begin{tabular}{lllllllll}
\hline & $\mathrm{N}$ & Média & Desvio Padrão & Mínimo & $1^{\circ}$ Quartil & Mediana & $3^{\circ}$ Quartil & Máximo \\
\hline Combinada & 5 & 1,55 & 0,08 & 1,46 & 1,50 & 1,54 & 1,57 & 1,66 \\
Desatenta & 7 & 1,54 & 0,11 & 1,42 & 1,46 & 1,54 & 1,59 & 1,72 \\
Hiperativa & 2 & 1,42 & 0,04 & 1,40 & 1,41 & 1,42 & 1,44 & 1,45 \\
\hline
\end{tabular}

Gráfico 18: Box-plot da variável Altura pela variável SNAP-IV Pais.

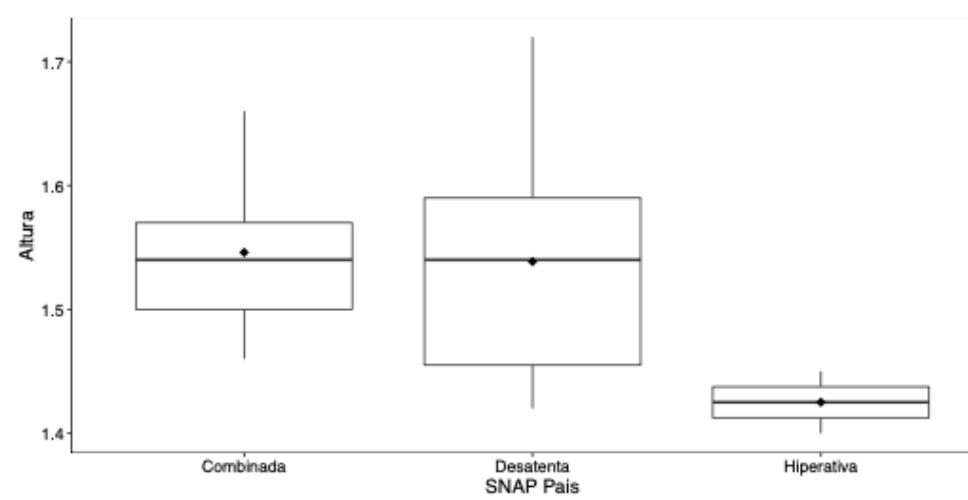

10.3.1.5 SNAP-IV PAIS de acordo com a variável IMC

Na Tabela 23 e no Gráfico 19, vemos que, em geral, a média do IMC das pessoas classificadas, pelos pais, como apresentação combinada ou como apresentação predominantemente desatenta é maior do que a média do IMC das pessoas classificadas como apresentação predominantemente hiperativa/impulsiva, tendo em vista que a média e mediana do grupo predominantemente hiperativa/impulsiva é menor. Entretanto, esta diferença observada na amostra não é estatisticamente significativa, a uma significância estatística de 5\%, tendo em vista que o p-valor do Teste $\mathrm{F}$ é maior que 0,05 . 
Tabela 23: Estatísticas descritivas da variável IMC pela variável SNAP-IV Pais na amostra $(\mathrm{p}=$ 0.465).

\begin{tabular}{lllllllll}
\hline & $\mathrm{N}$ & Média & Desvio Padrão & Mínimo & $1^{\circ}$ Quartil & Mediana & $3^{\circ}$ Quartil & Máximo \\
\hline Combinada & 5 & 19,87 & 2,68 & 15,60 & 20,13 & 20,25 & 20,31 & 23,04 \\
Desatenta & 7 & 18,24 & 2,49 & 14,50 & 16,91 & 18,75 & 19,59 & 21,46 \\
Hiperativa & 2 & 17,78 & 0,46 & 17,46 & 17,62 & 17,78 & 17,95 & 18,11 \\
\hline
\end{tabular}

Gráfico 19: Box-plot da variável IMC pela variável SNAP Pais.

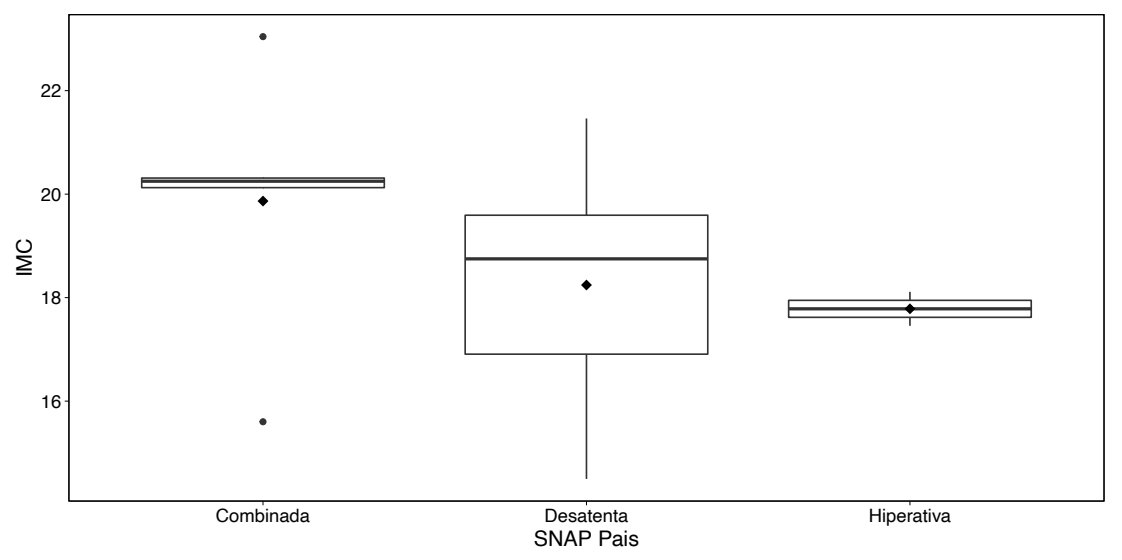

10.3.1.6 SNAP-IV PAIS e frequência das variáveis SDQ dos Pais

Na Tabela 24 e no Gráfico 20, vemos que, dentre os estudantes com SDQ Normal, todos possuem SNAP-IV com apresentação predominantemente desatenta de acordo com os pais, mas 57.14\% dos estudantes com SDQ Anormal foram classificados com a apresentação combinada no SNAP-IV. Essa associação observada na amostra entre SDQ Pais e SNAP-IV Pais não é estatisticamente significativa a 5\%, tendo em vista que o p-valor do Teste Exato de Fisher é maior que 0.05 . 
Tabela 24: Frequência das variáveis SDQ Pais e SNAP-IV Pais na amostra $(\mathrm{p}=0.175)$.

\begin{tabular}{rllll}
\hline & Combinada & Desatenta & Hiperativa & Total \\
\hline Normal & $0(0 \%)$ & $4(100 \%)$ & $0(0 \%)$ & $4(28.57 \%)$ \\
Limítrofe & $1(33.33 \%)$ & $1(33.33 \%)$ & $1(33.33 \%)$ & $3(21.43 \%)$ \\
Anormal & $4(57.14 \%)$ & $2(28.57 \%)$ & $1(14.29 \%)$ & $7(50 \%)$ \\
\hline Total & $5(35.71 \%)$ & $7(50 \%)$ & $2(14.29 \%)$ & $14(100 \%)$ \\
\hline
\end{tabular}

Gráfico 20: Frequência da variável SNAP-IV Pais em cada categoria da variável SDQ Pais.

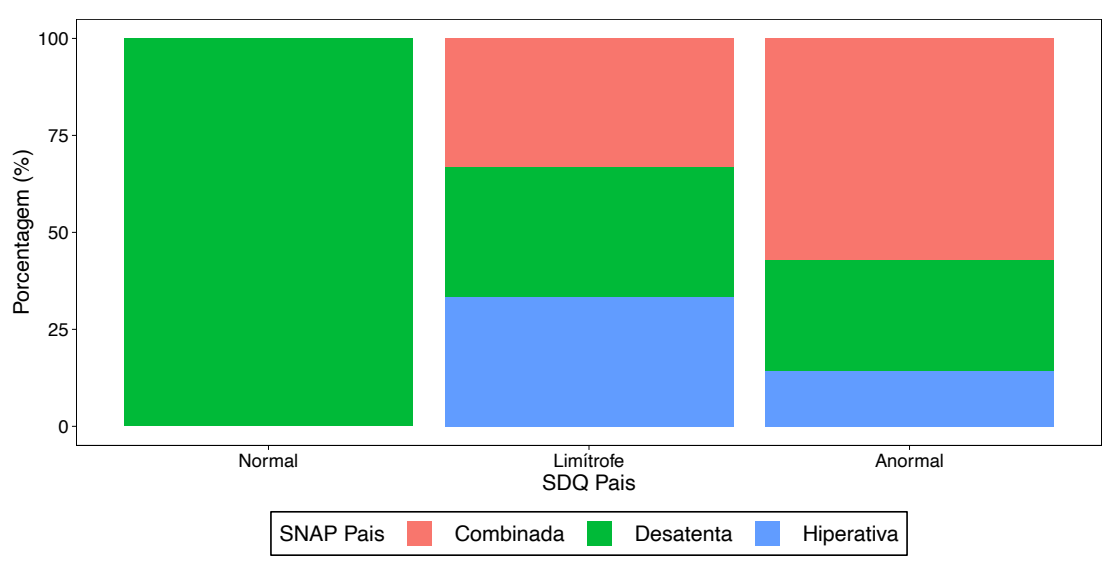

10.3.1.7 SNAP-IV PAIS e frequência das variáveis Pró-social dos Pais

Na Tabela 25 e no Gráfico 21, vemos que, na subescala Pró-social, todas as pessoas classificadas como Anormal possuem apresentação predominantemente desatenta de acordo com os pais, mas $50 \%$ das pessoas classificadas como Pró-social Limítrofe foram classificadas nas apresentações predominantemente desatenta e 50\% predominantemente hiperativa/impulsiva do SNAP-IV. Essa associação observada na amostra entre Pró-social Pais e SNAP-IV Pais não é estatisticamente significativa a 5\%, tendo em vista que o p-valor do Teste Exato de Fisher é maior que 0.05 . 
Tabela 25: Frequência das variáveis Pró-social Pais e SNAP-IV Pais na amostra $(p=0.487)$.

\begin{tabular}{rllll}
\hline & Combinada & Desatenta & Hiperativa & Total \\
\hline Normal & $5(45.45 \%)$ & $5(45.45 \%)$ & $1(9.09 \%)$ & $11(78.57 \%)$ \\
Limítrofe & $0(0 \%)$ & $1(50 \%)$ & $1(50 \%)$ & $2(14.29 \%)$ \\
Anormal & $0(0 \%)$ & $1(100 \%)$ & $0(0 \%)$ & $1(7.14 \%)$ \\
\hline Total & $5(35.71 \%)$ & $7(50 \%)$ & $2(14.29 \%)$ & $14(100 \%)$ \\
\hline
\end{tabular}

Gráfico 21: Frequência da variável SNAP-IV Pais em cada categoria da variável Pró-social Pais.

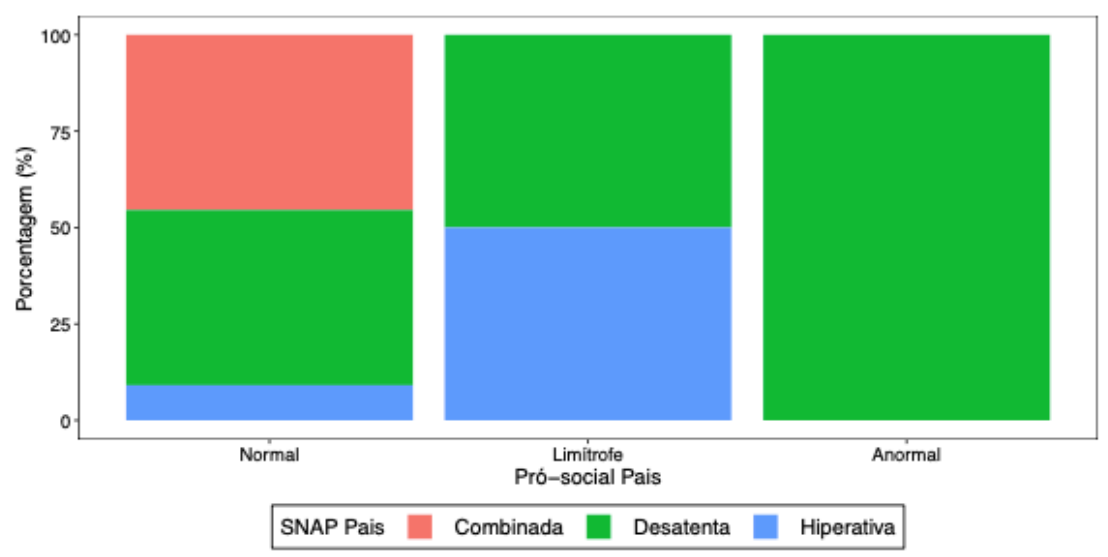

10.3.1.8 SNAP-IV PAIS e frequência das variáveis SDQ dos Professores

Na Tabela 26 e no Gráfico 22 vemos que, dentre as pessoas classificadas como limítrofe no SDQ pelos professores, $66.67 \%$ possuem apresentação combinada e $33.33 \%$ foram classificados como apresentação predominantemente desatenta de acordo com os pais. Essa associação observada na amostra entre SDQ Professores e SNAP-IV Pais não é estatisticamente significativa a 5\%, tendo em vista que o p-valor do Teste Exato de Fisher é maior que 0.05. 
Tabela 26: Frequência das variáveis SDQ Professores e SNAP-IV Pais na amostra $(p=0.38)$.

\begin{tabular}{rllll}
\hline & Combinada & Desatenta & Hiperativa & Total \\
\hline Normal & $1(20 \%)$ & $4(80 \%)$ & $0(0 \%)$ & $5(35.71 \%)$ \\
Limítrofe & $2(66.67 \%)$ & $1(33.33 \%)$ & $0(0 \%)$ & $3(21.43 \%)$ \\
Anormal & $2(33.33 \%)$ & $2(33.33 \%)$ & $2(33.33 \%)$ & $6(42.86 \%)$ \\
\hline Total & $5(35.71 \%)$ & $7(50 \%)$ & $2(14.29 \%)$ & $14(100 \%)$ \\
\hline
\end{tabular}

Gráfico 22: Frequência da variável SNAP-IV Pais em cada categoria da variável SDQ Professores.

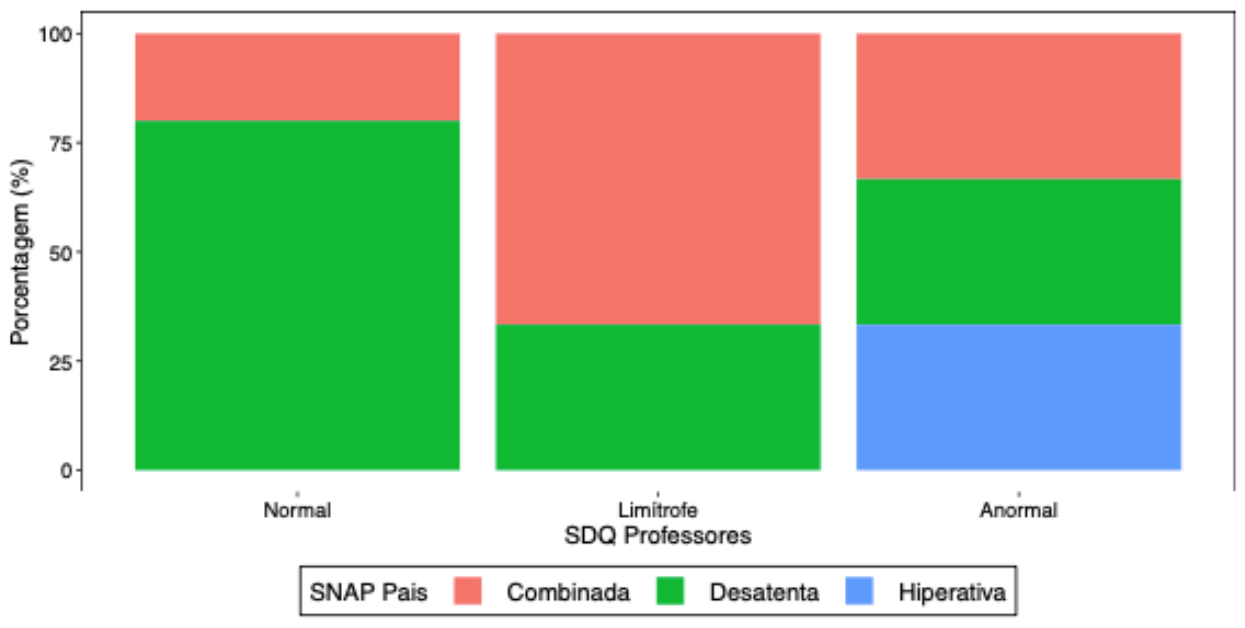

10.3.1.9 SNAP-IV PAIS e frequência das variáveis Pró-social dos Professores

Na Tabela 27 e no Gráfico 23, vemos que, dentre as pessoas classificadas como limítrofe na subescala Pró-social pelos professores, todos possuem apresentação predominantemente desatenta de acordo com os pais. Essa associação observada na amostra entre Pró-social Professores e SNAP-IV Pais não é estatisticamente significativa a 5\%, tendo em vista que o p-valor do Teste Exato de Fisher é maior que 0.05 . 
Tabela 27: Frequência das variáveis Pró-social Professores e SNAP-IV Pais na amostra $(\mathrm{p}=1)$.

\begin{tabular}{rllll}
\hline & Combinada & Desatenta & Hiperativa & Total \\
\hline Normal & $5(38.46 \%)$ & $6(46.15 \%)$ & $2(15.38 \%)$ & $13(92.86 \%)$ \\
Limítrofe & $0(0 \%)$ & $1(100 \%)$ & $0(0 \%)$ & $1(7.14 \%)$ \\
Anormal & $0(0 \%)$ & $0(0 \%)$ & $0(0 \%)$ & $0(0 \%)$ \\
\hline Total & $5(35.71 \%)$ & $7(50 \%)$ & $2(14.2 \%)$ & $14(100 \%)$ \\
\hline
\end{tabular}

Gráfico 23: Frequência da variável SNAP-IV Pais em cada categoria da variável Pró-social Professores.

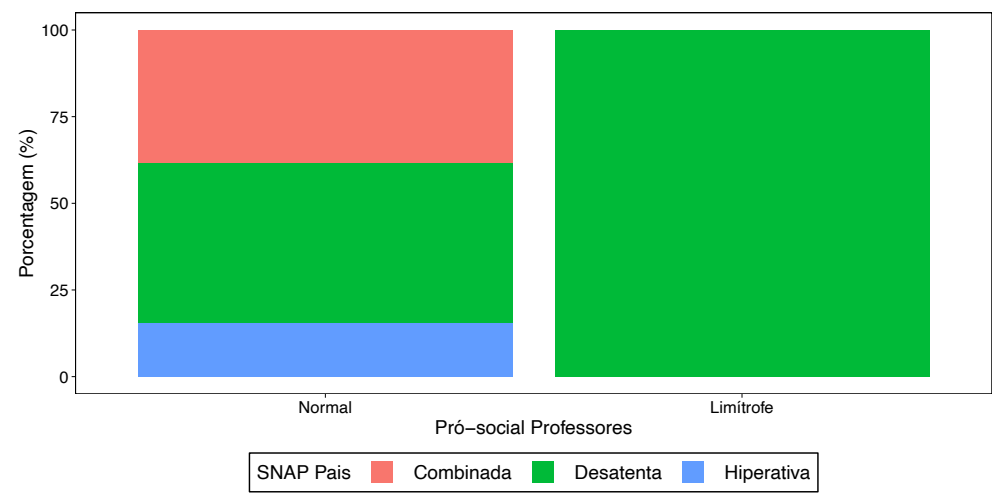

10.3.1.10 SNAP-IV PAIS e frequência das variáveis TOD dos Pais

Na Tabela 28 e no Gráfico 24, vemos que, 60\% da amostra que apresentou indicativos do TOD de acordo com os pais foi classificada na apresentação combinada pelos pais. E que $20 \%$ da amostra que apresentou indicativos do TOD foi classificada como predominantemente desatenta, enquanto $20 \%$ foi classificada como predominantemente hiperativa/impulsiva. Essa associação observada na amostra entre TOD Pais e SNAP-IV Pais não é estatisticamente significativa a 5\%, tendo em vista que o p-valor do Teste Exato de Fisher é maior que 0.05 . 
Tabela 28: Frequência das variáveis TOD Pais e SNAP-IV Pais na amostra $(\mathrm{p}=0.248)$.

\begin{tabular}{rllll}
\hline & Combinada & Desatenta & Hiperativa & Total \\
\hline Não & $2(22.22 \%)$ & $6(66.67 \%)$ & $1(11.11 \%)$ & $9(64.29 \%)$ \\
Sim & $3(60 \%)$ & $1(20 \%)$ & $1(20 \%)$ & $5(35.71 \%)$ \\
\hline Total & $5(35.71 \%)$ & $7(50 \%)$ & $2(14.29 \%)$ & $14(100 \%)$ \\
\hline
\end{tabular}

Gráfico 24: Frequência da variável SNAP-IV Pais em cada categoria da variável TOD Pais.

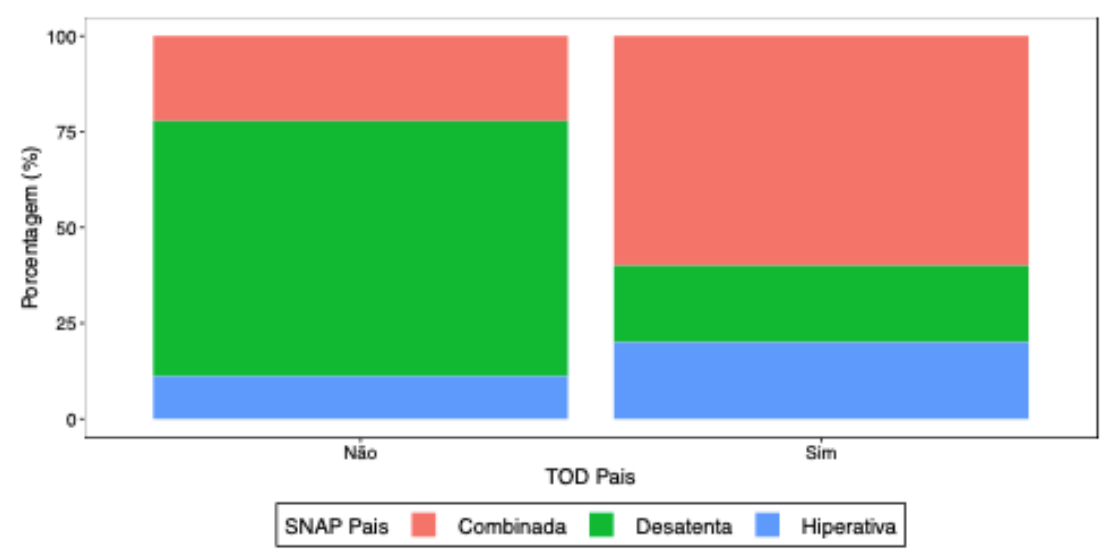

\subsubsection{SNAP-IV PAIS e frequência das variáveis TOD dos Professores}

Na Tabela 29 e no Gráfico 25, vemos que $100 \%$ da amostra que apresentou indicativos do TOD de acordo com os professores foi classificado na apresentação predominantemente hiperativa/impulsiva pelos pais. Em 53.85\% da amostra como apresentação predominantemente desatenta, segundo os pais, não apresentou indicativos do TOD de acordo com os professores. Essa associação observada na amostra entre TOD professores e SNAP-IV Pais não é estatisticamente significativa a $5 \%$, tendo em vista que o p-valor do Teste Exato de Fisher é maior que 0.05.

Tabela 29: Frequência das variáveis TOD Professores e SNAP-IV Pais na amostra $(p=0.143)$.

\begin{tabular}{rllll}
\hline & Combinada & Desatenta & Hiperativa & Total \\
\hline Não & $5(38.46 \%)$ & $7(53.85 \%)$ & $1(7.69 \%)$ & $13(92.86 \%)$ \\
Sim & $0(0 \%)$ & $0(0 \%)$ & $1(100 \%)$ & $1(7.14 \%)$ \\
\hline Total & $5(35.71 \%)$ & $7(50 \%)$ & $2(14.29 \%)$ & $14(100 \%)$ \\
\hline
\end{tabular}


Gráfico 25: Frequência da variável SNAP-IV Pais em cada categoria da variável TOD Professores.

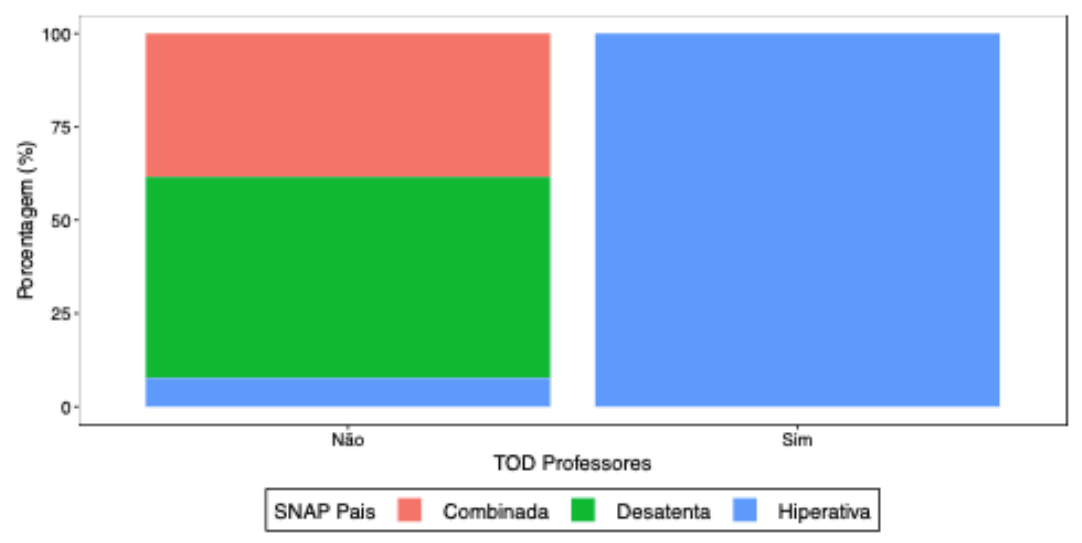

10.3.1.12 SNAP-IV PAIS e frequência das variáveis TOD dos Professores

Na Tabela 30 e no Gráfico 26, vemos que 75\% da amostra que apresentou indicativos do TOD foi classificado na apresentação predominantemente desatenta pelos pais. Em $25 \%$ da amostra que apresentou indicativos do TOD foi classificada como apresentação predominantemente desatenta, segundo os pais. Essa associação observada na amostra entre TOD e SNAP-IV Pais não é estatisticamente significativa a 5\%, tendo em vista que o p-valor do Teste Exato de Fisher é maior que 0.05 .

Tabela 30: Frequência das variáveis TOD e SNAP-IV Pais na amostra $(p=0.079)$.

\begin{tabular}{rllll}
\hline & Combinada & Desatenta & Hiperativa & Total \\
\hline Não & $3(50 \%)$ & $1(16.67 \%)$ & $2(33.33 \%)$ & $6(42.86 \%)$ \\
Sim & $2(25 \%)$ & $6(75 \%)$ & $0(0 \%)$ & $8(57.14 \%)$ \\
\hline Total & $5(35.71 \%)$ & $7(50 \%)$ & $2(14.29 \%)$ & $14(100 \%)$ \\
\hline
\end{tabular}


Gráfico 26: Frequência da variável SNAP-IV Pais em cada categoria da variável TOD.

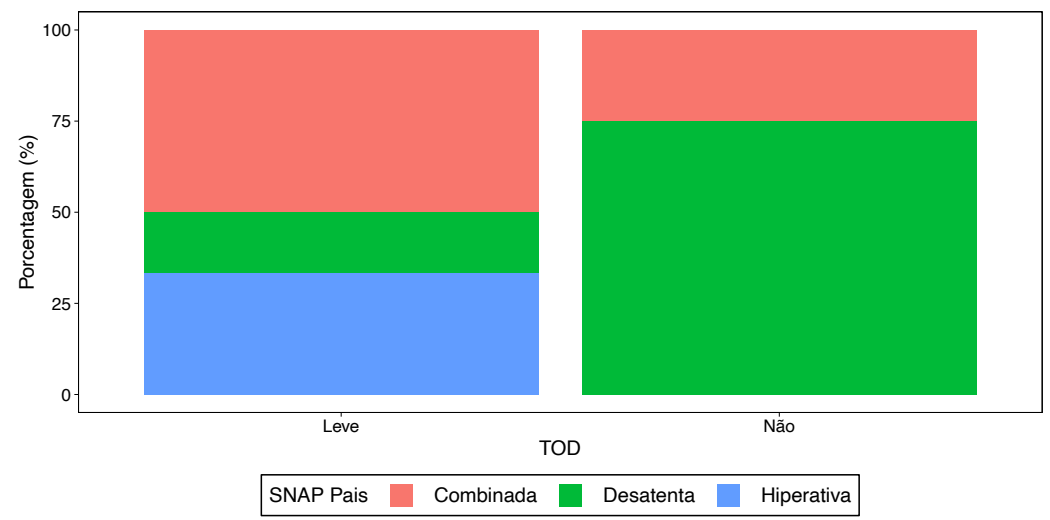

\subsubsection{SNAP-IV PROFESSORES}

\subsubsection{SNAP-IV PROFESSORES de acordo com a variável Sexo}

Na Tabela 31 e no Gráfico 27, vemos que, em relação à variável Sexo todas as meninas e $54.55 \%$ dos meninos foram classificados pelos professores como apresentação predominantemente desatenta, e em relação aos meninos $27.27 \%$ foram classificados como apresentação combinada e $18.18 \%$ foram classificados como apresentação predominantemente hiperativa/impulsiva. Entretanto, esta diferença observada na amostra não é estatisticamente significativa, a uma significância estatística de $5 \%$, tendo em vista que o p-valor do Teste $\mathrm{F}$ é maior que 0,05 .

Tabela 31: Frequência das variáveis Sexo e SNAP-IV Professores na amostra $(p=0.703)$.

\begin{tabular}{rllll}
\hline & Combinada & Desatenta & Hiperativa & Total \\
\hline Feminino & $0(0 \%)$ & $3(100 \%)$ & $0(0 \%)$ & $3(21.43 \%)$ \\
Masculino & $3(27.27 \%)$ & $6(54.55 \%)$ & $2(18.18 \%)$ & $11(78.57 \%)$ \\
\hline Total & $3(21.43 \%)$ & $9(64.29 \%)$ & $2(14.29 \%)$ & $14(100 \%)$ \\
\hline
\end{tabular}


Gráfico 27: Frequência da variável SNAP-IV Professores em cada categoria da variável Sexo.

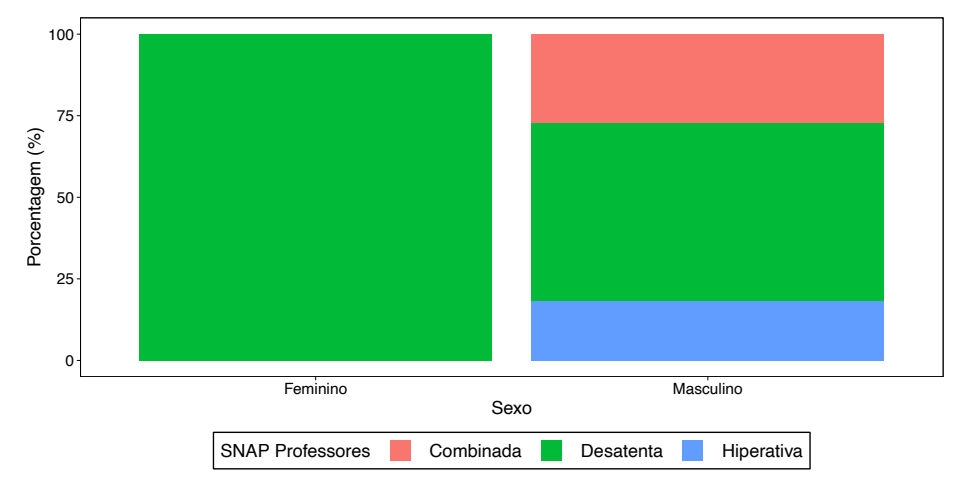

\subsubsection{SNAP-IV PROFESSORES de acordo com a variável Idade}

Na Tabela 32 e no Gráfico 28, vemos que, em geral, a média das idades das pessoas classificadas pelos professores como apresentação combinada foi de 11,67 e as médias das pessoas classificadas como apresentação predominantemente desatenta e como apresentação predominantemente hiperativa/impulsiva foi, respectivamente, 12,33 e 12,50. Tendo em vista que em relação à média e mediana do grupo, apresentação combinada foi menor. Entretanto, esta diferença observada na amostra não é estatisticamente significativa, a uma significância estatística de 5\%, tendo em vista que o p-valor do Teste F é maior que 0,05 .

Tabela 32: Estatística descritiva da variável Idade pela variável SNAP-IV Professores na amostra $(p=0.621)$.

\begin{tabular}{lllllllll}
\hline & $\mathrm{N}$ & Média & Desvio Padrão & Mínimo & $1^{0}$ Quartil & Mediana & $3^{0}$ Quartil & Máximo \\
\hline Combinada & 3 & 11,67 & 1,15 & 11 & 11 & 11 & 12 & 13 \\
Desatenta & 9 & 12,33 & 1,12 & 11 & 11 & 13 & 13 & 14 \\
Hiperativa & 2 & 12,50 & 0,71 & 12 & 12,25 & 12,50 & 12,75 & 13 \\
\hline
\end{tabular}


Gráfico 28: Box-plot da variável Idade pela variável SNAP-IV Professores.

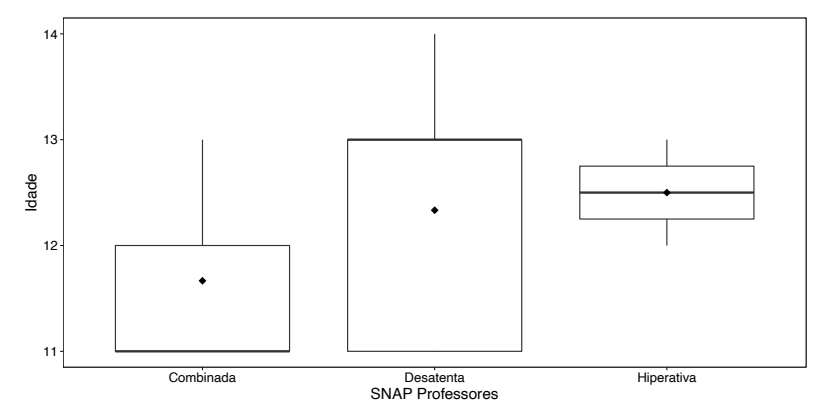

\subsubsection{SNAP-IV PROFESSORES de acordo com a variável Peso}

Na Tabela 33 e no Gráfico 29, vemos que, em geral, a média e mediana dos pesos das pessoas classificadas, pelos professores, como apresentação predominantemente desatenta é maior do que a média e mediana dos pesos das pessoas classificadas como apresentação combinada e apresentação predominantemente hiperativa/impulsiva. Entretanto, esta diferença observada na amostra não é estatisticamente significativa, a uma significância estatística de 5\%, tendo em vista que o p-valor do Teste F é maior que 0,05 .

Tabela 33: Estatística descritiva da variável Peso pela variável SNAP-IV Professores na amostra ( $\mathrm{p}$ $=0.087)$.

\begin{tabular}{lllllllll}
\hline & $\mathrm{N}$ & Média & Desvio Padrão & Mínimo & $1^{0}$ Quartil & Mediana & $3^{0}$ Quartil & Máximo \\
\hline Combinada & 3 & 36,83 & 5,52 & 32,10 & 33,80 & 35,50 & 39,20 & 42,90 \\
Desatenta & 9 & 48,04 & 9,08 & 30,90 & 45,70 & 49,50 & 55,80 & 58 \\
Hiperativa & 2 & 36,85 & 0,21 & 36,70 & 36,78 & 36,85 & 36,92 & 37 \\
\hline
\end{tabular}


Gráfico 29: Box-plot da variável Peso pela variável SNAP-IV Professores.

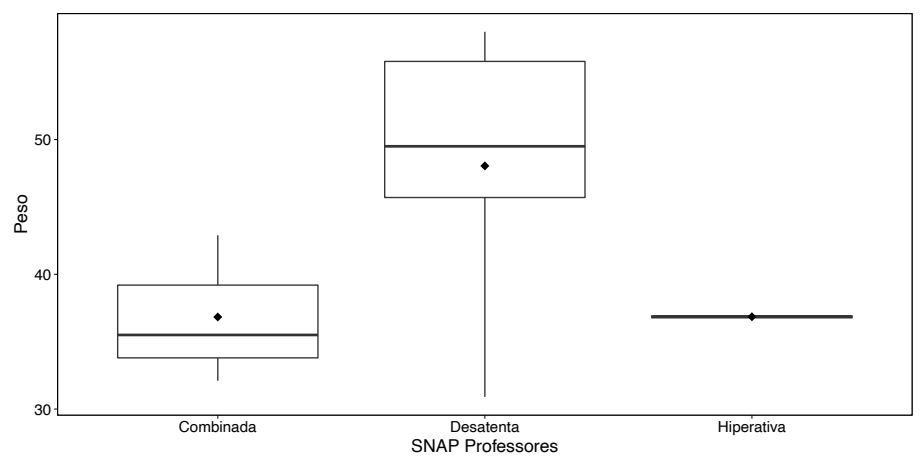

\subsubsection{SNAP-IV PROFESSORES de acordo com a variável Altura}

Na Tabela 34 e no Gráfico 30, vemos que, em geral, a média e mediana de altura das pessoas classificadas, pelos professores, como apresentação predominantemente desatenta ou como apresentação predominantemente hiperativa/impulsiva é maior do que a média e mediana de altura das pessoas classificadas como apresentação combinada. Entretanto, esta diferença observada na amostra não é estatisticamente significativa, a uma significância estatística de $5 \%$, tendo em vista que o p-valor do Teste F é maior que 0,05 .

Tabela 34: Estatísticas descritivas da variável Altura pela variável SNAP-IV Professores na amostra $(\mathrm{p}=0.116)$.

\begin{tabular}{lllllllll}
\hline & $\mathrm{N}$ & Média & Desvio Padrão & Mínimo & $1^{0}$ Quartil & Mediana & $3^{0}$ Quartil & Máximo \\
\hline Combinada & 3 & 1,44 & 0,03 & 1,40 & 1,42 & 1,45 & 1,46 & 1,46 \\
Desatenta & 9 & 1,56 & 0,09 & 1,42 & 1,50 & 1,57 & 1,59 & 1,72 \\
Hiperativa & 2 & 1,50 & 0,06 & 1,45 & 1,47 & 1,50 & 1,52 & 1,54 \\
\hline
\end{tabular}


Gráfico 30: Box-plot da variável Altura pela variável SNAP-IV Professores.

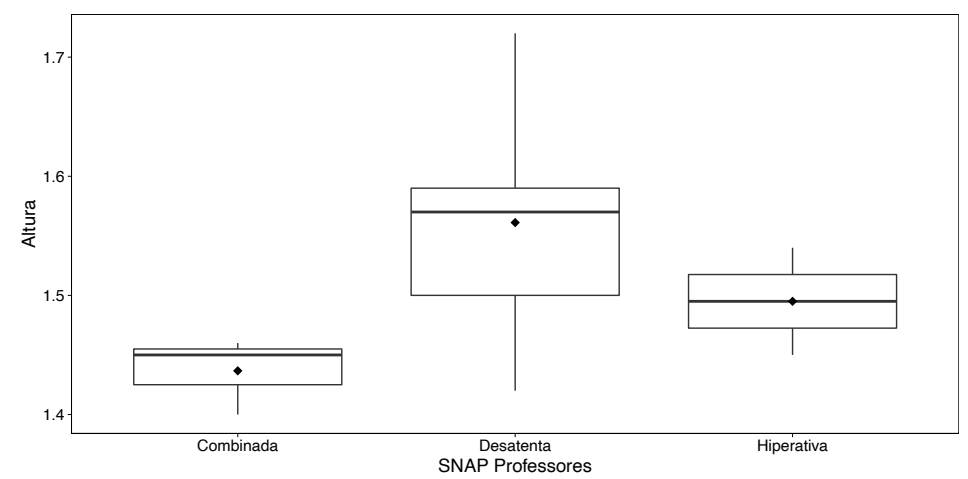

\subsubsection{SNAP-IV PROFESSORES de acordo com a variável IMC}

Na Tabela 35 e no Gráfico 31, vemos que, em geral, a média do IMC das pessoas classificadas, pelos pais, como apresentação combinada ou como apresentação predominantemente desatenta é maior do que a média do IMC das pessoas classificadas como apresentação predominantemente hiperativa/impulsiva, tendo em vista que a média e mediana do grupo predominantemente hiperativa/impulsiva é menor. Entretanto, esta diferença observada na amostra não é estatisticamente significativa, a uma significância estatística de 5\%, tendo em vista que o p-valor do Teste F é maior que 0,05 .

Tabela 35: Estatísticas descritivas da variável IMC pela variável SNAP-IV Professores na amostra $(p=0.22)$.

\begin{tabular}{lllllllll}
\hline & $\mathrm{N}$ & Média & Desvio Padrão & Mínimo & $1^{0}$ Quartil & Mediana & $3^{0}$ Quartil & Máximo \\
\hline Combinada & 3 & 17,84 & 2,44 & 15,27 & 16,69 & 18,11 & 19,12 & 20,13 \\
Desatenta & 9 & 19,56 & 2,35 & 14,50 & 18,75 & 19,61 & 20,31 & 23,04 \\
Hiperativa & 2 & 16,53 & 1,31 & 15,60 & 16,06 & 16,53 & 16,99 & 17,46 \\
\hline
\end{tabular}


Gráfico 31: Box-plot da variável IMC pela variável SNAP-IV Professores.

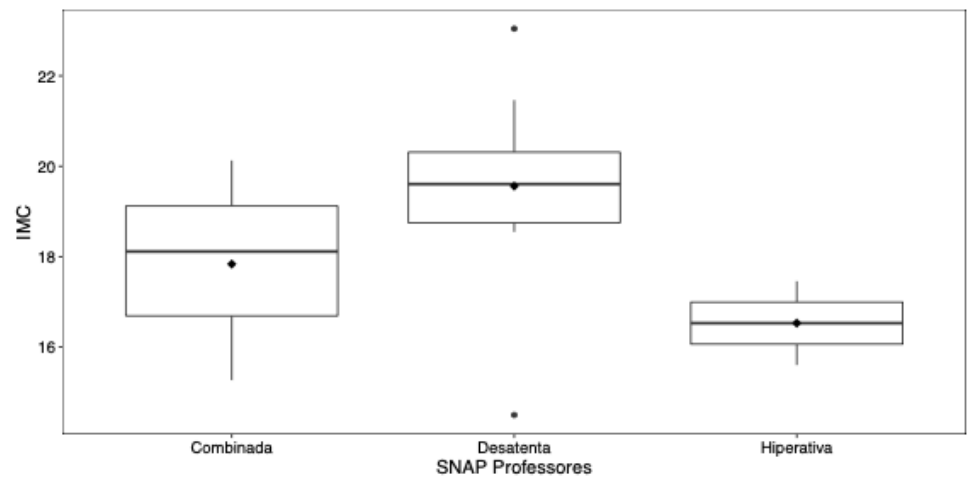

10.3.2.6 SNAP-IV PROFESSORES e frequência das variáveis SDQ dos Pais

Na Tabela 36 e no Gráfico 32 vemos que, dentre os(as) estudantes com SDQ Normal de acordo com os pais, todos possuem SNAP-IV Desatenta de acordo com os professores. Dentre os(as) estudantes com SDQ Limítrofe de acordo com os pais, todos possuem SNAP-IV Combinada de acordo os professores. Essa associação observada na amostra entre SDQ Pais e SNAP-IV Professores é estatisticamente significativa a 5\%, tendo em vista que o p-valor do Teste Exato de Fisher é menor que 0.05 .

Tabela 36: Frequência das variáveis SDQ Pais e SNAP-IV Professores na amostra $(p=0.004)$.

\begin{tabular}{rllll}
\hline & Combinada & Desatenta & Hiperativa & Total \\
\hline Normal & $0(0 \%)$ & $4(100 \%)$ & $0(0 \%)$ & $4(28.57 \%)$ \\
Limítrofe & $3(100 \%)$ & $0(0 \%)$ & $0(0 \%)$ & $3(21.43 \%)$ \\
Anormal & $0(0 \%)$ & $5(71.43 \%)$ & $2(28.57 \%)$ & $7(50 \%)$ \\
\hline Total & $3(21.43 \%)$ & $9(64.29 \%)$ & $2(14.29 \%)$ & $14(100 \%)$ \\
\hline
\end{tabular}


Gráfico 32: Frequência da variável SNAP-IV Professores em cada categoria da variável SDQ Pais.

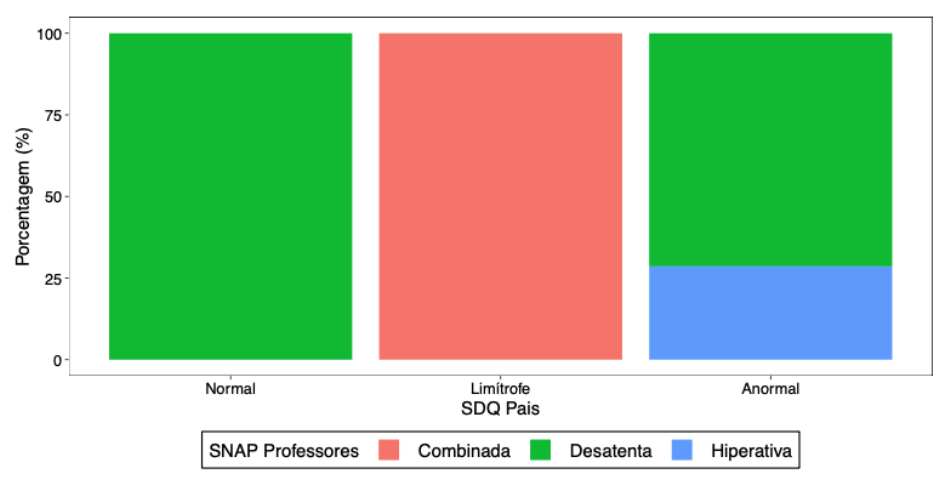

10.3.2.7 SNAP-IV PROFESSORES e frequência da variável Pró-social dos Pais

Na Tabela 37 e no Gráfico 33 vemos que, dentre as pessoas classificadas como limítrofe, na subescala Pró-social pelos pais, 50\% possuem apresentação predominantemente desatenta e 50\% possuem apresentação combinada, de acordo com os professores. Essa associação observada na amostra entre Pró-social Professores e SNAP-IV Pais não é estatisticamente significativa a 5\%, tendo em vista que o p-valor do Teste Exato de Fisher é maior que 0.05.

Tabela 37: Frequência das variáveis Pró-social Pais e SNAP-IV Professores na amostra $(\mathrm{p}=0.769)$.

\begin{tabular}{rllll}
\hline & Combinada & Desatenta & Hiperativa & Total \\
\hline Normal & $2(18.18 \%)$ & $7(63.64 \%)$ & $2(18.18 \%)$ & $11(78.57 \%)$ \\
Limítrofe & $1(50 \%)$ & $1(50 \%)$ & $0(0 \%)$ & $2(14.29 \%)$ \\
Anormal & $0(0 \%)$ & $1(100 \%)$ & $0(0 \%)$ & $1(7.14 \%)$ \\
\hline Total & $3(21.43 \%)$ & $9(64.29 \%)$ & $2(14.29 \%)$ & $14(100 \%)$
\end{tabular}


Gráfico 33: Frequência da variável SNAP-IV Professores em cada categoria da variável Pró-social Pais.

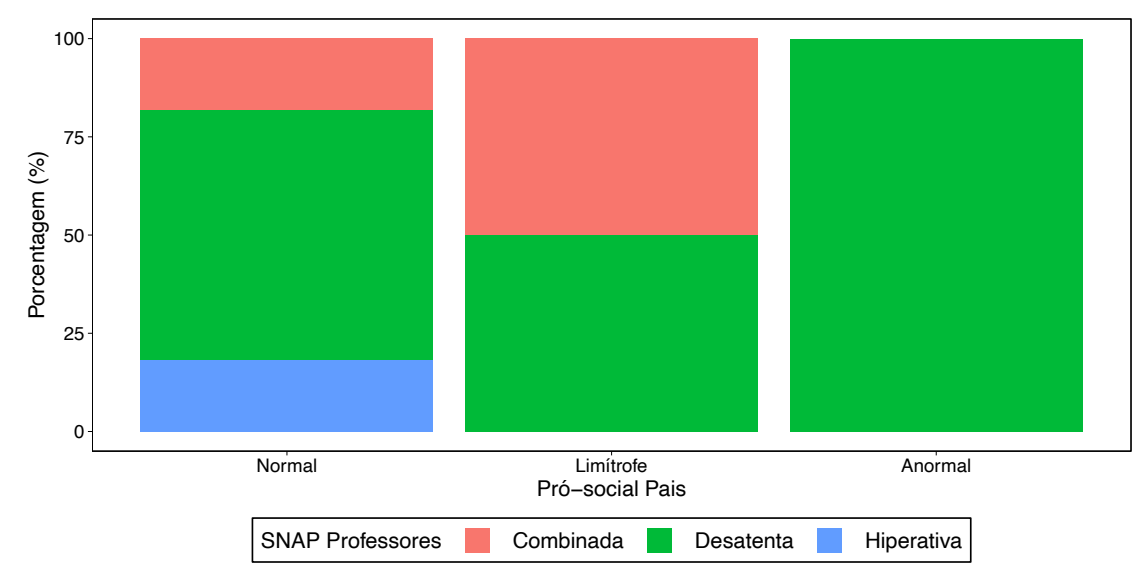

\subsubsection{SNAP-IV PROFESSORES e frequência das variáveis SDQ dos Professores}

Na Tabela 38 e no Gráfico 34 vemos que, dentre as pessoas classificadas como limítrofe, na variável SDQ, pelos professores, 66.67\% possuem apresentação combinada, $33.33 \%$ possuem apresentação predominantemente desatenta e nenhuma pessoa foi classificada como apresentação predominantemente hiperativa/impulsiva, de acordo as respostas do SNAP-IV pelos professores. Essa associação observada na amostra entre SDQ Professores e SNAP-IV Professores não é estatisticamente significativa a 5\%, tendo em vista que o p-valor do Teste Exato de Fisher é maior que 0.05.

Tabela 38: Frequência das variáveis SDQ Professores e SNAP-IV Professores na amostra ( $p=$ $0.124)$.

\begin{tabular}{rllll}
\hline & Combinada & Desatenta & Hiperativa & Total \\
\hline Normal & $0(0 \%)$ & $5(100 \%)$ & $0(0 \%)$ & $5(35.71 \%)$ \\
Limítrofe & $2(66.67 \%)$ & $1(33.33 \%)$ & $0(0 \%)$ & $3(21.43 \%)$ \\
Anormal & $1(16.67 \%)$ & $3(50 \%)$ & $2(33.33 \%)$ & $6(42.86 \%)$ \\
\hline Total & $3(21.43 \%)$ & $9(64.29 \%)$ & $2(14.29 \%)$ & $14(100 \%)$ \\
\hline
\end{tabular}


Gráfico 34: Frequência da variável SNAP-IV Professores em cada categoria da variável SDQ Professores.

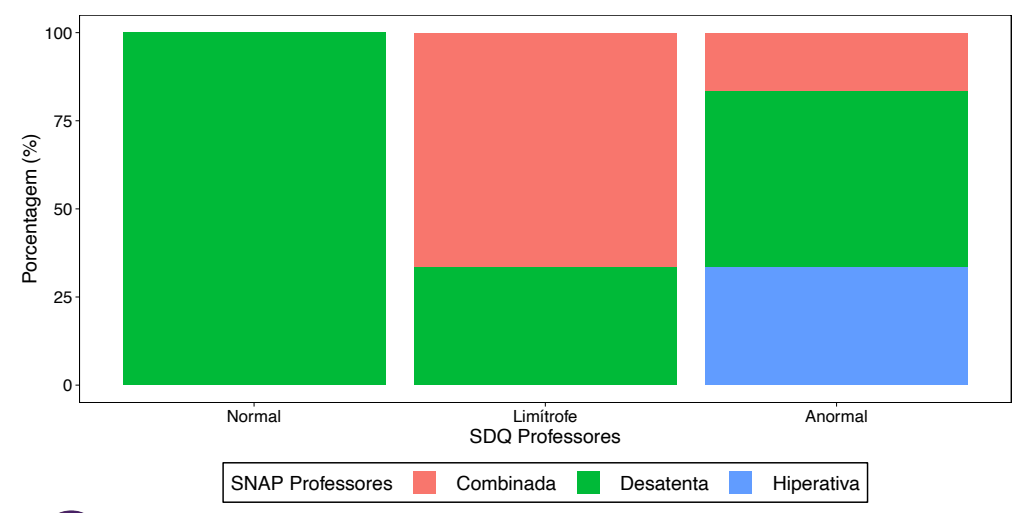

10.3.2.9 SNAP-IV PROFESSORES e frequência das variáveis Pró-social dos Professores

Na Tabela 39 e no Gráfico 35 vemos que, dentre as pessoas classificadas como limítrofe, na subescala pró-social pelos professores, todos possuem apresentação predominantemente desatenta de acordo com os professores. Essa associação observada na amostra entre Pró-social Professores e SNAP-IV Professores não é estatisticamente significativa a 5\%, tendo em vista que o p-valor do Teste Exato de Fisher é maior que 0.05.

Tabela 39: Frequência das variáveis Pró-social Professores e SNAP-IV Professores na amostra $(\mathrm{p}=$ $1)$.

\begin{tabular}{rllll}
\hline & Combinada & Desatenta & Hiperativa & Total \\
\hline Normal & $3(23.08 \%)$ & $8(61.54 \%)$ & $2(15.38 \%)$ & $13(92.86 \%)$ \\
Limítrofe & $0(0 \%)$ & $1(100 \%)$ & $0(0 \%)$ & $1(7.14 \%)$ \\
Anormal & $0(0 \%)$ & $0(0 \%)$ & $0(0 \%)$ & $0(0 \%)$ \\
\hline Total & $3(21.43 \%)$ & $9(64.29 \%)$ & $2(14.29 \%)$ & $14(100 \%)$ \\
\hline
\end{tabular}


Gráfico 35: Frequência da variável SNAP-IV Professores em cada categoria da variável Pró-social Professores.

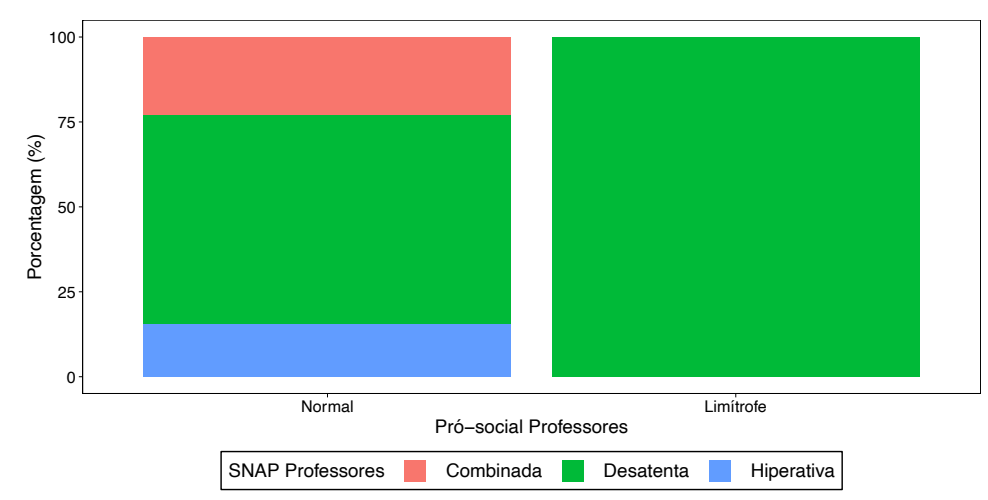

10.3.2.10 SNAP-IV PROFESSORES e frequência das variáveis TOD dos Pais

Na Tabela 40 e no Gráfico 36, vemos que $60 \%$ da amostra que apresentou TOD, de acordo com os pais, foi classificada na apresentação desatenta pelos professores. Além disso, $40 \%$ da amostra que apresentou o TOD, de acordo com os pais, foi classificada como apresentação combinada. Essa associação observada na amostra entre TOD pais e SNAP-IV Professores não é estatisticamente significativa a $5 \%$, tendo em vista que o p-valor do Teste Exato de Fisher é maior que 0.05.

Tabela 40: Frequência das variáveis TOD Pais e SNAP-IV Professores na amostra $(p=0.559)$.

\begin{tabular}{rllll}
\hline & Combinada & Desatenta & Hiperativa & Total \\
\hline Não & $1(11.11 \%)$ & $6(66.67 \%)$ & $2(22.22 \%)$ & $9(64.29 \%)$ \\
Sim & $2(40 \%)$ & $3(60 \%)$ & $0(0 \%)$ & $5(35.71 \%)$ \\
\hline Total & $3(21.43 \%)$ & $9(64.29 \%)$ & $2(14.29 \%)$ & $14(100 \%)$
\end{tabular}


Gráfico 36: Frequência da variável SNAP-IV Professores em cada categoria da variável TOD Pais.

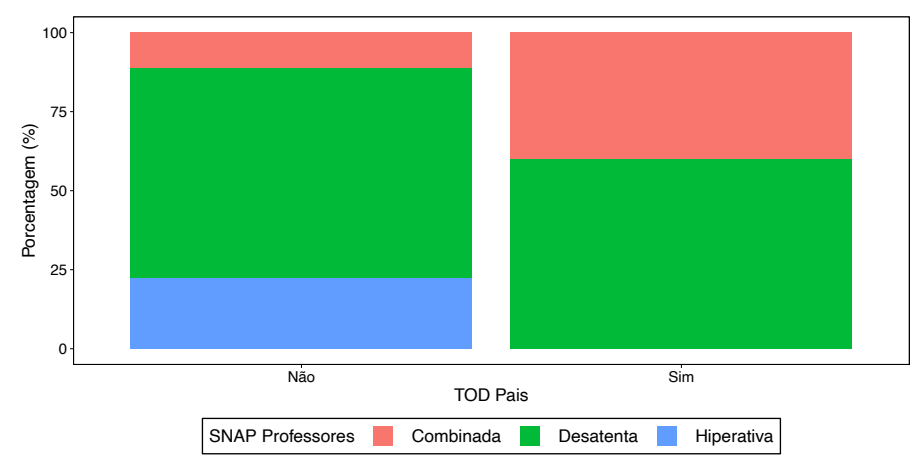

10.3.2.11 SNAP-IV PROFESSORES e frequência das variáveis TOD dos Professores

Na Tabela 41 e no Gráfico 37, vemos que todas as pessoas que apresentaram indicativos do TOD, de acordo com os professores, foram classificadas na apresentação predominantemente hiperativa/impulsiva, pelos professores. Essa associação observada na amostra entre TOD pais e SNAP-IV Professores não é estatisticamente significativa a 5\%, tendo em vista que o p-valor do Teste Exato de Fisher é maior que 0.05 .

Tabela 41: Frequência das variáveis TOD Professores e SNAP-IV Professores na amostra ( $\mathrm{p}=$ $0.143)$.

\begin{tabular}{rllll}
\hline & Combinada & Desatenta & Hiperativa & Total \\
\hline Não & $3(23.08 \%)$ & $9(69.23 \%)$ & $1(7.69 \%)$ & $13(92.86 \%)$ \\
Sim & $0(0 \%)$ & $0(0 \%)$ & $1(100 \%)$ & $1(7.14 \%)$ \\
\hline Total & $3(21.43 \%)$ & $9(64.29 \%)$ & $2(14.29 \%)$ & $14(100 \%)$
\end{tabular}


Gráfico 37: Frequência da variável SNAP-IV Professores em cada categoria da variável TOD Professores.

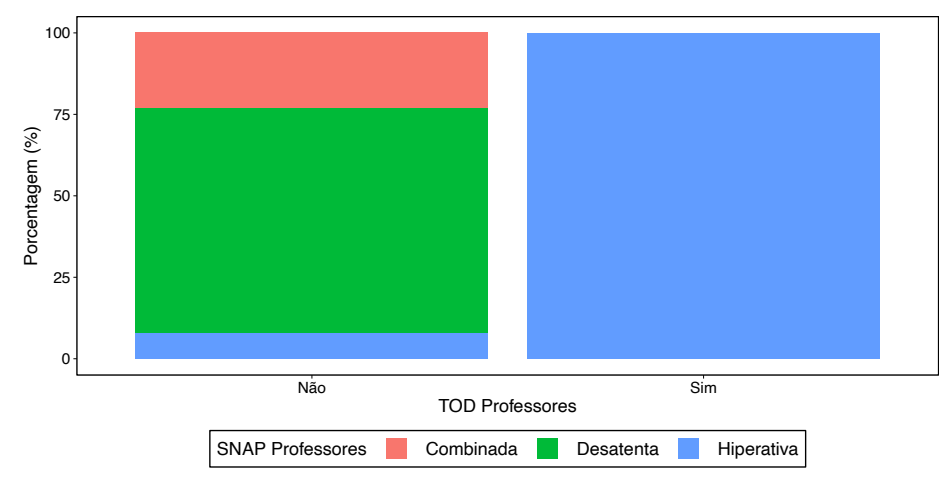

10.3.2.12 SNAP-IV PROFESSORES e frequência das variáveis TOD

Na Tabela 42 e no Gráfico 38, vemos que $75 \%$ da amostra que apresentou indicativos do TOD foi classificado na apresentação predominantemente desatenta pelos professores. Em $12.50 \%$ da amostra que apresentou indicativos do TOD foi classificada como apresentação combinada e 12.50\% como apresentação predominantemente hiperativa/impulsiva, segundo os professores. Essa associação observada na amostra entre TOD e SNAP-IV Professores não é estatisticamente significativa a 5\%, tendo em vista que o p-valor do Teste Exato de Fisher é maior que 0.05.

Tabela 42: Frequência das variáveis TOD e SNAP-IV Professores na amostra $(\mathrm{p}=0.748)$.

\begin{tabular}{rllll}
\hline & Combinada & Desatenta & Hiperativa & Total \\
\hline Não & $2(33.33 \%)$ & $3(50 \%)$ & $1(16.67 \%)$ & $6(42.86 \%)$ \\
Sim & $1(12.50 \%)$ & $6(75 \%)$ & $1(12.50 \%)$ & $8(57.14 \%)$ \\
\hline Total & $3(21.43 \%)$ & $9(64.29 \%)$ & $2(14.29 \%)$ & $14(100 \%)$ \\
\hline
\end{tabular}


Gráfico 38: Frequência da variável SNAP-IV Professores em cada categoria da variável TOD.

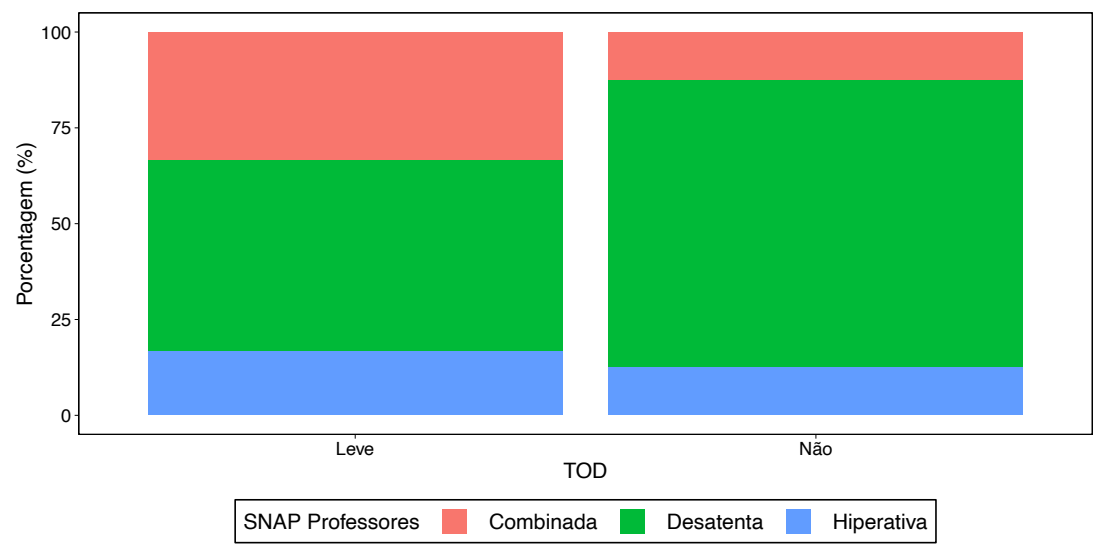




\section{DISCUSSÃO}

O objetivo do presente estudo foi identificar o perfil socioemocional de escolares do ensino fundamental II (de dez a quinze anos), com indicativos do transtorno do déficit de atenção/hiperatividade em dois contextos: nas aulas de educação física e no âmbito familiar, de acordo com as informações dos professores de educação física e dos familiares (pai, mãe ou responsável).

Houve a preocupação em identificar o índice de massa corporal dos(as) escolares pesquisados, para contribuir com futuras avaliações biométricas de acompanhamento do desenvolvimento do(a) escolar, pois ao identificar o(a) escolar com indicativos do TDAH, as famílias serão comunicadas e todos os dados da pesquisa serão disponibilizados.

Para organização da discussão dos resultados, iniciaremos com a análise descritiva, seguindo pela análise de concordância e, por fim, a relação do TDAH (SNAP-IV) e o SDQ-Por.

Em relação ao gênero, como foi descrito na revisão de literatura deste estudo, nota-se uma maior prevalência do sexo masculino em relação ao feminino, com uma proporção de cerca de 2:1 nas crianças em amostras populacionais, e 10:1 em amostras clínicas (SCAHILL E SCHWAB-STONE, 2000; WILLCUTT, 2012; APA, 2013). Este estudo foi composto por 78.6\% de adolescentes do sexo masculino e $21.4 \%$ de adolescentes do sexo feminino, mostrando conformidade com estudos epidemiológicos que apontaram ser maior o número de meninos na fase da infância e adolescência com o TDAH (POLANCZYK et al., 2007; FARAONE et al., 2015).

A média da idade obtida neste estudo foi de 12 anos e todos(as) escolares se encontravam na fase da adolescência. Ocorreram variações das apresentações do TDAH e a idade, de acordo com os informantes. É informado no DSM-5 (APA, 2013) que quanto mais nova a criança, mais sintomas de hiperatividade são verificados e com o decorrer do tempo, os sintomas vão mudando. Na adolescência, como é constituída a amostra desta pesquisa, os sinais da hiperatividade (exemplo: correr e pular) são menos comuns, sendo mais frequentes o comportamento irrequieto e a impulsividade.

Em relação ao IMC, encontramos, em nossa amostra, a média de $18,8 \mathrm{Kg} / \mathrm{m}^{2}$, desta forma pudemos constatar que todas as pessoas constituintes da amostra se encontram em baixo risco para problemas relacionados à saúde física, pois possuíam uma relação adequada entre peso e altura. Talvez isso se deva à abordagem utilizada para o tratamento do TDAH ou ao desconhecimento do possível transtorno pelas famílias. Os pesquisadores Poutron et al. (2013) acompanharam o crescimento e desenvolvimento de 65 meninos, de 12 a 15 anos, que utilizavam drogas estimulantes para o tratamento do TDAH, por aproximadamente 3 anos e compararam com um grupo controle de 174 meninos. Tais 
autores concluíram que o tratamento prolongado do TDAH com medicamentos estimulantes está associado a menores valores do índice de massa corporal e menor taxa desenvolvimento físico. Por outro lado, uma revisão de literatura feita pelos pesquisadores Damiani et al. (2010) não achou um consenso sobre os prejuízos no crescimento dos pacientes quanto ao déficit estatural. Tais autores acreditam que as crianças e adolescentes em tratamento com estimulantes devam ser monitoradas no tocante ao seu crescimento. Em relação às apresentações do TDAH pudemos observar que, na apresentação predominantemente hiperativa/impulsiva, o IMC obteve os valores das médias e medianas mais baixos tanto para os pais quanto para os professores, entretanto todos se encontraram nos valores saudáveis de saúde de acordo com a OMS.

De acordo com os resultados do SNAP-IV, a apresentação do TDAH predominantemente desatenta foi observada em $100 \%$ das meninas de acordo com os professores, enquanto os pais apontaram 66\% das meninas nessa apresentação. Esse achado está em conformidade com a DSM-5 (APA, 2013) pois consta que existe uma maior probabilidade de pessoas do sexo feminino estarem primariamente com características de desatenção, quando comparadas com as do sexo masculino. Tanto na visão de pais como na de professores, nenhuma menina foi classificada com a apresentação do TDAH predominantemente hiperativa/impulsiva. Os autores Thorell et al. (2008) pesquisaram as associações entre os problemas comportamentais e déficits sociais associados ao TDAH e as diferenças entre a idade e o gênero, encontrando uma maior apresentação combinada do TDAH nos meninos do que nas meninas. Em nossa pesquisa, a apresentação combinada foi relatada pelos pais em $36.36 \%$ dos meninos e em 33.33\% das meninas, já os professores encontraram em $27.27 \%$ dos meninos e não encontraram a apresentação combinada nas meninas.

O SDQ foi analisado de duas maneiras: dificuldades totais e comportamento pró-social. Em uma análise foi utilizado o escore das dificuldades totais, observando as quatro subescalas referentes aos problemas de conduta, à hiperatividade, aos problemas com os pares e aos problemas emocionais, excluindo a pontuação referente ao comportamento pró-social, que foi analisado separadamente. Com essas análises, a amostra pode ser classificada em normal, limítrofe e anormal. Em relação às dificuldades totais apontadas no SDQ, pudemos observar que houve concordância de $64.3 \%$ entre as respostas de pais e de professores. A frequência da classificação normal foi de $28.6 \%$ para os pais e de $35.7 \%$ para os professores, a classificação limítrofe foi de $21.4 \%$ tanto para os pais quanto para os professores e a classificação anormal foi de $50 \%$ para os pais e de $42.9 \%$ para os professores. A amostra foi classificada como anormal nos aspectos socioemocionais para ambos os informantes, pais e 
professores, porém a associação da concordância estabelecida foi baixa. Uma possível explicação pode estar relacionada ao pequeno tamanho da amostra.

No estudo de Mendes (2020) também foi encontrado um valor médio do SDQ total, maior para os pais do que o valor encontrado pelos professores, embora a faixa etária investigada tenha sido menor (quatro a seis anos), os aspectos socioemocionais foram classificados como anormais, como em nossa pesquisa. Os pesquisadores Ramos e Golfeto (2003) utilizaram o SDQ para rastrear possíveis transtornos psiquiátricos, entre crianças de seis a onze anos, e as pontuações encontradas nos questionários dos pais foram mais elevadas do que aquelas dadas pelos professores. Silva et al. (2020), através de comparações entre as respostas do SDQ de professoras e mães, concluíram que as mães identificaram mais problemas que as professoras em todas as subescalas, especialmente para os meninos. Os autores Stivanin et al. (2008) sugerem um olhar mais criterioso ao compararem as respostas de pais e professores, pois a criança pode apresentar comportamentos diferentes em diferentes contextos como em casa ou na escola, ou mesmo quando se relaciona com diferentes pessoas. Para os estudiosos Korsch e Petermann (2014), é preciso considerar que o comportamento pode ser interpretado como inadequado ou não dependendo dos padrões estabelecidos pelo avaliador.

Em relação à subescala pró-social do SDQ, pudemos observar que houve concordância de $85.7 \%$ entre as respostas de pais e de professores, em nossa pesquisa. A frequência da classificação normal foi de $78.6 \%$ para os pais e de $92.9 \%$ para os professores, a classificação limítrofe foi de $14.3 \%$ para os pais e de $7.1 \%$ para os professores e a classificação anormal foi de $7.1 \%$ para os pais e ninguém foi classificado com o anormal pelos professores. A amostra foi classificada como normal nos aspectos pró-sociais para ambos os informantes, pais e professores, porém a associação da concordância estabelecida foi baixa. Uma possível explicação pode estar relacionada ao pequeno tamanho da amostra. A autora Figueira (2017) relata que o comportamento pró-social é observado nas ações voltadas para ajudar, partilhar e confortar o outro e isto trás implicações para o bem-estar e desenvolvimento social saudável.

Em relação ao TOD, Polanczyk et al. (2015) realizaram um estudo populacional, incluindo 28 pesquisas sobre o TOD, e estimaram em 3,6\% a prevalência mundial entre crianças e adolescentes. Em nossa pesquisa, o valor encontrado foi de 1,8\% do total de 328 escolares pesquisados na escola. Dos (as) escolares com indicativos do TDAH, 42.9\% foram classificados como "leve" e 57.1\% não apresentaram o TOD. A frequência da classificação "leve" foi de $64.3 \%$ para os pais e de $7.1 \%$ para os professores, mostrando que os pais relataram uma maior ocorrência do TOD na amostra. Na visão dos professores, o único que apresentou o TOD foi do sexo masculino e da apresentação 
hiperativa/impulsiva, ao passo que na visão dos pais $60 \%$ dos que apresentaram TOD foram classificados na apresentação combinada do TDAH. Esse achado corrobora com o estudo de Thorell et al. (2008) que encontrou uma maior prevalência de meninos com TDAH e problemas associados ao comportamento inadequado. A literatura pesquisada aponta que o diagnóstico do TOD está associado em 60\% ao TDAH (GRETEV et al., 2007). De acordo com a revisão bibliográfica realizada pela autora Silva (2017), os meninos apresentam um padrão de sintomas e comportamentos mais persistente do TOD, que se inicia por volta dos oito anos de idade e se intensifica na adolescência.

No SNAP-IV houve concordância de $57.1 \%$ entre as respostas de pais e de professores, pois o coeficiente de associação foi positivo (0.26). No SDQ houve concordância de $64.3 \%$ entre as respostas de pais e de professores, pois o coeficiente de associação foi positivo $(0,44)$. Na subescala Pró-social houve concordância de $85.7 \%$ entre as respostas de pais e de professores, pois o coeficiente de associação foi positivo $(0,45)$. Ao observarmos o Coeficiente de Kappa podemos perceber que as associações são baixas. Em relação ao TOD, houve discordância de 57.1\% entre as respostas de pais e de professores, pois o coeficiente de associação foi negativo $(-0,14)$.

Em relação às apresentações do TDAH, de acordo com os professores e relacionados com as classificações do SDQ quanto as dificuldades totais, de acordo com os pais, podemos observar uma associação significativa em todas as categorias. Dentre os(as) estudantes com SDQ Normal, de acordo com os pais, todos possuem SNAP-IV Desatenta, de acordo com os professores. Dentre os(as) estudantes com SDQ Limítrofe, de acordo com os pais, todos possuem SNAP-IV Combinada, de acordo os professores. 


\section{CONCLUSÃO}

O objetivo do presente estudo foi identificar o perfil socioemocional de escolares do ensino fundamental II (de dez a quinze anos), com indicativos do transtorno do déficit de atenção/hiperatividade em dois contextos: nas aulas de educação física e no âmbito familiar, que cursavam um colégio da rede privada de ensino, do município de São Paulo. Tendo a seguinte pergunta norteadora, "Qual o perfil socioemocional de escolares do ensino fundamental II com indicativos do transtorno do déficit de atenção/hiperatividade em dois contextos: nas aulas de educação física e no âmbito familiar? Para responder essa questão, os seguintes objetivos específicos foram explicitados: identificar os(as) escolares com indicativos do TDAH; identificar a comorbidade do TDAH com o transtorno de oposição desafiante (TOD); pesquisar o perfil socioemocional dos(as) escolares com indicativos do TDAH, e; pesquisar o índice de massa corporal dos (as) escolares com indicativos do TDAH.

Portanto, identificamos 14 escolares com indicativos do TDAH, sendo a maior parte do sexo masculino, corroborando com a literatura pesquisada. O TOD foi mais frequente no âmbito familiar quando comparado ao contexto escolar. Talvez isso se deva ao fato de que na escola as regras e os combinados estão mais explicitados e as sanções mais esclarecidas. Em relação ao perfil socioemocional pró-social, os escolares foram classificados como normais tanto no ambiente familiar quanto no escolar, permitindo inferir que os escolares possuem empatia e solidariedade. Entretanto, o perfil socioemocional em relação às dificuldades totais foi considerado anormal tanto para os pais quanto para os professores, o que nos leva a suspeitar que as dificuldades dos(as) escolares possam estar mais concentrados nos problemas emocionais e nos problemas relacionados à hiperatividade $\mathrm{e}$ não nos problemas de conduta ou nos problemas entre os pares. Em relação aos escolares que os pais relataram possuírem problemas socioemocionais classificados como limítrofes, foram categorizados(as) com tendo indicativos do TDAH na apresentação combinada, de acordo com os professores. E aqueles(as) com indicativos do TDAH na apresentação predominantemente desatenta, de acordo com os professores, não obtiveram problemas socioemocionais de acordo com os pais.

Por fim, com relação ao IMC, pudemos constatar que todos(as) os(as) escolares constituintes da amostra se encontram em baixo risco para problemas relacionados à saúde física, pois possuem uma relação adequada entre peso e altura. Apoiamos a ideia de se fazer avaliações biométricas periódicas no período de desenvolvimento da criança e do adolescente com indicativos do TDAH para monitoramento do seu crescimento. 
Em conclusão, apontamos como limitação deste nosso estudo o pequeno tamanho da amostra e sugerimos que, em novas pesquisas, seja incluída um número maior de participantes e que as subescalas do questionário SDQ sejam pontuadas separadamente para uma melhor avaliação dos comportamentos socioemocionais dos adolescentes. Um grande entrave encontrado em nossa pesquisa foi a pandemia do COVIDE 19, pois as aulas presenciais foram paralisadas e nós, pesquisadores, não conseguimos realizar a bateria de testes motores nos (as) adolescentes, inviabilizando identificar o perfil motor dos (as) escolares com indicativos do TDAH, que era um dos objetivos iniciais desta pesquisa. Sendo assim, em futuros estudos, sugerimos investigar o nível de desempenho motor desses (as) educandos (as). Dessa forma, acreditamos na importância da utilização de instrumentos rastreadores durante os anos escolares para investigar possíveis indicativos de transtornos do neurodesenvolvimento, favorecendo encaminhamentos e intervenções preventivas necessárias. 


\section{REFERÊNCIAS BIBLIOGRÁFICAS}

AHN, S.; FEDEWA, F. A Meta-analysis of the Relationship Between Children's Physical Activity and Mental Health. Journal of Pediatric Psychology, v. 36, n. 4, p. 385-97, Apr., 2011.

AMERICAN PSYCHIATRIC ASSOCIATION (APA). Diagnostic and statistical manual of mental disorders (2nd ed.). Washington, DC: Author, 1968.

. Diagnostic and statistical manual of mental disorders (3rd ed.).

Washington, DC: Author, 1980.

. Diagnostic and statistical manual of mental disorders (3rd ed., rev).

Washington, DC: Author, 1987.

. Diagnostic and statistical manual of mental disorders (4th ed.).

Washington, DC: Author, 1994.

. Diagnostic and statistical manual of mental disorders (5th ed.).

Washington, DC: Author, 2013.

AMIRI, S.; FAKHARI, A.; MAHERI, M.; ASGHAR, A. M. Attention deficit/hyper- activity disorder in primary school children of Tabriz, North-West Iran. Paediatric Perinatal Epidemiology, v. 24, n. 6, p. 597-601, Aug., 2010.

ANDRADE, M. C. L.; BONA, M.; PEREIRA, G. R. M. Pedagogia e educação dos costumes num antigo livro infantil: Der Struwwelpeter. Educação \& Sociedade, v. 30, n. 106, jan./apr, Campinas, 2009.

ANDRADE, P. F. S; VASCONCELOS, M. M. Transtorno do déficit de atenção com hiperatividade. Residência Pediátrica, v. 8, supl.1, Rio de Janeiro, 2018.

ANDREWS, P.; PINE, D.S.; HOBBS, M. J.; ANDERSON, T. M.; SUNDERLAND, M. Neurodevelopmental disorders: Cluster 2 of the proposed meta-structure for DSM-V and ICD-11, Psychological Medicine, v. 39, p. 2013-23, 2009.

ARAUJO, M.; SILVA, S.A.P.S. Comportamentos indicativos do transtorno de déficit de atenção e hiperatividade em crianças: alerta para pais e professores. Revista Digital, v. 9, n. 62, Buenos Aires, 2004. Disponível em: http:/www.efdesportes.com 
ARTIGAS-PALLARES, J. Comorbidad en el transtorno por déficit de atención/ hiperatividade. Revista de Neurologia, v. 36, Suppl. 1, p. 68-78, 2003.

ASONITOU; KOUTSOUKI; KOURTESSIS; CHARITOU. Rev Des Disabil. n. 33, v. 6, p. 996-1005. Jul/Aug, 2012.

AYAZ, A. B.; AYAZ, M.; YAZGAN, Y.; AKIN, E. A relação entre coordenação motora e problemas de comportamento social em adolescentes com transtorno de déficit de atenção/ hiperatividade. Psikofarmakoloji Bulteni. v. 23, n. 1, p. 33-41, 2013.

BANERJEE, T. D.; MIDDLETON, F.; FARAONE, S. V. Environmental risk factors for attentiondeficit hyperactivity disorder. Acta Paediatr, v. 96, n. 9, p. 1269-74, 2007.

BARKLEY, R. A. Attention deficit hyperactivity disorder: A handbook for diagnosis and treatment. New York: Guilford Press, 1990. . Linkages between attention and executive functions. In: G. R. Lyon \& N. A. Krasnegor (Eds.), Attention, memory, and executive function. Baltimore: Paul H. Brookes. p. 307-326, 1995. . https://youtu.be/OhlaHnMxw2U (acesso em 18/10/2018 às 15h26). . https://youtu.be/sA5YTp1UE1k (acesso em 18/10/2018 às 14h10).

\section{- Attention-deficit Hyperactivity Disorder: A Handbook for}

Diagnosis and Treatment. New York: Guilford Press, 1998. . International consensus statement on ADHD. Clinical Child and

Family Psychology Review, v. 5, n. 2, p. 89-111, Jan., 2002. . International consensus statement on ADHD. Clinical Child and Family Psychology Review, v. 5, n. 2, p. 89-111, Jun 2003.

BARKLEY, R. A.; PETERS, H. The earliest reference to ADHD in the medical literature? Melchior Adam Weikard's description in 1775 of "attention deficit" (Mangel der Aufmerksamkeit, Attentio Volubilis). Journal of Attentioan Disorders. v.16, n.8, p.623-30, Nov., 2012. 
BIEDERMAN, J. Attention-deficit/hyperactivity disorder: A life span perspective. Journal of Clinical Psychiatry, v. 59, n.7, p. 4-16, 1998.

BIEDERMAN, J.; FARAONE, S. V.; TAYLOR, A.; SIENNA, M.; WILLIAMSON, S.; FINE, C. Diagnostic continuity between child and adolescent ADHD: findings from a longitudinal clinical sample. Journal of American Academic Child Adolesc Psychiatry, v. 37, n. 3, p. 305-13, 1998.

BIEDERMAN, J.; MICK, E.; FARAONE, S. V. Age-dependent decline of symptoms of attention deficit hyperactivity disorder: impact of remission definition and symptom type. American Journal of Psychiatry, v. 157, n. 5, p. 816-8, 2000.

CÂMARA, F. P. Comportamento Agressivo. Psychiatry Online Brasil. Mar., 2018. (Acesso em: 5/ 02/2019).

CAIRNEY, J.; RIGOLI, D.; PIEK, J. Developmental coordination disorder and internalizing problems in children: The environmental stress hypothesis elaborated. Developmental Review, v. 33, n.3, p. 224-238, 2013.

CAMPBELL, S. B.; PAULAUKAS, S. Peer relations in hyperactive children. Child Psychology \& Psychiatry \& Allied Disciplines, v. 20, n. 3, p. 233-246, 1979.

CASEY, B. J.; NIGG, J. T.; DURSTON, S. New potential leads in the biology and treatment of attention deficit-hyperactivity disorder. Current Opinion in Neurology, n. 20, p. 119-124, 2007.

COHEN, J. A coefficient of agreement for nominal scales. Educational and psychological measurement, v. 20, n. 1, p. 37-46, 1960.

CLEMENTS, S. D. Minimal brain dysfunction in children. DHEW Publication, University of Arkansas Medical Center, Little Rock, n. 1415, p. 1-18, 1966.

COLlares, C. A. L.; MOYSÉS, M. A. A. Dislexia e TDAH: uma análise a partir da ciência médica. In: Conselho Regional de Psicologia de São Paulo e Grupo Interinstitucional de Queixa 
Escolar (Orgs.). Medicalização de crianças e adolescentes: conflitos silenciados pela redução de questões sociais a doença de indivíduos. São Paulo: Casa do Psicólogo, p.71-109, 2010.

CONOVER, W. J. Practical nonparametric statistics (3.o ed.). Ed. Jhon Wiley and Sons. New York. 1999.

COSTELlO, E. J.; KEELER, G. P.; ANGOLD, A. Poverty, race/ethnicity, and psychi- atric disorder: a study of rural children. American Journal Public Health, n. 91, p. 1494-1498. 2001.

CUNNINGHAM, C. E.; SIEGEL, L. S. Peer interactions of normal and attention-deficit-disordered boys during free-play, cooperative task, and simulated classroom situations. Journal of Abnormal Child Psychology, v. 15, n. 2, p. 247-268, Jun., 1987.

CURATOLO, P.; D'AGATI, E.; MOAVERO, R. The neurobiological basis of ADHD. Italian Journal of Pediatrics. v. 36, n. 1, p. 79, Dec., 2010.

CRICHTON, A. An Inquiry Into The Nature And Origin Of Mental Derangement. Comprehending A Concise System Of The Physiology And Pathology Of The Human Mind. And A History Of The Passions And Their Effects. Londres, v.1, p. 254 - 290, 1798.

CURY, C. R.; GOLFETO, J. H. Strengths and difficulties questionnaire (SDQ): a study of school children in Ribeirão Preto. Revista Brasileira de Psiquiatria, v. 25, n. 3, set., São Paulo, 2003.

DAMIANI, D.; DAMIANI, D.; CASELLA, E. Hiperatividade e déficit de atenção - o tratamento prejudica o crescimento estatural? Arquivos Brasileiros de Endocrinologia e Metabologia, v.3, n. 54 , p. $262-68,2010$.

DEL PRETTE, Z. A. P.; DEL PRETTE, A.; PAVARINO, M. G. O desenvolvimento da empatia como prevenção da agressividade na infância. Psico, v. 36, n. 2, p. 127-134, mai./ago., 2005.

DEMPSEY, A. M. Movement and attention: an examination of the relationship between movements and ADHD manifestations in middle school students with ADHD. Dissertation (Doctorship). Carson-Newman University. Spring., p. 93, 2017. 
DIAMOND, A. Close Interrelational of Motor Development and of the Cerebellum Prefrontal Cortex. Child Development, v. 71, n. 1, p. 44-56, Jan./Feb., 2000.

DOPFNER, M.; HAUTMANN, C.; GORTZ-DORTEN, A.; KLASEN, F.; RAVENS- SIEBERER, U. Long-term course of ADHD symptoms from childhood to early adulthood in a community sample. Eur Child Adolesc Psychiatry, v. 24, n. 6, p. 665-73, 2014.

DOPHEIDE, J. A.; PLISZKA, S. R. Attention-deficit-hyperactivity disorder: an update. Pharmacotherapy, v. 6, n. 29, p. 656-79, Jun., 2009.

DUPAUL, G. J., STONER, G. TDAH nas escolas: Estratégias de Avaliação e Intervenção. 1.a ed. São Paulo: M. Books do Brasil Editora Ltda, 2007.

DURSTON, S.; MULDER, M.; CASEY, B. J.; ZIERMANS, T., VAN ENGELAND, H. Activation in ventral prefrontal cortex is sensitive to genetic vulnerability for attention-deficit hyperactivity disorder. Biol Psychiatry, v. 15, n. 10, p. 1062-70, 2006.

FARAONE, S. V.; MICK, E. Molecular Genetics of Attention Deficit Hyperactivity Disorder. Psychiatric Clinics North Americana. Mar, v. 33, n. 1, p. 159-180, 2010.

FARAONE, S. V.; PERLIS, R. H.; DOYLE, A. E.; SMOLlER, J. W.; GORALNICK, J. J.; HOLMGREN, M. A.; SKLAR, P. Molecular genetics of attention-deficit/hyperactivity disorder. Biol Psychiatry, v. 57, n. 11, p. 1313-23, 2005.

FARAONE, S., ASHERSON, P., BANASCHEWSKI, T. et al. Attention-deficit/hyperactivity disorder. Nature Reviews Disease Primers, v. 1, 2015.

FARAONE, S. V.; BIEDREMAN, J. M. D.; WEBER, W. B. A.; RUSSELL, R. L. B. A. Psychiatric, Neuropsychological, and Psychosocial Features of DSM-IV Subtypes of AttentionDeficit/Hyperactivity Disorder: Results From a Clinically Referred Sample. Journal of the American Academy of Child \& Adolescent Psychiatry, v. 37, n. 2, p. 185-193, 1998. 
FARAONE, S.; BIEDERMAN, J.; MONUTEAUX, M. C. Further evidence for the diagnostic continuity between child and adolescent ADHD. Journal of Attention Disorders, v. 6, n. 1, p. 5-13, 2002.

FRANÇA, M. T. B. Transtorno de Déficit de Atenção e Hiperatividade (TDAH): ampliando o entendimento. Jornal de Psicanálise, v.82, n.45, p. 191-207, 2012.

FARRE - RIBA, A., NARBONA, J. TDAH: Escala para la evaluación del transtorno por déficit de atención con hiperactividad. Madri: TEA, 2001.

FERREIRA, P. V. C. Uma Revisão Teórica sobre o Transtorno de déficit de atenção hiperatividade (TDAH) e estratégias educacionais de atendimento ao aluno com TDAH. Revista de Psicologia, Fortaleza, v. 2, n. 2, p. 57-75, jul./dez. 2011.

FIGUEIRA, T. D. F. Comportamentos desajustados e Comportamentos pró-sociais nas crianças: Relação com Empatia, Impulsividade e Propensão para o risco. 2020. Dissertação (Mestrado em Criminologia) - Faculdade de Direito, Universidade do Porto, 2017.

FLEITLICH; BACY; CORTÁZAR; PILAR GARCIA; GOODMAN; ROBERT. Questionário de capacidades e dificuldades (SDQ)/Strengths and Difficulties Questionnaire (SDQ). Infanto revista neuropsiquiatr. infanc. adolesc, v. 8, n. 1, p. 44-50, abr, 2000.

FREIRE, A.C. C.; PONDÉ, M. P. Estudo Piloto da prevalência do Transtorno de Déficit de Atenção e Hiperatividade entre crianças escolares na cidade de Salvador, Bahia, Brasil. Arquivos de Neuropsiquiatria, v. 63, n. 2B, p. 474-478, 2005.

GADOW, K.; NOLAN, E. E.; LITCHER, L.; CARLSON, G. A.; PANINA, N.; GOLOVAKHA, E. et al. Comparison of attention-deficit/hyperactivity disorder symptom subtypes in Ukrainian schoolchildren. Journal of the American Academy of Child \& Adolescent Psychiatry, v. 39, n. 12, p. $1520-1527,2000$. 
GIACOMINI, M. C. C., GIACOMINI, O. Transtorno do Déficit de atenção/hiperatividade e educação física. Revista Digital, Buenos Aires, ano.11, n. 99, ago., 2006. Disponível em: http: www.efdeportes.com/ (Acessado em: 22/06/2019).

GUIDOLIM, K. et al. Habilidades sociais em crianças com queixas de hiperatividade e desatenção. Revista Psicopedagogia, São Paulo, v. 30, n. 93, p. 159-168, 2013.

GOODMAN, R. The Strengths and Difficulties Questionnaire: A research note. Journal of Child Psychology and Psychiatry, v 38, p. 581-586, 2001.

GOODMAN, R. Psychometric properties of the strengths and difficulties questionnaire. Journal of the American Academy of Child and Adolescent Psychiatry, v. 40, n. 11, p. 1337-1345, 2001.

GOULARDINS, J. B.; MARQUES, J. C.; CASELLA, E. B. Quality of life and psychomotor profile of children with attention deficit hyperactivity disorder (ADHD). Arquivos de Neuropsiquiatria, v. 69, n. 4, p. 630-5, Aug., 2011.

GOULARDINS, J. B.; MARQUES, J. C.; CASELlA, E. B.; NASCIMENTO, R. O.; OLIVEIRA, J. A. Motor profile of children with attention deficit hyperactivity disorder, combined type. Rev. Dev Disabil, v. 34, n. 1, p. 40-5, Jan 2013.

GOULARDINS, J. B. Desempenho motor de crianças com transtorno do déficit de atenção e hiperatividade e transtorno do desenvolvimento da coordenação. Tese (Doutorado em ciências) Escola de Educação Física e Esporte, Universidade de São Paulo. São Paulo, p. 11- 18. 2016.

GREVET, E. H.; SALGADO, C. A. I.; ZENI, G.; BELMONTE-DE-ABREU, P. Transtorno de oposição e desafio e transtorno de conduta: os desfechos no TDAH em adultos. Jornal Brasileiro de Psiquiatria [online], v. 56, suppl.1, p. 34-38, 2007. (Acesso em: 2/2/2019).

HALLOWELL, E. M.; RATEY, J.J. Tendência à Distração: identificação egerência do distúrbio do déficit de atenção da infância à vida adulta. Rio de Janeiro: Editora Rocco, 1994.

HALLDORSON, B.; CRESWELL, C. Social anxiety in pre-adolescent children: What do we know about maintenance? Behaviour Research and Therapy, n.99, p. 19-36, 2017. 
HINSHAW, S. P. Academic underachievement, attention deficits, and aggression: Comorbidity and implications for intervention. Journal of Consulting And Clinical Psychology, v. 60, n. 6, p. 893903, 1992.

HINSHAW, S. P; MELNICK, S. M. Peer relationships in boys with attention-deficit hyperactivity disorder with and without comorbid aggression. Development And Psychopathology, v. 7, n. 4, p. 627-647, 1995.

HORA, A. F.; SILVA, S.; RAMOS, M.; PONTES, F.; NOBRE, J. P. A prevalência do Transtorno do Déficit de Atenção e Hiperatividade (TDAH): uma revisão de literatura. Revista de Psicologia, v. 29, n. 2, p. 47-62, 2015.

JOHNSTON, C; PELHAM, W. E.; MURPHY, H. A. Peer relationships in ADDH and normal children: a developmental analysis of peer and teacher ratings. Journal Abnorm Child Psychol, v. 13, n. 1, p. 89-100, Mar., 1985.

JOU, G. I., AMARAL, B.; PAVAN, C. R.; SCHAEFER, L. S.; ZIMMER, M. Transtorno de Déficit de Atenção e Hiperatividade: Um Olhar no Ensino Fundamental. Psicologia: Reflexão e Critica, v. 23, n. 1, Jan./Abr., 2010.

KORSCH, F.; PETERMANN, F. Agreement Between Parents and Teachers on Preschool Children's Behavior in a Clinical Sample with Externalizing Behavioral Problems. Child Psychiatry Hum Dev, n. 45, p. 617-627, 2014. https://doi.org/10.1007/s10578-013-0430-6 (Acesso em: 08/09/2020).

LEHN, H.; DERKS, E. M.; HUDZIAK, J. J.; HEUTINK, P.; VAN BEIJSTERVELDT, T. C.; BOOMSMA, D. I. Attention problems and attention-deficit/hyperactivity disorder in discordant and concordant monozygotic twins: evidence of environmental mediators. Journal of American Academy of Child Adolesc Psychiatry, v. 46, n. 1, p. 83-91, 2007.

LOOS, H.; RANGEL JÚNIOR, E. B. Self-beliefs, school context, and attention deficit hyperactivity disorder (ADHD): Perceptions from Brazilian teenagers and young adults [resumo]. International Journal of Psychology, 2008.

LOUZÃ NETO, M. R. et al. TDAH ao longo da vida. Porto Alegre: Editora Artmed, 2009. 
LOUZÃ NETO, M. R. TDAH transtorno de déficit de atenção/ hiperatividade ao longo da vida. Porto Alegre: Artmed 2010.

MARTURANO, E. M., TRIVELLATO-FERREIRA, M.; GARDINAL, E. C. Estresse cotidiano na transição da $1^{\text {a }}$ série: percepção dos alunos e associação com desempenho e ajustamento. Psicologia:

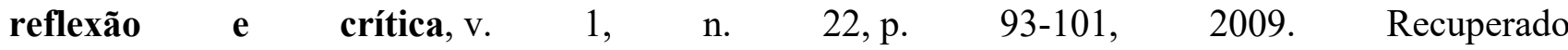
de https://www.scielo.br/pdf/prc/v22n1/13.pdf [Links] (Acesso em: 2/10/2020).

MATTOS, P.; SERRA-PINHEIRO, M.; ROHDE, L.; PINTO, D. A Brazilian version of the MTASNAP-IV for evaluation of symptoms of attention-deficit/hyperactivity disorder and oppositionaldefiant disorder. Revista de Psiquiatria, Rio Gd. Sul, v. 28, n. 3, 2006.

MENDES, L. O. PERFIL SOCIOEMOCIONAL E MOTOR DE CRIANÇAS COM INDICATIVO DO TRANSTORNO DO DÉFICIT DE ATENÇÃO E HIPERATIVIDADE DO ENSINO INFANTIL DE ESCOLAS DA REDE MUNICIPAL DA CIDADE DE SÃO PAULO. 2020. Dissertação (Mestrado em Ciências) - Escola de Educação Física e Esporte, Universidade de São Paulo. São Paulo, 2020.

NETER, J. Kutner, M. H.; NACHTSHEIM, C. J.; WASSERMAN, W. Applied linear statistical models. Irwin, Chicago, 3 edition, 1990.

ORGANIZAÇÃO MUNDIAL DA SAÚDE, O. M. S. Classificação Internacional de Funcionalidade, Incapacidade e Saúde Lisboa. Direção-geral da Saúde, p. 238, 2004.

- Classificação Estatística Internacional de Doenças e Problemas Relacionados à Saúde. $2018 . \quad$ Disponível em: https://www.paho.org/bra/index.php?option=com_content\&view=article\&id=5702:oms-divulga-

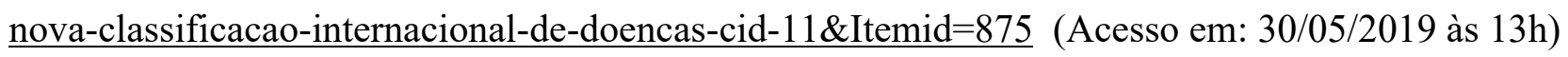
- Growth reference data for 5-19 years. 2007. Disponível em: https://www.who.int (Acesso em: 20/04/2019 às 12h) 
ORGANIZAÇÃO PAN-AMERICANA DA SAÚDE, O. P. A. S. Manual para vigilância do desenvolvimento infantil no contexto da AIDPI. Washington, D.C, Organização Pan-Americana da Saúde, 2005.

PASTOR, P.; REUBEN, C. Diagnosed attention deficit hyperactivity disorder and learning disability: United States. Vital and Health Statistics. National Health Survey, v. 237, n. 10, 2008. Disponível em http://europepmc.org/abstract/ MED/1899827 (Acesso em: 20/04/2019 às 13h)

PASTURA, G.; MATTOS, P.; ARAÚJO, A. P. Q. C. Prevalência do transtorno do déficit de atenção e hiperatividade e suas comorbidades em uma amostra de escolares. Arq. Neuro-Psiquiatr, São Paulo. v. 65, n. 4, Dec., 2007.

PEARSALL-JONES, J. G.; PIEK, J. P. RIGOLI, D.; MARTIN, N.; LEVY, F. Motor disorder and anxiety and depressive symptomatology: A monozygotic co-twin control approach. Research in Developmental Disabilities, n. 32, p. 1245-1252, 2010.

PELHAM; BENDER. Peer relationships in hyperactive children: Description and treatment. In R. A. Barkley (Ed.), Attention-deficit hyperactivity disorder: A handbook for diagnosis and treatment (p. 210-222). New York: The Guilford Press, 1982.

PINEDA, D. A; ARDILA, A.; ROSSELLI, M. Prevalence of attention- deficit/hyperactivity disorder symptoms in 4- to 17-year-old children in the general population. Journal Abnorm Child Psychol, v.27, p. 455-462, 1999.

PIEK, J. P.; KANE, R.; RIGOLI, D.; MCLAREN, S.; ROBERTS, C. M.; ROONEY, R.; STRAKER, L. Does the Animal Fun program improve social-emotional and behavioural outcomes in children aged 4- 6 years? Human Movement Science, n. 43, p. 155-163, 2015.

PIEK, J. P.; MCLAREN, S.; KANE, R.; JENSEN, L.; DENDER, A.; ROBERTS, C. O programa Animal Fun melhora o desempenho motor de crianças de 4 a 6 anos? Ciência do Movimento Humano, v. 32, n. 5, p. 1086-1096, 2013. 
POETA, L. S.; ROSA NETO, F. Epidemiological study on symptoms of attention deficit/hyperactivity disorder and behavior disorders in public schools of Florianopolis/SC using the EDAH. Revista Brasileira de Psiquiatria, v. 26, n. 3, p. 150-5, Sep. 2004.

. Intervenção motora em uma criança com transtorno do déficit de atenção/hiperatividade (TDAH). Revista Digital, Buenos Aires, ano. 10, n. 89, Oct 2005. Disponível em http:www.efdeportes.com/ (Acesso em: 18/05/2019 às 15h)

. Motor assessment in school-aged children with indicators of the attention deficit/hyperactivity disorder. Review of Neurology, v. 44, n. 3, p. 146-9, 2007.

POLANCZYK, G.; DE LIMA, M. S.; HORTA, B. L.; BIEDERMAN, J.; ROHDE, L. A. The worldwide prevalence of ADHD: a systematic review and metaregression analysis. American Journal of Psychiatry, v. 164, n. 6, p. 942-8, Jun, 2007.

POLANCZYK, G. V; WILlCUTT, E. G; SAlUM, G. A; KIELING, C.; ROHDE, L. A. ADHD prevalence estimates across three decades: an updated systematic review and meta-regression analysis. International Journal of Epidemiology, v. 43, n. 2, p. 434-42, 2014.

POULTRON, A. S. et al. Growth and pubertal development of adolescent boys on stimulant medication for attention deficit hyperactivity disorder. The Medical Journal of Australia. Online. Jan, 2013. (Acesso em: 17/09/2020 às 17h)

POPE, A., BIERMAN, K.; MUMMA, G. 1989 Aggression, Hyperactivity, and InattentionImmaturity: Behavior Dimensions Associated with Peer Rejection in Elementary School Boys. Developmental Psychology, v. 27, n. 4, p. 663-7, 1991.

R Core Team. R: A Language and Environment for Statistical Computing. R Foundation for Statistical Computing, Vienna, Austria, 2018. 
RANGEL JÚNIOR, E. B.; LOOS, H. Escola de desenvolvimento psicossocial segundo percepções de jovens com TDAH. Padéia, v. 21, n. 50, p. 373-83, set. 2011.

REY, C. P. M. El terror de las neuronas Struwwelpeter. Terror of neurons. Revista de la Asociación Española de Neuropsiquiatria, v. 32, n. 116, Madrid, Oct./Dec., 2012.

ROHDE, L. A.; HALPERIN, R. Recent advances on attention deficit/hyperactivity disorder. Journal of Pediatric, Rio Janeiro, v. 80, n. 2, Suppl, p. S61-70, Apr., 2004.

SCAHILL, L.; SCHWAB-STONE, M. Epidemiology of ADHD in school-age children. Child Adolesc Psychiatric Clinics of North America, v. 9, n. 3, p. 541-55, Jul., 2000.

SCHACHAR, R.; TANNOK, R.; LOGAN, G. Deficient Inhibitory control in attention deficit hyperactivity disorder. Journal Abnormal Child Psychology, v. 23, n. 4, p. 411-37, Aug., 1995.

SEABRA-SANTOS M. J., GASPAR M. F.F. Pais, educadores e testes: estão de acordo na avaliação de aptidões de crianças pré-escolares? Psicologia: Reflexão e Crítica, v. 2, n. 25, p. 203-1, 2012.

SILVA, M. A. Investigação de Transtorno de Déficit de Atenção e Hiperatividade (TDAH) entre estudantes de odontologia e suas repercussões na destreza manual e desempenho cognitivo. Tese (Doutorado), Faculdade de Odontologia da Universidade de São Paulo, 2014, 151p.

SILVA, N. R.; BOLSONI-SILVA; T., A.; L., S. R. Problemas De Comportamento E Recurso PróSocial Na Avaliação De Mães E Professoras. Psicologia Escolar e Educacional, Maringá, v. 24, e. $193925,2020$.

SONUGA-BARKE, E. J. Causal models of attention-deficit/hyperactivity disorder: From common simple deficits to multiple developmental pathways. Biological Psychiatry. n. 57, p. 1231-1238, 2005.

SILVA, G. C. T. Transtorno Opositor Desafiador - como enfrentar o tod na escola. Monografia apresentada ao Instituto A Vez dos Mestre como requisito parcial para a obtenção do título de especialista em Educação Especial e Inclusiva. 2017. 
STIVANIN, L.; SCHEUER, C. I.; BAPTISTA, F.; ASSUMPÇÃO, J. R. S D Q (Strengths and Difficulties Questionnaire): identificação de características comportamentais de crianças leitoras. Psicologia: Teoria e Pesquisa, Brasília, v. 24, n. 4, p. 407-413, dec., 2008.

STROES, M. D; ALBERTS, E.D; JAAP, J. V.D.M. Boys with ADHD in Social Interaction with a Non familiar Adult: An Observational Study. Journal of the American Academy of Child \& Adolescent Psychiatry, v. 42, n. 3, 2003.

SUGDEN, D. Issues in diagnosis of children with developmental coordination disorder. Review Medicine Child Neurology, v. 54, n. 2, p. 101-2, 2012.

THOREL, L. B.; RYDELL, A.M. Behavior problems and social competence deficits associated with symptoms of attention-deficit/hyperactivity disorder: effects of age and gender. Child: care, health and development, v. 5, n. 34, p. $584-595,2008$.

VAN LIER, P. A. C.; VAN DER ENDE, J.; KOOT, H. M.; VERHULST, F. C. Which better predicts conduct problems? The relationship of trajectories of conduct problems with ODD and ADHD symptoms from childhood into adolescence. Journal of Child Psychology and Psychiatry, v. 48, n. 6 p. 601-608, 2007.

WILLCUTT, E. G. The prevalence of DSM-IV attention-deficit/hyperactivity disorder: a metaanalytic review. Neurotherapeutics. v. 9, n. 3, p. 490-9, Jul, 2012. 
ANEXOS 
ANEXO 1 - Termo de CONSENTIMENTO Livre e Esclarecido

\section{I - DADOS DE IDENTIFICAÇÃO DO SUJEITO DA PESQUISA OU RESPONSÁVEL LEGAL}

1. DADOS DO INDIVÍDUO

Nome completo

Sexo

Masculino

Feminino

RG

Data de nascimento

Endereço completo

CEP

Fone

e-mail

\section{RESPONSÁVEL LEGAL}

Nome completo

Natureza (grau de parentesco, tutor, curador, etc.)

Sexo $\square$ Masculino

RG

Data de nascimento

Endereço completo

CEP

Fone

e-mail

\section{II - DADOS SOBRE A PESQUISA CIENTÍFICA}

1. Título do Projeto de Pesquisa

Escolares Com Indicativos Do Transtorno Do Déficit De Atenção/Hiperatividade E Os Comportamentos Socioemocionais Em Aulas De Educação Física E No Âmbito Familiar: Estudo De Caso

3. Cargo/Função

Professor Doutor da Escola de Educação Física e Esporte da Universidade de São Paulo.

4. Avaliação do risco da pesquisa:

X RISCO MÍNIMO $\square$ RISCO MÉDIO $\square$ RISCO MAIOR
(probabilidade de que o indivíduo sofra algum dano como conseqüência imediata ou tardia do estudo)

5. Duração da Pesquisa

18 meses

III - EXPLICAÇÕES DO PESQUISADOR AO INDIVÍDUO OU SEU REPRESENTANTE LEGAL SOBRE A PESQUISA, DE FORMA CLARA E SIMPLES, CONSIGNANDO:

Caro (a) Pai/Mãe ou responsável,

Meu nome é Daniela, sou professora de Educação Física do Colégio Bandeirantes e faço Mestrado em Ciências, na Escola de Educação Física e Esporte da Universidade de São Paulo, sob a orientação do Prof. Dr. Jorge Alberto de Oliveira.

O título da nossa pesquisa é: Escolares Com Indicativos Do Transtorno Do Déficit De Atenção/Hiperatividade E Os Comportamentos Socioemocionais Em Aulas De Educação Física E No Âmbito Familiar: Estudo De Caso. O objetivo do estudo é identificar os alunos com indicativos do transtorno do déficit de atenção/ hiperatividade e analisar o perfil socioemocional. A finalidade deste trabalho é contribuir para o adequado desenvolvimento social e emocional dos (as) alunos (as) com o transtorno do déficit de atenção/hiperatividade. 
Dessa forma, solicitamos a sua colaboração para responder dois questionários, que serão enviados para o seu correio eletrônico, estes mesmos questionários, os professores também responderão, para fazermos uma comparação entre as respostas.

Os resultados deste estudo serão publicados em eventos da área de saúde e em revistas científicas nacional e/ou internacional. Por ocasião da publicação dos resultados, seu nome será mantido em sigilo absoluto. Informamos que essa pesquisa não oferece desconforto e os riscos são mínimos, os mesmos da aula de Educação Física. Esclarecemos que sua participação e do (a) seu (sua) filho (a) no estudo é voluntária e, portanto, o (a) senhor (a) não é obrigado (a) a fornecer as informações e/ou colaborar com as atividades solicitadas pelos pesquisadores. Os benefícios que seu (sua) filho (a) pode ganhar participando deste estudo são: ter identificado se ele (ela) apresenta sintomas do TDAH, saber qual o seu comportamento socioemocional em relação aos seus colegas.

Entretanto, caso seu (sua) filho (a) decida não participar do estudo, ou resolver a qualquer momento desistir do mesmo, não sofrerá nenhum dano. Os pesquisadores estarão a sua disposição para qualquer esclarecimento que considere necessário em qualquer etapa da pesquisa.

\section{IV - ESCLARECIMENTOS DADOS PELO PESQUISADOR SOBRE GARANTIAS DO SUJEITO DA PESQUISA:}

1. acesso, a qualquer tempo, às informações sobre procedimentos, riscos e benefícios relacionados à pesquisa, inclusive para dirimir eventuais dúvidas;

2. liberdade de retirar seu consentimento a qualquer momento e de deixar de participar do estudo, sem que isto traga prejuízo à continuidade da assistência;

3. salvaguarda da confidencialidade, sigilo e privacidade; e

4. disponibilidade de assistência no HU ou HCFMUSP, por eventuais danos à saúde, decorrentes da pesquisa.

\section{V - INFORMAÇÕES DE NOMES, ENDEREÇOS E TELEFONES DOS RESPONSÁVEIS PELO ACOMPANHAMENTO DA PESQUISA, PARA CONTATO EM CASO DE INTERCORRÊNCIAS CLÍNICAS E REAÇÕES ADVERSAS.}

Prof. Dr. Jorge A De Oliveira
Escola de Educação Física e Esporte - USP
Av. Prof. Mello Moraes, 65 - Cidade Universitária
CEP: 05508-030 - São Paulo - SP
Telefone (011) 3091-2119
E-mail: jadolive@usp.br

VI. - OBSERVAÇÕES COMPLEMENTARES

\author{
Profa. Daniela Coelho Lastória de Godoi \\ Colégio Bandeirantes \\ Rua Estela, 268, Paraíso. \\ CEP: 04011-001 - São Paulo - SP \\ Telefone (11) 5087-3519 \\ E-mail: danielac@colband.com.br
}

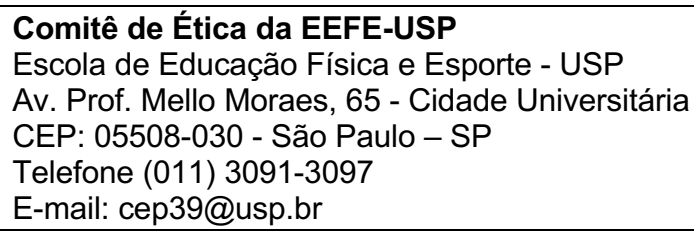

\section{VII - CONSENTIMENTO PÓS-ESCLARECIDO}

Declaro que, após convenientemente esclarecido pelo pesquisador e ter entendido o que me foi explicado, consinto em participar do presente Projeto de Pesquisa.

São Paulo, __________

assinatura do sujeito da pesquisa ou responsável legal
JORGE ALBERTO DE OLIVEIRA EEFEUSP 
ANEXO 2 - SNAP - IV

MTA-SNAP-IV - Escala sobre o comportamento da CRIANÇAIADOLESCENTE

Nome da criança/adolescente:

Data de Nascimento: Idade: Ano/Série: Sala:

Nome do Informante: $\square$ Responsável ¿ Professor(a)

Contato do informante (telefone e/ou e-mail): Data de hoje:

\begin{tabular}{|c|c|c|c|c|}
\hline $\begin{array}{l}\text { Por favor, responda as questões abaixo referentes à criança/adolescente } \\
\text { participante. Para cada item, escolha a coluna que melhor descreve a } \\
\text { criança/adolescente, NESTE MOMENTO. (CIRCULE o número que corresponde } \\
\text { à coluna desejada): }\end{array}$ & $\begin{array}{l}\text { Nem um } \\
\text { pouco }\end{array}$ & $\begin{array}{l}\text { Só um } \\
\text { pouco }\end{array}$ & Bastante & Demais \\
\hline $\begin{array}{l}\text { 1. Não consegue prestar muita atenção a detalhes ou comete erros por } \\
\text { descuido nos trabalhos da escola ou tarefas. }\end{array}$ & 0 & 1 & 2 & 3 \\
\hline 2. Tem dificuldade de manter a atenção em tarefas ou atividades de lazer. & 0 & 1 & 2 & 3 \\
\hline 3. Parece não estar ouvindo quando se fala diretamente com ele. & 0 & 1 & 2 & 3 \\
\hline $\begin{array}{l}\text { 4. Não segue instruções até o fim e não termina deveres de escola, tarefas } \\
\text { ou obrigações. }\end{array}$ & $0 \ldots$ & 1 & 2 & 3 \\
\hline 5. Tem dificuldade para organizar tarefas e atividades. & 0 & 1 & 2 & 3 \\
\hline $\begin{array}{l}\text { 6. Evita, não gosta ou se envolve contra a vontade em tarefas que exigem } \\
\text { esforço mental prolongado. }\end{array}$ & 0 & 1 & 2 & 3 \\
\hline $\begin{array}{l}\text { 7. Perde coisas necessárias para atividades (p.ex.: brinquedos, deveres da } \\
\text { escola, lápis ou livros). }\end{array}$ & 0 . & 1 & 2 & 3 \\
\hline 8. Distrai-se com estimulos externos. & 0 & 1 & 2 & 3 \\
\hline 9. É esquecido em atividades do dia-a-dia. & 0 & 1 & 2 & 3 \\
\hline 10. Mexe com as mãos ou os pés ou se remexe na cadeira. & 0 & 1 & 2 & 3 \\
\hline $\begin{array}{l}\text { 11. Sai do lugar na sala de aula ou em outras situações em que se espera } \\
\text { que fique sentado. }\end{array}$ & 0 & 1 & 2 & 3 \\
\hline $\begin{array}{l}\text { 12. Corre de um lado para outro ou sobe demais nas coisas em situações } \\
\text { em que isto é inapropriado. }\end{array}$ & 0 & 1 & 2 & 3 \\
\hline $\begin{array}{l}\text { 13. Tem dificuldade em brincar ou envolver-se em atividades de lazer de } \\
\text { forma calma. }\end{array}$ & 0 & 1 & 2 & 3 \\
\hline 14. Não pára ou freqüentemente está a "mil por hora". & 0 & 1 & 2 & 3 \\
\hline 15. Fala em excesso. & 0 & 1 & 2 & 3 \\
\hline $\begin{array}{l}\text { 16. Responde as perguntas de forma precipitada antes delas terem sido } \\
\text { terminadas. }\end{array}$ & 0 & 1 & 2 & 3 \\
\hline 17. Tem dificuldade de esperar sua vez. & 0 & 1 & 2 & 3 \\
\hline $\begin{array}{l}\text { 18. Interrompe os outros ou se intromete (por exemplo, mete-se nas } \\
\text { conversas/jogos). }\end{array}$ & 0 & 1 & 2 & 3 \\
\hline 19. Descontrola-se. & 0 & 1 & 2 & 3 \\
\hline 20. Discute com adultos. & 0 & 1 & 2 & 3 \\
\hline 21. Desafia ativamente ou se recusa a atender pedidos ou regras de adultos. & 0 & 1 & 2 & 3 \\
\hline 22. Faz coisas de propósito que incomodam outras pessoas. & 0 & 1 & 2 & 3 \\
\hline 23. Culpa os outros pelos seus erros ou mau comportamento. & 0 & 1 & 2 & 3 \\
\hline 24. É irritável ou facilmente incomodado pelos outros. & 0 & 1 & 2 & 3 \\
\hline 25. É zangado e ressentido. & 0 & 1 & 2 & 3 \\
\hline 26. É maldoso ou vingativo. & 0 & 1 & 2 & 3 \\
\hline \multicolumn{5}{|c|}{$\begin{array}{l}\text { Alguns desses comportamentos estão presentes antes dos } 7 \text { anos de idade? ( )Sim ( )Não } \\
\text { Esses comportamentos causam dificuldades em casa, na escola, nas relações sociais da criança/adolescente ou em } \\
\text { outras áreas importantes? ( )Sim ( )Não }\end{array}$} \\
\hline
\end{tabular}


ANEXO 3 - SDQ-Por

\section{Questionário de Capacidades e Dificuldades (SDQ-Por)}

Instruções: Por favor, em cada item marque com uma cruz o quadrado que melhor descreva a criança. Responda a todas as perguntas da melhor maneira possivel, mesmo que você não tenha certeza absoluta ou se a pergunta lhe parecer estranha. Dê suas respostas com base no comportamento da criança nos últimos seis meses.

Nome da Criança

Masculino/Feminino

Data de Nascimento

Mais ou menos

Falso verdadeiro Verdadeiro

Tem consideração pelos sentimentos de outras pessoas

Não consegue parar sentado quando tem que fazer a lição ou comer; mexe-se muito, esbarrando em coisas, derrubando coisas

Muitas vezes se queixa de dor de cabeça, dor de barriga ou enjôo

Tem boa vontade em compartilhar doces, brinquedos, lápis ... com outras crianças

Frequentemente tem acessos de raiva ou crises de birra

É solitáno, prefere brincar sozinho

Geralmente é obediente e faz normalmente o que os adultos lhe pedem

Tem muitas preocupações, muitas vezes parece preocupado com tudo

Tenta ser atencioso se alguém parece magoado, aflito ou se sentindo mal

Está sempre agitado, balançando as pernas ou mexendo as mãos

Tem pelo menos um bom amigo ou amiga

Frequentemente briga com outras crianças ou as amendronta

Frequentemente parece triste, desanimado ou choroso

Em geral, é querido por outras crianças

Facilmente perde a concentração

Fica inseguro quando tem que fazer alguma coisa pela primeira vez, facilmente perde a confiança em si mesmo

\begin{tabular}{lll}
\hline É gentil com crianças mais novas & $\square$ \\
\hline Frequentemente engana ou mente & Outras crianças 'pegam no pé' ou atormentam-no \\
\hline Frequentemente se oferece para ajudar outras pessoas (pais, professores, outras crianças) \\
\hline Pensa nas coisas antes de fazê-las & $\square$ \\
\hline Rouba coisas de casa, da escola ou de outros lugares & $\square$ \\
\hline Se dá melhor com adultos do que com outras crianças & $\square$ \\
\hline Tem muitos medos, assusta-se facilmente & $\square$
\end{tabular}

Você tem algum outro comentário ou preocupações? Descreva-os abaixo. 
Pensando no que acabou de responder, você acha que seu filho/a tem alguma dificuldade? Pode ser uma dificuldade emocional, de comportamento, pouca concentracão ou para se dar bem com outras pessoas.

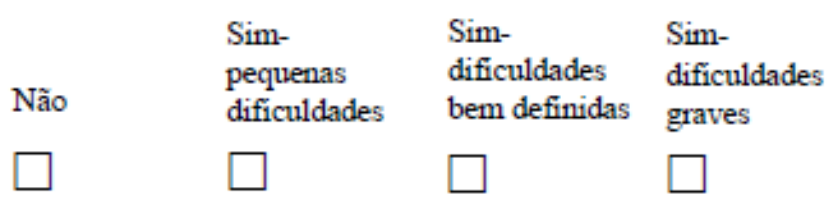

Se você respondeu "Sim", por favor responda às seguintes questões sobre estas dificuldades:

- Há quanto tempo estas dificuldades existem?

$\begin{array}{llll}\begin{array}{l}\text { Menos de } \\ 1 \text { mes }\end{array} & 1-5 & 6-12 & \text { Mais de } \\ \text { mêses } & \text { mêses } & 1 \text { ano } \\ \square & \square & \square & \square\end{array}$

- Estas dificuldades incomodam ou aborrecem seu filho/a?

$\begin{array}{llll}\text { Nada } & \begin{array}{l}\text { Um } \\ \text { pouco }\end{array} & \text { Muito } & \text { Mais } \\ \square & \square & \square & \square\end{array}$

- Estas dificuldades atrapalham o dia-a-dia do seu filho/a em alguma das situações abaixo?

$\begin{array}{lllll} & \text { Nada } & \text { um } & \text { Maico } & \text { Mais } \\ \text { DIA-A-DIA EM CASA } & \square & \square & \square & \square \\ \text { AMIZADES } & \square & \square & \square \\ \text { APRENDIZADO ESCOLAR } & \square & \square & \square & \square \\ \text { ATIVIDADES DE LAZER } & \square & \square & \square & \square \\ \text { (PASSEIOS, ESPORTES ETC.) } & \square & \square & \square\end{array}$

- Estas dificuldades são um peso para você ou para a familia como um todo?

$\begin{array}{lll}\text { Nada } & \text { Um } & \text { Mais } \\ \text { pouco } & \text { Muito } & \text { que muito }\end{array}$

Nome completo (em letra de forma)

Data

Mãe/pai/outro (especifique): 
ANEXO 4 - Termo de Anuência da escola - Mensagem eletrônica enviada aos pais/responsáveis

\section{TERMO DE ANUÊNCIA}

Declaramos, para os devidos fins, que concordamos em receber a PósGraduanda, Daniela Coelho Lastória de Godoi, número USP 451907, sob orientação do pesquisador principal Prof. Dr. Jorge Alberto de Oliveira e Pesquisadores(as) ligados ao projeto de pesquisa, no Colégio Bandeirantes. para realização do projeto de pesquisa referente à dissertação de mestrado intitulada: Identificação dos niveis de desempenho motor e comportamento socioemocional de alunos com indicativos do transtorno do déficit de atenção/hiperatividade em aulas de educação fisica, desenvolvida junto à Escola de Educaçăo Física da Universidade de São Paulo - EEFEUSP.

O estudo citado nẵo gerará danos e/ou riscos aos participantes desta pesquisa, como também, será explicitado os procedimentos a serem realizados, as garantias de confidencialidade e esclarecimentos permanentes. Além do que, a participação deste estabelecimento de ensino está isenta de despesas.

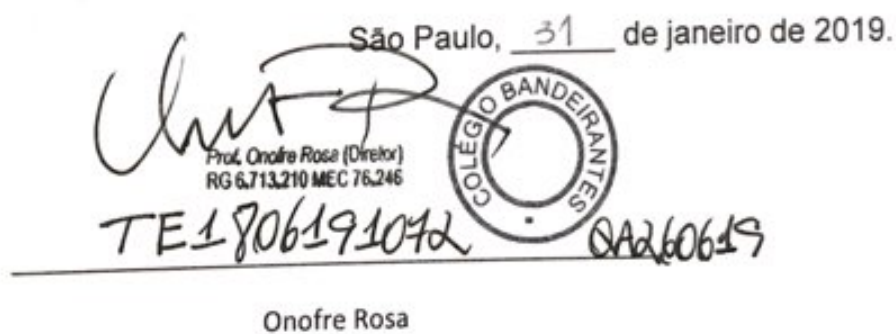

Diretor Pedagógico 
ANEXO 5- Mensagem eletrônica enviada aos pais/responsáveis

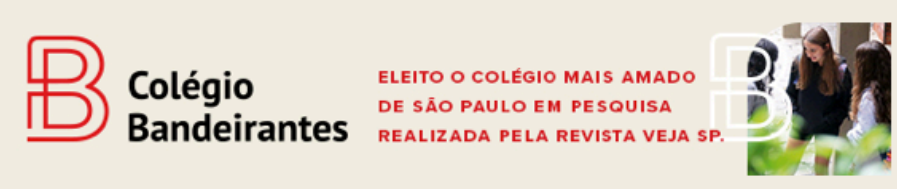

Pesquisa de mestrado da professora Daniela Godoi

Prezados Pais

o Colégio Bandeirantes tem a excelência como um de seus valores primordiais. Ela se expressa, também, pela formação continuada de seus professores, sempre buscando ampliar seus conhecimentos e autodesenvolvimento.

Alinhada a esse valor, a professora de Educação Física, Daniela Godoi, realiza Mestrado em Ciências, na Escola de Educação Física da Universidade de São Paulo (USP), com total apoio do Colégio Bandeirantes. O estudo tem por objetivo trabalhar com alunos (as) do ensino fundamental que apresentem indicativos de TDA ou TDAH (transtorno do déficit de atenção/hiperatividade), analisando seus níveis de desempenho motor e comportamento socioemocional e, com isso, contribuir para o adequado desenvolvimento dessas habilidades.

Na primeira etapa do estudo, solicitamos a colaboração dos pais/responsáveis para responderem a dois questionários indicados nos botões abaixo. . Os professores, também contribuirão respondendo aos mesmos questionários, para uma posterior comparação entre as respostas. Após a análise dos questionários, os pais/responsáveis participantes, receberão um e-mail contendo informações detalhadas sobre o estudo e termo de consentimento para a participação na pesquisa.

\section{Clique aqui para Questionário SNAP IV}

Clique aqui para Questionário SDQ-Por

A professora Daniela estará à disposição para qualquer esclarecimento que considerem necessário em qualquer etapa da pesquisa, pelo seu e-

mail: danielac@colband.com.br ou por meio da Orientação Educacional.

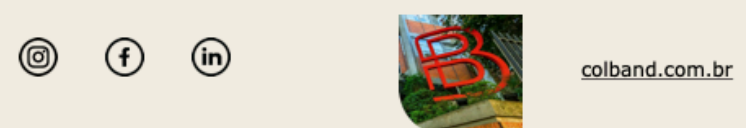

Colégio Bandeirantes - Rua Estela, 268 | 04011-001 I São Paulo - SP ITel: (11) 5087-3500 Caso não queira mais receber nossos e-mails, clique aqui. 
ANEXO 6 - Parecer do Comitê de Ética em Pesquisa

USP - ESCOLA DE EDUCAÇÃO
FÍSICA E ESPORTE DA
UNIVERSIDADE DE SÃO
PAULO / EEFE-USP

DADOS DO PROJETO DE PESQUISA

Título da Pesquisa: IDENTIFICAÇÃO DOS NÍVEIS DE DESEMPENHO MOTOR E COMPORTAMENTO SOCIOEMOCIONAL DE ALUNOS COM INDICATIVOS DO TRANSTORNO DO DÉFICIT DE ATENÇÃO/HIPERATIVIDADE EM AULAS DE EDUCAÇÃO FÍSICA

Pesquisador: Jorge Alberto de Oliveira

Área Temática:

Versão: 3

CAAE: 04938818.8 .0000 .5391

Instituição Proponente: UNIVERSIDADE DE SAO PAULO

Patrocinador Principal: Financiamento Próprio

\section{DADOS DO PARECER}

Número do Parecer: 3.681 .885

Apresentação do Projeto:

Trata-se do terceiro relato do projeto de pesquisa em que são respondidas as questões apontadas em relato anterior.

Objetivo da Pesquisa:

Os objetivos do projeto foram padronizados no projeto e na Plataforma Brasil.

Avaliação dos Riscos e Benefícios:

As informações sobre riscos e benefícios às crianças diagnosticadas com transtorno do Déficit de Atenção/hiperatividade (TDAH) foram complementadas no Termo de Consentimento para os pais/responsável.

\section{Comentários e Considerações sobre a Pesquisa:}

Em relação ao número de participantes no estudo, foi esclarecido que serão abordados 800 alunos da rede privada de ensino do município de São Paulo, de ambos os sexos, de 11 e 15 anos de idade.

Destes, espera-se encontrar uma amostra de 40 alunos com diagnóstico de TDAH, os quais realizarão os testes de desempenho motor e demais procedimentos previstos no protocolo (orientações, conversa com psicólogo, reunião de pais).

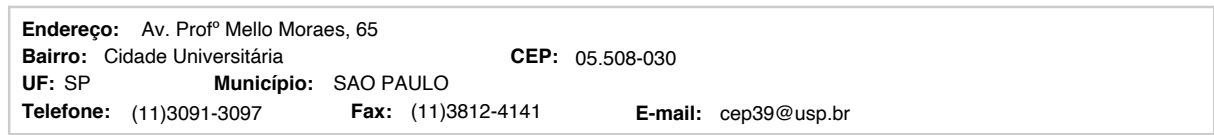




\section{USP - ESCOLA DE EDUCAÇÃO \\ FÍSICA E ESPORTE DA \\ UNIVERSIDADE DE SÃO \\ PAULO / EEFE-USP}

Continuação do Parecer: 3.681 .885

Considerações sobre os Termos de apresentação obrigatória:

Foram realizados os ajustes solicitados em relato anterior no Termo de Consentimento Livre e Esclarecido (TCLE):

1- Foram descritos os testes motores que as crianças realizarão;

2- O item IV do TCLE foi adequado no termo e;

3- Foi incluído um TCLE dirigido aos professores que serão envolvidos no estudo (20 professores do colégio pesquisado responderão aos questionários).

Recomendações:

Sem recomendações adicionais.

O cronograma de execução do projeto no formulário da Plataforma Brasil foi atualizado.

Conclusões ou Pendências e Lista de Inadequações:

Projeto aprovado

Considerações Finais a critério do CEP:

Este parecer foi elaborado baseado nos documentos abaixo relacionados:

\begin{tabular}{|c|c|c|c|c|}
\hline Tipo Documento & Arquivo & Postagem & Autor & Situação \\
\hline $\begin{array}{l}\text { Informações Básicas } \\
\text { do Projeto }\end{array}$ & $\begin{array}{l}\text { PB_INFORMAÇÕES_BÁSICAS_DO_P } \\
\text { ROJETO_1267349.pdf }\end{array}$ & $\begin{array}{c}11 / 10 / 2019 \\
16: 36: 49 \\
\end{array}$ & & Aceito \\
\hline $\begin{array}{l}\text { Projeto Detalhado / } \\
\text { Brochura } \\
\text { Investigador } \\
\end{array}$ & BrochuraCEP.pdf & $\begin{array}{c}11 / 10 / 2019 \\
16: 36: 09\end{array}$ & $\begin{array}{l}\text { DANIELA COELHO } \\
\text { LASTORIA DE } \\
\text { GODOI } \\
\end{array}$ & Aceito \\
\hline Outros & respostaautores.docx & $\begin{array}{c}11 / 10 / 2019 \\
16: 31: 02\end{array}$ & $\begin{array}{l}\text { DANIELA COELHO } \\
\text { LASTORIA DE } \\
\text { GODOI } \\
\end{array}$ & Aceito \\
\hline $\begin{array}{l}\text { TCLE / Termos de } \\
\text { Assentimento / } \\
\text { Justificativa de } \\
\text { Ausência } \\
\end{array}$ & TCLEPROFESSORES.docx & $\begin{array}{c}11 / 10 / 2019 \\
09: 15: 00\end{array}$ & $\begin{array}{l}\text { DANIELA COELHO } \\
\text { LASTORIA DE } \\
\text { GODOI }\end{array}$ & Aceito \\
\hline $\begin{array}{l}\text { TCLE / Termos de } \\
\text { Assentimento / } \\
\text { Justificativa de } \\
\text { Ausência }\end{array}$ & TCLE.docx & $\begin{array}{c}10 / 10 / 2019 \\
14: 59: 58\end{array}$ & $\begin{array}{l}\text { DANIELA COELHO } \\
\text { LASTORIA DE } \\
\text { GODOI }\end{array}$ & Aceito \\
\hline Folha de Rosto & FolhaRosto_ProjDani_15Jul19.pdf & $15 / 07 / 2019$ & Jorge Alberto de & Aceito \\
\hline
\end{tabular}

Endereço: Av. Prof ${ }^{\circ}$ Mello Moraes, 65

Bairro: Cidade Universitária

CEP: $05.508-030$

UF: SP Município: SAO PAULO

Telefone: (11)3091-3097 Fax: (11)3812-4141 E-mail: cep39@usp.br 


\section{USP - ESCOLA DE EDUCAÇÃO \\ FÍSICA E ESPORTE DA \\ UNIVERSIDADE DE SÃO \\ PAULO / EEFE-USP}

Continuação do Parecer: 3.681 .885

\begin{tabular}{|c|c|c|c|c|}
\hline Folha de Rosto & FolhaRosto_ProjDani_15Jul19.pdf & 10:35:00 & Oliveira & Aceito \\
\hline $\begin{array}{l}\text { TCLE / Termos de } \\
\text { Assentimento / } \\
\text { Justificativa de } \\
\text { Ausência } \\
\end{array}$ & Anuencia.pdf & $\begin{array}{c}05 / 07 / 2019 \\
19: 49: 08\end{array}$ & $\begin{array}{l}\text { DANIELA COELHO } \\
\text { LASTORIA DE } \\
\text { GODOI }\end{array}$ & Aceito \\
\hline Outros & resp.docx & $\begin{array}{c}05 / 07 / 2019 \\
19: 41: 22\end{array}$ & $\begin{array}{l}\text { DANIELA COELHO } \\
\text { LASTORIA DE } \\
\text { GODOI }\end{array}$ & Aceito \\
\hline $\begin{array}{l}\text { TCLE / Termos de } \\
\text { Assentimento / } \\
\text { Justificativa de } \\
\text { Ausência }\end{array}$ & Assentimento.docx & $\begin{array}{c}05 / 07 / 2019 \\
19: 12: 29\end{array}$ & $\begin{array}{l}\text { DANIELA COELHO } \\
\text { LASTORIA DE } \\
\text { GODOI }\end{array}$ & Aceito \\
\hline $\begin{array}{l}\text { TCLE / Termos de } \\
\text { Assentimento / } \\
\text { Justificativa de } \\
\text { Ausência }\end{array}$ & TCL.pdf & $\begin{array}{c}05 / 07 / 2019 \\
19: 11: 36\end{array}$ & $\begin{array}{l}\text { DANIELA COELHO } \\
\text { LASTORIA DE } \\
\text { GODOI }\end{array}$ & Aceito \\
\hline
\end{tabular}

Situação do Parecer:

Aprovado

Necessita Apreciação da CONEP:

Não

SAO PAULO, 04 de Novembro de 2019

Assinado por:

Edilamar Menezes de Oliveira

(Coordenador(a))

Endereço: Av. Prof ${ }^{\circ}$ Mello Moraes, 65

Bairro: Cidade Universitária

UF: SP

Município: SAO PAULO

Telefone: (11)3091-3097

Fax: (11)3812-4141

CEP: $05.508-030$

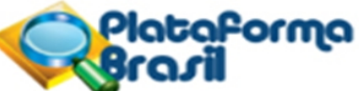

8 